

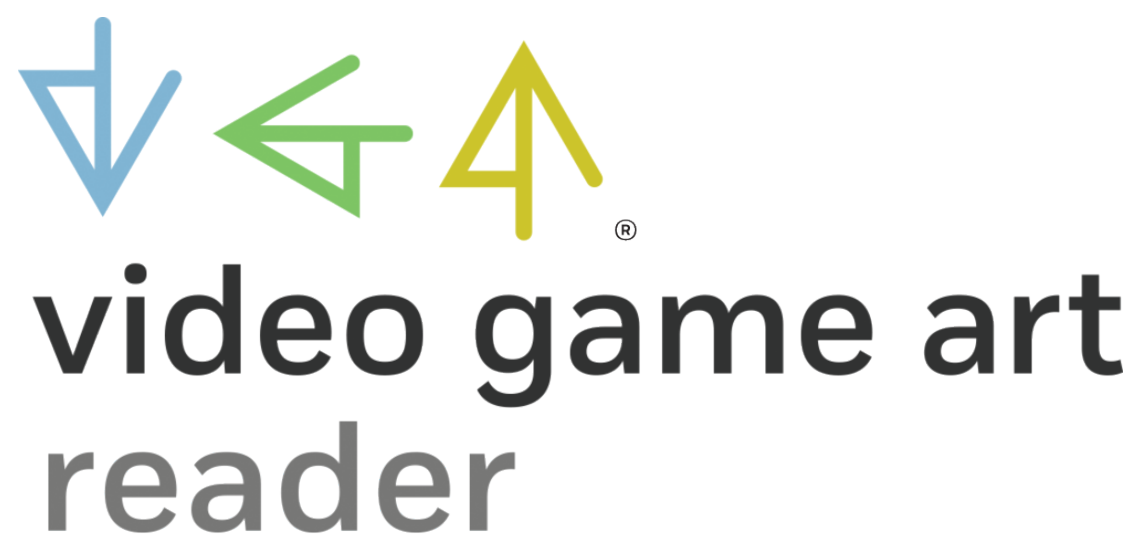

version_2.1.2018 


\section{Video Game Art Reader}

version_2.1.2018

Volume 2, Number 1

Editor-in-Chief Tiffany Funk

Managing Editor Michael Reed

Publications Intern Addie Barron

Staff Editor Maureen Ryan

Designer Levi Sherman

Editorial Board James Conley, Meredith Espino, Angus Forbes, William Ford, Ian Hartman, Reem Hilu, Stephan Moore, Whitney Pow, Maureen Ryan, Joyce Rudinsky, Brian Schrank, Victoria Szabo, Kelli Wood, Nate Zoba

\section{VGA Director of Exhibitions and Programs Chaz Evans}

\section{VGA Executive Director Jonathan Kinkley}

The VGA Reader (ISSN 2574-4712) is published by VGA Gallery, an Illinois 501(c)(3): 2418 W. Bloomingdale Ave, Chicago, IL 60647. Compilation copyright (C) 2018 VGA Reader. Contents copyright (C) 2018 by the respective authors, artists, and other rights holders. Except as permitted by the Copyright Act, including section 107 (the fair use doctrine), or other applicable law, no part of the contents of the VGA Reader may be reproduced without the written permission of the author(s) and/or other rights holders. The opinions expressed in this journal are those of the authors and not necessarily of the editors and the VGA Reader.

Authorization to copy or photocopy texts for internal or personal use (beyond uses permitted by sections 107 and 108 of the US Copyright Law) is granted by the VGA Reader without charge. For educational uses, such as course pack or academic course intranet websites, please contact the Copyright Clearance Center at www.copyright.com/. For other uses, please first contact the individual author and/or other rights holder to obtain written permission, then the VGA Reader.
Advertising, subscriptions, and back issues: Send inquiries to Michael Reed, c/o VGA Gallery,mreed@vgagallery.org.

VGA Reader Mission: The VGA Readers a peer-reviewed journal for video game audiences and video game practitioners interested in the history, theory, and criticism of video games, explored through the lens of art history and visual culture. Its primary aim is to facilitate conversation and exploration of video game art, documenting and disseminating discourse about the far-reaching influence of video games on history, society, and culture.

Cover: Jakob Kudsk Steensen, PrimalTourism: Island, headset view, 2016. Image courtesy of the artist. 


\section{Contents}

Letter From the Editor

5 IT'S DANGEROUSTO GO ALONE! TAKE THIS. Tiffany Funk

Interview

6 Make Beautiful, Creative Things Together:

An Interview with Anna Anthropy

Anna Anthropy and Tiffany Funk

\section{Essays}

15 Survival Interventions in GTA:

On the Limits of Performance in Virtual Environments

Martin Zeilinger

28 Thunderbird Strike:

Survivance in/of an Indie Indigenous Game

Elizabeth LaPensée

38 Fantastic Places and Where to Find Them: Pseudo-Indexical

Realities Within Video Games and Game Art

Andrew Bailey

51 Playing with Dick Pics:

Networked Technologies and Digital Closets

Michael Anthony DeAnda

64 These Wars of Mine:

Why It Matters How Video Games Represent War

Luisa Salvador Dias

75 Virtual Intimacy and Queer Confrontations in The Last of

Us: Left Behind

Michael Paramo

86 Playing, Performing, Policing:

Navigating Avatar Expression in Second Life

Treva Michelle Legassie 



\title{
Letter From the Editor:
}

\section{IT'S DANGEROUS TO GO ALONE! TAKE THIS.}

\section{Tiffany Funk}

\author{
Editor-in-Chief, VGA Reader
}

IT'S DANGEROUS TO GO ALONE! TAKE THIS. —Old Man, The Legend of Zelda (Nintendo, 1986)

It's hard to deny the reality that we're living in an era of ecological, social, and political crisis. While the virtual affordance of video games offers a valuable means of psychological escape, games-as uniquely participatory works of art—can also model both individual and collaborative means of survival through the experience of play. Video games offer opportunities to navigate both historical and fictional conflicts, traverse landscapes devastated by climate change or nuclear holocaust, and manage the limited resources of individuals, or even whole civilizations, on earth and beyond. They offer players a dizzying array of dystopian scenarios in which to build and invent, cooperate to achieve shared goals, or sometimes merely learn how to survive another day. Video games focus attention, hone visuospatial skills, and shape cognitive control and physical reflexes.

As all video games can be considered as methods of human conditioning, coping, and creating, we at the VGA Reader agree that critically analyzing video game art as a means of survival is a crucial step in supporting the creators of video games that participate in the larger context of radical, activist artworks that challenge destructive norms embedded in structures of power. In our second call for papers, we asked: How do video games, through these unique methods, participate in the larger context of radical, activist artworks that challenge destructive norms and structures of power? How can we harness the skills we develop through play-or "game the system"- to imagine our best possible future(s) in trying times?

The response to our call was heartening in its breadth and diversity. The artists, art historians, developers, and cultural theorists whose essays we showcase here found survival to be both commensurate and at odds with the dominant cultural, political, and literal-in the case of early text adventure Colossal Cave Adventure (William Crowther and Don Woods, 1976/7) and its mapping of the very real Mammoth Cave-landscape; many of our writers engaged with the survival strategies gaming presented for queer and trans communities, from offering virtual escapism to representation and recognition. Others found video games a compelling platform for engaging politically with the rights, resistance, and survival of minorities and indigenous peoples. Still others found meaningful discourse spawned by works that critique the ways in which violence and war are so often portrayed in popular media. All of our writers found that games provide serious strategies for surviving in our embattled present, and these strategies hinge on inclusion, understanding, and cooperation. No matter your prefered video game genre, survival is multiplayer. $\rightarrow$ 

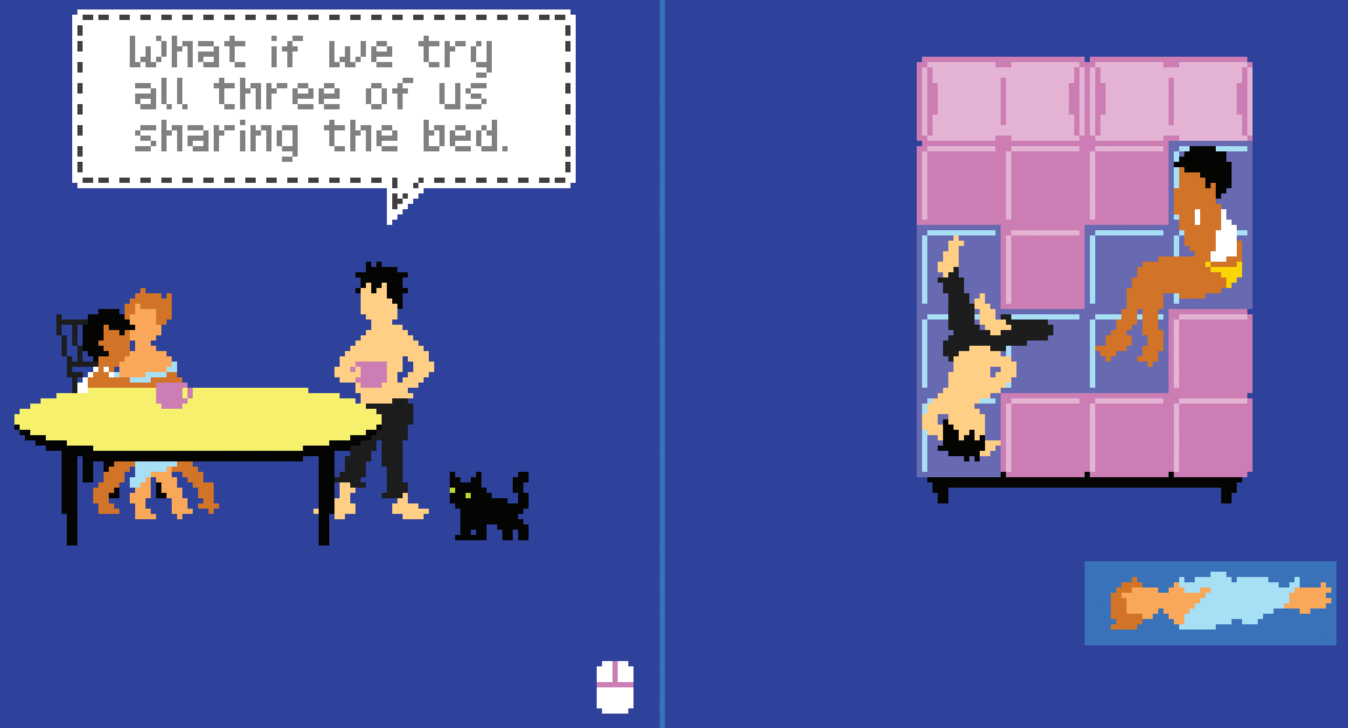

Anna Anthropy, screenshots from Triad, 2013. Image courtesy of the artist.

\section{Make Beautiful, Creative Things Together: An Interview with Anna Anthropy}

\section{Interviewer: Tiffany Funk}

Editor-in-Chief, VGA Reader

\section{Interviewee: Anna Anthropy}

Independent video game developer, critic, and writer; Game Designer in Residence, DePaul University, College of Computing and Digital Media

\section{Abstract}

Anna Anthropy is a game developer, critic, teacher, and writer, best known for creating numerous independent video games, including Lesbian Spider-Queens of Mars, Mighty Jill Off, Queers in love at the end of the world, and $D y$ s4ia. She is the author of Rise of the Videogame Zinesters: How Freaks, Normals, Amateurs, Artists, Dreamers, Drop-outs, Queers, Housewives, and People Like You Are Taking Back an Art Form (Seven Stories Press, 2012); in her book, she discusses the "zine" game model, highlighting the importance of inclusion and diversity in video game production. She is currently the game designer in residence at the DePaul University College of Computing and Digital Media in Chicago.

Editor-in-Chief Tiffany Funk and Anna Anthropy discuss pizza, survival and collaboration in video games, the frustrations and wins in teaching video games and game design, and how video games are suited to transforming the mundane into poetic, narrative, ritualistic experiences for players. The interview has been edited for clarity. 
Tiffany Funk: Where did you grow up?

Anna Anthropy: I grew up in the Bronx, New York-in a small Italian neighborhood in the east Bronx where there is a pizzeria on every street corner (but I'm not snobby about New York pizza). In young adulthood, I moved to California for seven years and then to Chicago recently. But I'm a New York native.

TF: What's your earliest and most formative video game memory?

AA: It was probably playing some game with my mom, probably Mario Bros. Not Super Mario Bros., but the weird Atari port, or Bubble Bobble. But Mario Bros., there's a bonus round where you have to collect all the coins in a certain amount of time, and it's impossible to do it unless you both coordinate as a team really well. I think it was a cool moment for me, learning to do that. Of all the moments that have stuck with me, I think one of the most important was learning the importance of communication, and spending time with my mom.

TF: That's interesting-your connection with video games began with collaborative gaming, and not in the head-to-head fighting or singleplayer modes that seem to define so many video game genres. That's certainly relevant to this issue of the VGA Reader, which is about "survival strategy." Though it exists as an incredibly popular genre on its own, we want to approach video games as participatory works of art that can uniquely model both individual and collaborative means of survival through the experience of play. So these formative experiences in collaborative gaming-do you think that mode of cooperative gaming is becoming more popular? AA: We're definitely seeing more collaborative games now, particularly in competition between teams, but it's amazing how stark the differences are between so many popular video games and tabletop game-playing environments, and roleplaying games in particular. In tabletop gaming, players come with the expectation of working together, to tell a story, to spring off each other and support teammates. But collaboration isn't what we necessarily expect from video games.

Recently I've become much more interested in these tabletop collaborative environments because I don't have the time and energy to engage in the mode of "you will perfect your body through endless hours of competition in steel and fire." I don't have time for that shit, and I don't particularly enjoy it. That school of thoughtthe large camp of people interested in refining skill in hundreds of hours of gameplay-carries over into a lot of academic practices in games. The same people have this very similar macho approach to how games are taught in academic settings, and they engage in hours of fierce, competitive debate. I just don't have the energy for that sort of thing, either in my academic life, or in the games I enjoy playing in the company of my friends.

Returning to the theme of "survival," a lot of my experience and that of marginalized creators is that they have had to spend a lot of time in survival mode, and so that mode does not lead to hours of debate. There's a degree of privilege that someone needs to have in order to engage in these academic debates, and since they aren't dealing with survival in everyday life, they need to turn an intellectual debate into a battlefield. I'm so exhausted of having to be in survival mode all the time that I don't want to fight anymore! I don't want to do endless battle with all of my colleagues. That's so exhausting. This 
mentality of always being in competition with everyone-it's such a shitty way of viewing human relationships. I want to collaborate with my friends. I want to make beautiful, creative things together.

TF: This kind of collaborative, creative encouragement seems to be a theme in a lot of your lectures and writing. For example, your text Rise of the Videogame Zinesters has been so helpful to so many people in the gaming community, both students and teachers. ${ }^{1}$ Because it is aimed at an audience that may have limited to no experience in coding, what are some of the unique challenges you've encountered teaching game design? Can you describe your approach to teaching gaming?

AA: I teach undergraduate classes at all levels of the [DePaul University Computing and Digital Media] program. I've taught some of the first classes freshman take when they come into the program, and I've taught the capstone project before they graduate-pretty much all over the board. For me, a lot of the challenge is that game students arrive very set in their ways about a lot of things. This, I imagine, is true of a lot of disciplines, but I think it's especially true of games. They arrive with rigid ideas of what games are, what they are capable of, what they are for, and what it takes to make games. A lot of my struggle is to shake them out of that and get them to think critically, think about themselves as artists, engage them in conversations about games in the field, and show them a wider range of experimental work. I enjoy it because of the handful of students that connect with what I'm offering. But it's also frustrating because it's an uphill battle in terms of capturing students' interest, and also [university] administration often doesn't see the value of experimental work either.
There's a huge debate going on with games programs, which are still very new-the idea of going to university to get a degree in game design is still super new-about whether soft skills or hard skills are more important to teach. Hard skills are developed in learning the tools, like, how you use Unity, or Unreal. The soft skills deal with learning how you design an experience, how you frame it in a certain way, how you think critically about the art you're making-all the stuff that makes you a better artist. But it's hard to quantify. The administration is very outcome-oriented. They want measurable metrics. I go to meetings once a quarter where someone shows me a series of bar graphs for two hours. That, to me, is not what the program is about. A program that focuses only on hard skills is not a good program, because those tools will all be replaced when they're outdated. You can learn how to use tools from the internet. I have done that. I used to be an Adobe Flash game developer. What's more important and what will carry over from tool to tool is to know how to think critically, develop a design sensibility, and cultivate your own aesthetic. It's much more useful to you in the long run. You spend four years-or more!-in an academic environment where you have access to people who are critical thinkers and engaged in the field of game design. That's such a tremendous resource. My perpetual struggle is for the program to be more of an arts education. There are other forces that are pushing for it to be more of a trade school. For administration, it's more marketable. But that's a disservice to students.

TF: In teaching games with this more arts-oriented sensibility, what texts and games do you find it helpful to assign?

AA: I actually keep a list as a Google Doc, which 


\section{WHEN WE HAVE EACH OTHER WE HWV

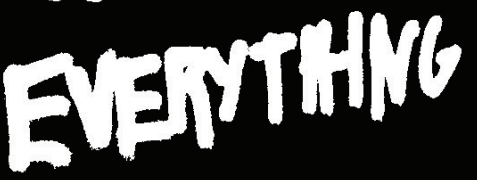

Anna Anthropy, afterword from Queers in love at the end of the world, 2013. Image courtesy of the artist.

I made public, of all the examples I use in my class. ${ }^{2}$ For example, in a class I will be teaching again this quarter called Advanced Games Design, students work on two projects over the course of the quarter. One is a comedy game, the other is a game about intimacy. Those are the most challenging subjects for game design. I assign all short, small games. They are so much better at communicating ideas, and also better at communicating comedy. You can't sustain a joke for 80 hours. There's a game called Tiny Sorceress (Leon Arnott, 2012) which is only a couple of minutes long, and it has impeccable comic timing. Also, its comedy emerges within the interaction in the game, which is so rarely the case for comedy in games. Usually, the comedy comes from presentation and writing, aspects of the game that are not unique to their game experiences. And the Crows, Crows, Crows game Dr. Langeskov, the Tiger, and the Terribly Cursed Emerald: A Whirlwind Heist (2015), where you are essentially running around backstage of a one-player game, operating the special effects. It's such a perfect example of situation comedy in games done really well. The idea is that the humor flows from the interactivity rather than a surface layer. I'm always on the lookout for succinct games that have a useful idea. I feel teaching has transformed the way I consume games, so now, whenever I'm playing a video game, I'm constantly thinking, "Can I use this?" It's been surreal playing on that level. I play even more than I used to, since I'm accumulating all this teaching material that I think will resonate with students.

TF: I love the idea of assigning both a comedy and intimacy project. It reminds me of a game of yours I so often use to teach game design, Queers in love at the end of the world (2013). It's a perennial favorite of mine-it's a hypertext game made in Twine, originally created for a game jam with the theme "ten seconds." It's an incredibly af- 
fecting, albeit short, text "adventure" supposing you only have ten seconds left in which to interact with your partner before "everything is wiped away." Though its apocalyptic conceit of a ten-second timer ensures that you won't survive, Queers in love approaches another kind of survival, namely the survival and transcendental power of queer love. Why do you think your approach to portraying this subject works so well in a Twine/text adventure format?

AA: With Twine, and Bitsy as well-Bitsy is the current exciting platform for a lot of outsider authors-they are really great at showcasing expressive works because they're way more accessible to people who are marginalized. Both Twine and Bitsy involve not a lot of scripting and no real programming for the most part, so it breaks down barriers for people who have the most to say about intimacy, relationships, and emotional struggle. These people are able to actually make work in those formats and distribute them. Also, there's a lot of human experience and complexity that's a lot easier to communicate in text than in, maybe, a more visual approach to game design. These are prohibitive barriers for the people who are the best equipped to tackle these subjects. It's all about access, I think.

TF: I'd like to ask you about some of the other games you've made, all of which approach the concept of "survival" from different directions.

Your game REDDER (2010) conforms more to recognizable modes of survival in gaming; it's

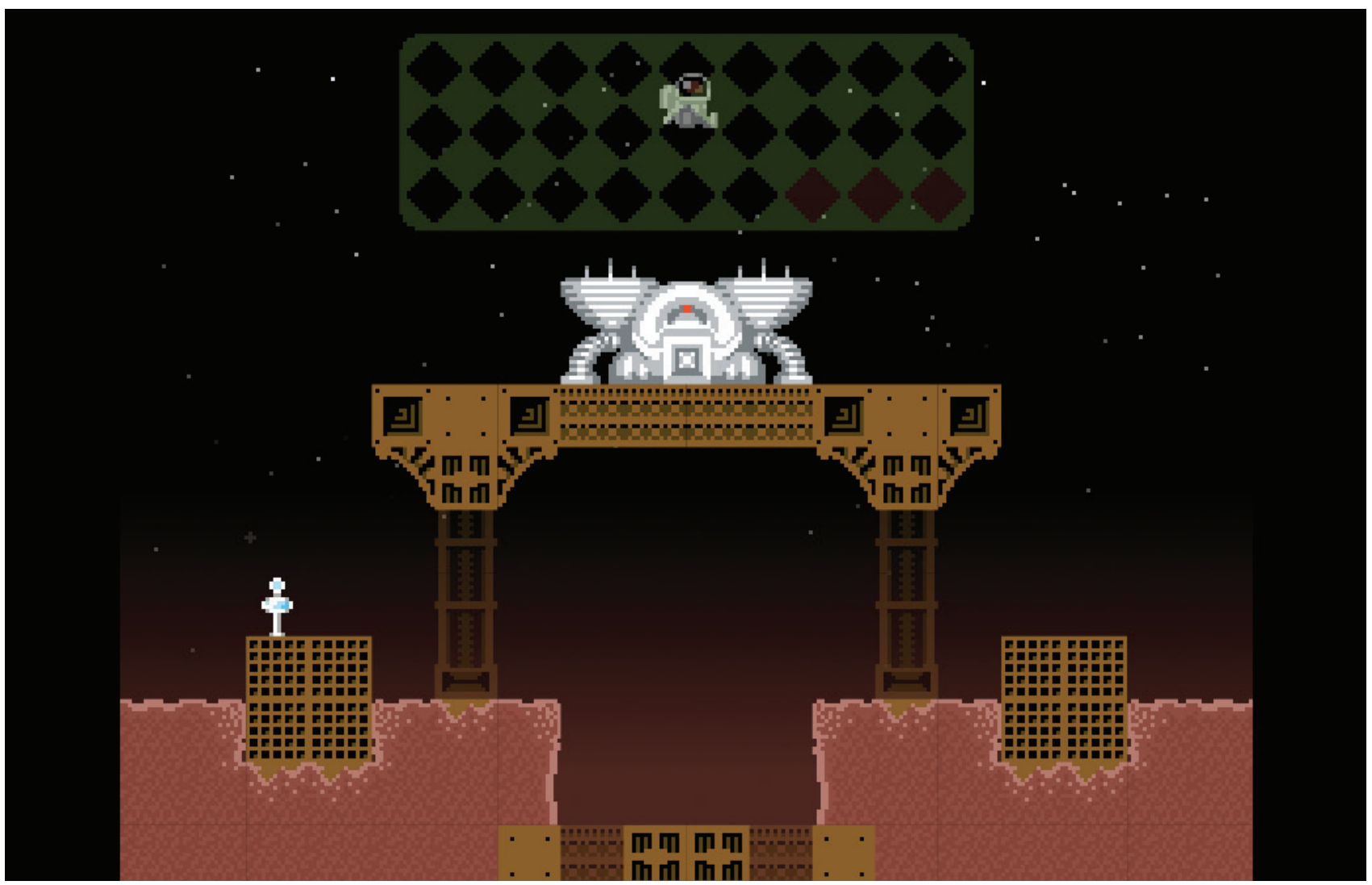


a puzzle-platformer in which a stranded astronaut needs to collect crystals to power a starship. However, the aesthetic choices you made in developing the game speak to the more fundamental issues of resource depletion and/or mental health. How did you come to use intentional glitching as an aesthetic choice within the game narrative? Was that something you planned early on, or did it come later?

AA: Oh, it's so interesting-I actually hit on the idea really, really late in coding the game. That game was originally designed as a really boring puzzle-platform game, and then became this other thing near the end. There are two layers to the work, the first being the platformer, but the other is this willful destruction of the world due to completionism. And those two layers are completely authentic, because the game was designed sincerely to be both things. It's a really disjointed work.

Speaking of survival strategies, I just needed to finish and sell a Flash game that would pay my rent for another few months. And so I was trying to make something that I thought would be marketable-a puzzle-platformer taking place in an explorable, open world, what people call Metroidvanias. I was really frustrated working on it. It was a potboiler for a long time that I was working on out of necessity. It felt incomplete to me, lacking in something interesting to say. I was literally on a phone call when I finally hit on the idea that became the finish of the game. It was interesting that it was a layer that I added on at the very end, and it became another thing entirely and made it exciting to work on again. It's cool because a lot of my strategy for working on games at that point in my career was creating a Trojan horse-like situation that inserted things that I thought were interesting into indie games. In this case, it's an explorable puzzle-platformer, but it slowly becomes more monstrous over the course of playing, and transforms into something interesting to me, which is the bullshit, artsy-fartsy thing. It's a magic trick I liked to pull at the time.

TF: That's also like your game Lesbian SpiderQueens of Mars (2011), and how it approaches subjects of BDSM and consent. I had originally heard about the game because it was included in the 2011 Bad Bitches exhibition at Brooklyn's Babycastles, curated by the prolific video game writer Leigh Alexander. Alexander often writes about how games with themes of sexuality are good for us. Even so, your disclaimer for the game on your itch.io page warns: "this is the TOTALLY UNCENSORED version of the game, and is not recommended for people who are uncomfortable with the thought of a half-human half-arachnid space dominatrix eschewing a bra." It was originally shared through the Adult Swim website, correct? How did this game come about?

AA: [The Babycastles exhibition] is the first time the uncensored version of the game had been shown in public. I somehow managed to convince Time Warner to give me a lot of money for that game. I originally set out with the intention to sell the game to Adult Swim. It was a particular moment in the flash games bubble where there was a lot of money in those games, and Adult Swim was a really exciting and interesting Flash web games publisher. They were working with Mark Essen [Messhof game studio, Nidhogg (2014)], Cactus [Jonatan Söderström, Hotline Miami (2012)], and a lot of other developers and the more experimental indie bros of the time. So I 


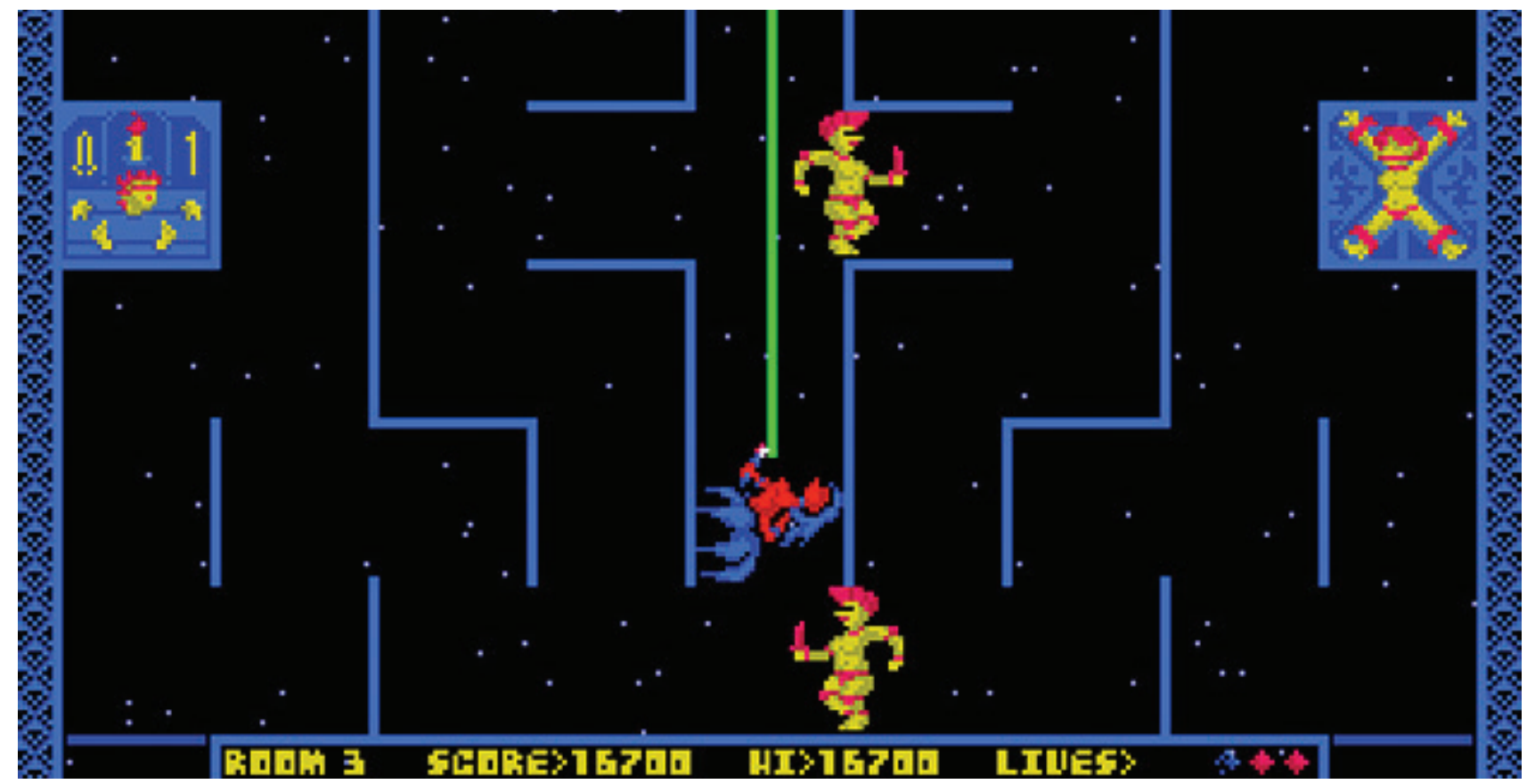

Anna Anthropy, screenshot from Lesbian Spider-Queens of Mars (2011). Image courtesy of the artist.

knew someone who knew someone, and I was like, "If they could do it, why not I?"

The premise of the game came from the title, Lesbian Spider-Queens of Mars, which was given to me as a gift. A friend of mine was a student, and for his capstone project he had brainstormed a bunch of different names for potential game projects. One of them that was particularly beautiful and perfect was "Lesbian Spider-Queens of Mars," and they were like, "We can't really do justice to this. This is not really for us." He said, "Anna, we came up with this title, and it's for you. You just have to think up what the game is." I actually spent a lot of time working out that knot-What game is this? What will I do with it? There were a lot of false starts finding the thing that would become that game. Once I found it, it was pretty clear that it had to marry the tropes of formative 1980s coin-op arcade games with sci-fi, B movie, pulp fiction and make a weird hybrid that was also specifically about kink. That was the tail end of that phase of mine that I mentioned earlier, where I would take ideas that were interesting to me personally, such as queer spider doms with bondage lasers, and putting them into formal digital games that could be played by people interested in a more traditional video game experience. I could shoot them with queer beams the same way they do in the video game.

It's connected to a lot of the work that I'm doing right now, which is a lot of short, playable, role-playing experiences. It's finding a particular moment that I experienced, or a thought process: like being on the train and noticing someone's got a polka dot shirt, and mentally drawing constellations by drawing lines connecting the dots. It's a moment that happened in my head that I can try to put it out in the world, much like how poems are experiences the poet tries to commu- 


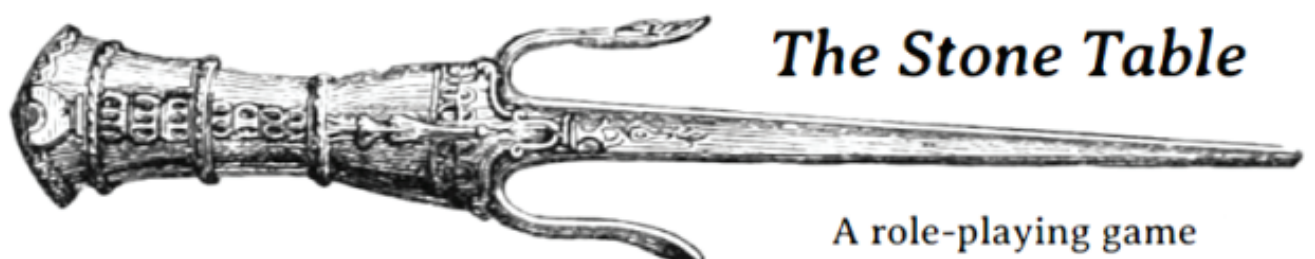

You are someone much loved by your people, perhaps a prince or priestess. Today you will be given their highest honor: You will be sacrificed in a ceremony of blood and violence to appease your gods.

Play this game while preparing and cooking a meal. It can be any dish that takes time to prepare, but the bloodier and wetter the better.

Anna Anthropy, excerpt from The Stone Table, 2018. Image courtesy of the artist.

nicate to the larger world. What I've been doing lately is trying to take mundane settings and situations-like making food or getting dressed in the morning - and trying to build a layer of storytelling around that and make it into a ritualized experience in a way that games are particularly good at.

TF: Of these recent games you have made, which is your favorite right now?

AA: One game that I think is under-loved that I'm really proud of that I made recently is called The Stone Table (2018), which is essentially a roleplaying game about being groomed as a human sacrifice, but the game is played over the course of preparing a meal. The idea that every action that you take in preparing this meal-setting out ingredients, boiling the water-has meaning within the story of the protagonist being groomed by attendants, being washed in oils, wrapped in silks, and ultimately torn apart in a really violent, bloody ritual during the consumption of the meal. It's a really dark game, but for me it's also a perfect way to take this mundane activity and re-contextualize it in a way that is extremely narratively interesting to me. No one seemed to cared about it when I put it out, so that's why I think it's my favorite thing that I've done recently.

TF: Anna, thank you so much for agreeing to this interview.

AA: Yes, and thank you. $\rightarrow$ 


\section{Notes}

1. Anna Anthropy, Rise of the Videogame Zinesters: How Freaks, Normals, Amateurs, Artists, Dreamers, Drop-outs, Queers, Housewives, and People Like You Are Taking Back an Art Form (Seven Stories Press, 2012).

2. The Google Doc, as of August 24, 2018, can be found here: https: / / docs.google.com / document/d / 1oSphenHNqcSaBlO2BlruYTx7i0GyLXoJaCFatAZuzrY / edit?usp=sharing. 


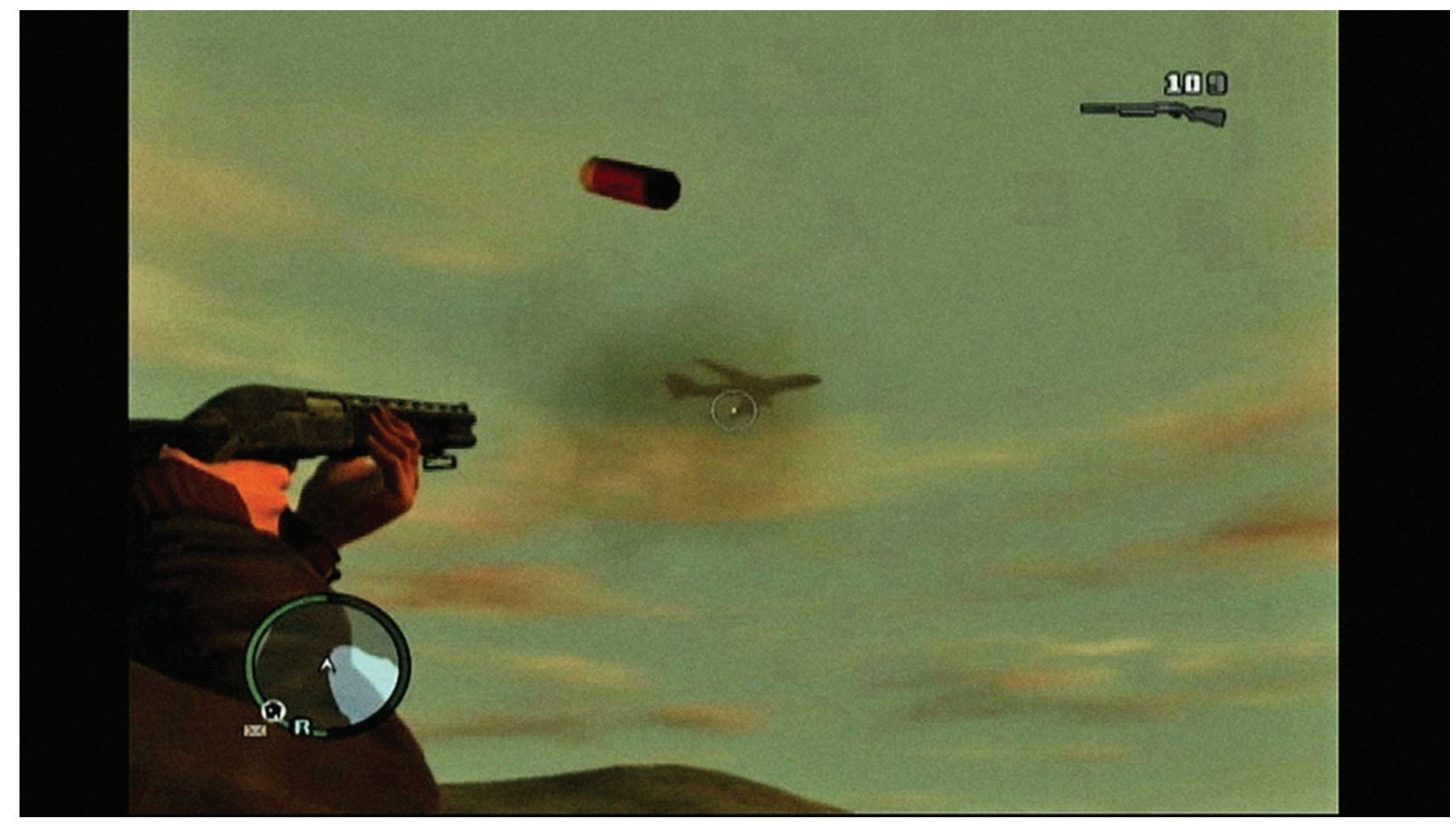

Figure 1. Clint Enns, 747, 2011. Image courtesy of the artist.

\section{Survival Interventions in GTA: On the Limits of Performance in Virtual Environments}

\section{Martin Zeilinger}

Senior Lecturer in Media, Anglia Ruskin University

\section{Abstract}

The subject of survival in virtual environments has emerged as a potent site of critical and artistic intervention in video games. Influenced by traditions in performance art practices, in particular the critiquing of sociopolitical power systems through the radical, performative use of bodies, many current artists effectively use existing game platforms to address conflicts at the intersection between the individual and system. This essay ex- plores the performative affordances of Grand Theft Auto (GTA) game worlds as a research tool, subject of critique, or theatrical stage. Though survival is difficult to address successfully in virtual interventions, the trope of survival as coded in game environments can be mobilized by virtual performance artists to address problematic limits and constraints dictated by the algorithmic systems framing gameplay. 
Survival in the networked, late-capitalist, postdemocracy anthropocene, is a difficult undertaking, and a struggle that is powerfully gendered, racially marked, and speciesist. This holds true for many virtual game worlds simulating life and death in contemporary times; the existence of death in a game world might be interpreted as indicative of its "authenticity," yet virtual, simulated death is rarely authentic-except, perhaps, in how it perpetuates and exaggerates real-world inequities and conflicts. Regardless of how virtual death in game worlds is regarded, for player avatars and non-player characters alike it is intimately tied to both ideological and algorithmic rule systems governing their existence. Given that game worlds like those found in the virtual Grand Theft Auto (GTA) franchise localities of San Andreas and Liberty City are full of death and killing, shouldn't there be some room-or rather, a powerful need-for a meaningful critical discourse of survival?

"Survival" is often understood as an instinctual struggle against death, closely linked to the self-preservation drives of sentient creatures. However, the concept goes significantly beyond struggles to stay alive. For example, survivalism, as a lifestyle organized around the honing of survival skills, is frequently linked to libertarian political perspectives on self-reliance and independence from-or resistance againstdomineering political structures. Particularly in contemporary socio-political and cultural contexts, survival has taken on a wide variety of broader meanings: in cinema, it has become a dominant narrative trope of dystopian "battle royale" scenarios and near-future environmental disaster epics; it is a prevalent premise for reality television competitions focused on the mastery of difficult-to-attain survival skill sets, appealing to audiences fascinated with survivalist lifestyles; in video games, survival functions similarly, providing the underlying theme for horror games, or the operational logic of games foregrounding the simulation of survival struggles in open-world wilderness environments.

Overall, survival invokes a complex bundle of existential struggles, political convictions, and cultural experiences. What ties these together is that survival usually tends to indicate the opposite of "death," regardless of whether that concept is understood in its biological, social, or political permutations. To survive is to act or exist persistently within a system, struggling against the systematic constraints and obstacles encountered. Beyond simply "staying alive," the ongoing struggle to survive thus also serves to identify gaps and limits within systems. In other words, survival can, ideally, become a critical tool in highlighting problematic aspects that natural, political, social, or cultural systems force upon survivors.

Resisting death in virtual worlds has the potential to emerge as a key site of critical intervention in the cultural and computational logic of video games. This essay surveys a number of artistic experiments that pick up traditions of performance art, in particular the critiquing of socio-political power systems through the radical, performative use of bodies, in order to address conflicts at the intersection between the individual and system. In doing so, my aim is to explore the performative affordances of GTA game worlds specifically, and those of virtual worlds more generally. Contemporary video 
games often feature sophisticated built-in content creation and capturing tools, and are among the most complex simulation environments available to artists. These manipulable game environments can serve as research tool, subject of critique, or theatrical stage. How do struggles of survival become manifest in these simulation environments? How are political problems of survival taken up within the simulated spaces of game worlds, both in response to the prompts of game mechanics and game narratives, and in explicit resistance to them? What critical purpose might the virtual performance of survival seek to adopt in broader socio-political discourses on life and death, living and dying? And finally, can performance art, with its fundamental reliance on liveness and the connection between performer and audience/ participant, survive transposition into virtual environments? Though survival is difficult to address successfully in virtual interventions, the trope of survival as coded in game environments can be mobilized by virtual performance artists to address problematic limits and constraints dictated by the algorithmic systems framing gameplay.

In sketching some answers to the questions outlined above, my discussion will largely sidestep game-engine-prompted survival strategies. Bracketing what might be called "survival-bydesign" (such as mastering battle techniques, or avoiding accidental environmental death), the focus will be on critical invocation of survival in ways that are not anticipated by these algorithmic systems. My discussion of artistic experiments that problematize staying alive in algorithmic environments references works by Joseph DeLappe, Brent Watanabe, Jim Munroe,
Clint Enns, Georgie Roxby Smith, and COLL.EO. The artworks considered pursue different strategies and aims of survival; this chosen corpus of GTA-specific game art interventions will frame a consideration of the limits of performative action in highly structured algorithmic systems, addressing how algorithmic survival in "human-occupied" virtual spaces can become the focus of a new type of virtual, non-human performance art.

The Grand Theft Auto franchise has become a popular framework for the realization of digital artworks that engage performance art traditions. Among the more well known performances is Jim Munroe's My Trip to Liberty City, created within GTA III as part of the artist's Pleasure Circuit Overload series, completed in 2006. ${ }^{1}$ This machinima piece takes the form of a short travelogue that humorously chronicles the visit of a Canadian to GTA's fictional Liberty City. His touristic exploits there include exploring back alleys and rooftops, taking souvenir photographs, and performing a pantomime busking act on a street corner. Edited from in-game footage, the piece features a voiceover invoking casual "Let's Play" video commentary. Posited as an implicit critical engagement with Liberty City's notoriously violent environment, Munroe's piece attempts to steer away from all brutality. Given the work's emphasis on environmental exploration, enjoyment of scenery, and (attempted) non-violent interaction, it might be tempting to describe My Trip to Liberty City as a successful subversion—or "surviving" - of the game's proviolence prompts. This would be an incorrect interpretation, however, since the in-game footage used for the creation of the machinima was 
(and could only be) created in conscious and direct relation to the violent themes and mechanics of the game, which, as Ian Bogost has pointed out, "constantly structures freeform experience in relation to criminality." What Munroe's travelogue achieves instead is a foregrounding, by proxy, of the structural, systemic violence of GTA III. For example, the Canadian tourist's visit to the hospital (made necessary after he falls into the water on the shore) narrativizes a game mechanic directly connected to the game's life-death-spawning cycle. To give a different example, the player character's street-busker pantomiming (which consists of the enactment of pretend-fistfights) may initially also seem like a peaceful refusal of the game's violent tendencies. But again, the refusal is unsuccessful, better described as the reshaping of an incomplete act of aggression; the content of the busking act is a forced performance of actual virtual violence when the game engine, relentlessly focused on detecting and responding to violent action, registers the pantomiming as an actual attack on a non-player character (NPC) pedestrian. Munroe's piece does not successfully subvert the violence encoded in GTA III, but instead, enacting a literal performance in the form of a busking act within the game space, highlights that this violence exists in the game's computational fabric on an insurmountable, granular level. Even in acting non-violently, the artist constantly gestures towards this violence, which cannot, in fact, be negated. Here, attempted non-violent survival in Liberty City forever proceeds by provoking inevitable death.

Like My Trip to Liberty City, Georgie Roxby Smith's GTA-based machinima performance Fair
Game [Run Like a Girl] (2015) stages a struggle for survival that clashes with a hard-coded algorithmic system seeking to enforce constant violent interaction. Fair Game is strongly oriented towards performance art traditions. Described by the artist as a performative intervention, the work was created in GTA V Online, and is roughly fourteen minutes in length. For the entire duration, the artist, embodying the franchise's prototypical male player character, pursues a female NPC on foot. The NPC screams in horror, and is chased first through the city, then through a more rural area, and finally along a busy highway. As Smith explains, her intervention seeks to critique the male chauvinism inscribed in the game at code level by amplifying it: in the narrative and computational logic of the game world, whenever a male player character "encounters" female NPCs through simulated touch (such as bumping into them), the NPCs are designed to respond initially by giving the player some "attitude," and then to "screech and 'run like a girl."'3 This hard-coded behavior cannot be changed or counteracted by the player. It is sexist in multiple ways: the "sassy/terrified" reaction is established as normative, and many players will likely experience it as standard behavior once it has been triggered and witnessed repeatedly; additionally, the only way for the male player character not to behave in an intimidating and threatening fashion towards female NPCs is not to approach them at all, which suggests that in the game's register of male/female encounters, nothing outside of the predatory is possible.

The hardcoded survival instinct of GTA V's female NPCs enables Roxby Smith to performatively inhabit some of the game's sexist (and 
racist) stereotypes so that they may be re-contextualized and implicitly critiqued. Smith, who describes her work as feminist, has called this approach "teasing out societal glitches that perhaps go unnoticed in the everyday." ${ }^{4}$ An important corollary to the artist's critical role inversion here is that Smith's insistent and disturbing foot chase is also a search for the "exit condition" of the female NPC's hard-coded behavior: did the game designers include a computational scenario in which a female NPC can get away and "survive"? Unsurprisingly, this is not the case. The "end point" does not exist. ${ }^{5}$ While Fair Game [Run Like a Girl] feels more like a confirmation of this fact rather than a discovery, it nevertheless demonstrates quite powerfully that unless the player character "releases" their victim (an act that in itself would be a performance of a problematic power differential), there is no survival for the female NPC: at the end of Smith's intervention, she is run over by a car. Again, it might be argued that the key subject of the artist's performance here is not constituted by the narrative content of the piece; the body with and through which Roxby Smith's performs is the source code substrate of GTA $V$, which systematically dictates specific (and highly problematic) modes of survival.

Another GTA-based machinima foregrounding the impossibility of eliciting specific reactions within an algorithmic system is Clint Enns' 2011 video 747, which reenacts a 1973 Chris Burden performance of the same name (fig. 1). Where Roxby Smith shows the player character's inability to break out of game-dictated violent interactions, Enns' piece is based on provoking a violent response from GTA. However, the machinima performs a provocation which the game's AI cannot understand, and the violent response is therefore never issued. In Burden's original performance, the artist fired a handgun at a passenger plane taking off from LAX and documented the act photographically. The reenactment is staged in GTA IV's Liberty City, where Enns' player character fixes a passenger plane in the crosshairs of a shotgun (sharing the perspective with the viewer) and fires at it. Burden's original quixotic gesture helped foment the artist's position as a radical artist-terrorist. It simultaneously performed power and powerlessness in the face of rigid rule systems, and problematized the ways in which life under the rule of law flattens the critical difference between agency and futility to the point where it becomes difficult to distinguish between aggression and inertia. Reenacting (and mocking) art historical traditions of radical intervention, Burden provoked the rule-enforcing legal apparatus: shooting at flying planes is a crime virtually anywhere in the world. At the same time, he safely remained in a speculative domain, since his action failed to yield any "results" beyond unverifiable photographic documentation. As Daniel Cottom has noted, Burden's pistol is pointed critically at the concept of performance art itself, and at the simulacrum of "high art."

In Enns' piece, the shotgun that has replaced Burden's pistol is additionally pointed at the algorithmic regime that enforces the rule system to which Liberty City adheres. While this regime appears to strive for realism, designed to punish violations of its order often with the player character's death, it simply cannot recognize Enns' intervention. The aggressive act of shoot- 
ing at the plane remains unacknowledged and un-reified; it is not followed by the expected violent response. Following from the way in which audiences and critics have doubted that Burden's intervention was "real," one might ask about the meaning of Enns' in-game gesture in relation to the algorithmic system at which it takes aim. The system cannot recognize it, and it fails to trigger in-game reification-throughviolent-death. Does this mean that algorithmic logic is outsmarted through the performance of a gesture that cannot be meaningfully interpreted, and if so, is this a successful virtual survival tactic? Enns has suggested that he is hesitant to characterize his version of 747 as a performance work. ${ }^{7}$ I would propose that such a description is at least a fitting approximation: use of an avatar that serves as a surrogate for the artist represents a strong dramatic stance and gestures towards an embodied performance with all its requisite associations. In this sense, it is important to consider Enns' 747 as a performance work because it points to the potentially limited operability of performance art concepts as part of critical interventions staged in highly structured algorithmic game environments which, by design, will only permit predetermined sets of interactions.

Like Enns' machinima adaptation of Burden's 747, COLL.EO's Liberty City Crawl series (2017) restages performance art within a virtual environment to explore the extent to which subversive action can provoke (or fail to provoke) specific responses. In doing so, this work specifically foregrounds a convergence of ideology and computational logic encoded in NPC behavior. ${ }^{8}$ Colleen Flaherty and Matteo Bittanti, the media artists behind COLL.EO, created their recent se- ries Liberty City Crawl to reenact seminal performance pieces by William Pope.L in GTA IV. The series extends Roxby Smith's attention to gender to an exploration of the critical positions a player character might take vis-à-vis systemic racism. The original performances, in which William Pope.L crawled through parts of New York City without contextualizing his activity as "art" or "performance," were celebrated for the unsparing immediacy with which they allowed the artist to face off with inequalities and racism of contemporary NYC. COLL.EO's reenactmentsin which an avatar of William Pope.L replays his performances Tompkins Square Crawl (1991) and The Great White Way (2002) in GTA IV's virtual version/parody of New York, Liberty Cityclearly invoke these sentiments, but it is somewhat uncertain what they achieve beyond the translation of William Pope.L's gesture into a different medium. Ultimately, this translation represents a modal shift that inevitably recedes from the original's radical performative stance. The reactions that Liberty City Crawl manages to elicit from the virtual environment are a far cry from the shock and anger triggered by William Pope.L's performance work, and registers more as bafflement or indifference. ${ }^{9}$ As in Enns' version of 747 , here, too, the GTA game world cannot be provoked to elicit an adequate response to the intervention, since the recontextualized crawl remains illegible to its responsive environment and the NPCs that inhabit it. And again, this begs the question of what kinds of performance interventions virtual environments are useful for.

If the impact and effectiveness of performance work carried out in virtual spaces is inevitably re- 
stricted by the algorithmic constitution and rule system within which it occurs, should it have to be concluded that the performative gesture itself cannot survive transposition into virtual environments? What the artworks discussed so far share is that they force viewers to recognize the cultural logic of the "real world" in the complex, AI-driven simulations of the GTA game worlds, but also that these algorithmic environments are rarely designed to facilitate critiques of this cultural logic. When the NPCs of Liberty City remain indifferent to the simulation of a black man crawling through violence-ridden virtual urban space, this is decidedly different from the indifference William Pope.L faced in his IRL performances. The pieces under discussion serve to foreground the cultural logic as it is reflected in the code systems of virtual game worlds, but it is not so clear how effectively they can critique or even challenge it. Put differently, the artworks discussed draw our attention to a struggle with the limits of performativity in simulated environments. When neither a critique nor its recipients are "embodied," when an intervention is performed for an algorithmic system that cannot perceive it, or when the (simulated) action is entirely contingent upon a horizon of possibility and parameters of permission that are prescribed by the game logic, then one might wonder what meaningful critical element typically associated with performance art can remain. Can we adapt a familiar Internet adage and state that "In Grand Theft Auto, nobody knows you're a performance artist"?

One answer to this problem is that when artists begin to perform in and through embodied, simulated characters in virtual environments, we must reconsider both the object and the subject of the resulting performative act. In a brief discussion of two further GTA-based artworks, Brent Watanabe's San Andreas Deer Cam (2016) and Joseph DeLappe's Elegy: GTA USA Gun Homicides (2018), I want to conclude by asking whether (and how) virtual performance work can overcome the aforementioned challenges to recuperate some of the critical valence of performance in virtual environments. Watanabe's San Andreas Deer Cam was conceived as a realtime, long-term video broadcast based on a custom GTA $V \bmod$ in which the player-controlled protagonist is replaced by a virtual automaton taking the form of a quasi-autonomous deer freely roaming San Andreas. ${ }^{10}$ Watanabe designed the deer to respond fairly realistically to its environment, with the important exception that it appears to be immortal: the deer might have run-ins with gang members, be mowed down by highway traffic, get involved in police chases, witness a variety of NPC interactions, arrive at random picturesque locations, topple off cliffs, or get stuck in the landscape. Throughout all these encounters, the deer appears to exhibit basic instinctual behaviors-such as fleeing from harm-while overall displaying a profound disinterestedness in its surroundings. Over the course of the artwork's broadcast, the game world's responses to the deer's presence often took the form of a hysterical frenzy of violent pursuit or panicked evasion; however, San Andreas could not touch it and its uncanny survival skills.

In its original iteration, San Andreas Deer Cam was generated in realtime in the game engine and live-streamed on Twitch. ${ }^{11}$ This meant that the deer "lived" in a continuous, persistent time- 
frame that preceded any viewing of the broadcast, and continued beyond it. The deer thus existed not only in a strange narrative disregard for the virtual environment it inhabited, but also as detached from the material world for which it appeared to perform its continued survival. These characteristics are noteworthy because they facilitated the emergence of San Andreas Deer Cam as what might be considered a new type of algorithmically determined performance art. In 2016, Watanabe's San Andreas Deer Cam was shown at the Toronto-based Vector Festival. ${ }^{12}$ The work was included in the festival flagship exhibition at InterAccess Gallery, where it showed in a black-box setup on a wall-mounted monitor, as well as in a large-scale off-site screening on two massive, 30-foot LED screens in suburban Mississauga's Celebration Square (fig. 2). ${ }^{13}$ The screening took place on a mid-July weeknight, with a large audience of mostly unsuspecting members of the public holding picnics, playing in the fountains, practicing parkour routines, throwing footballs, and racing along on scooters. The screening began before darkness fell, so the massive screens were framed by the towering silhouettes of central Mississauga's faceless condominium towers. On the massive screens, the deer roamed San Andreas beyond the reach of players and NPCs alike, enacting feats no player could ever hope to achieve within the time and space constraints normally imposed by the game engine. While some in the audience may have

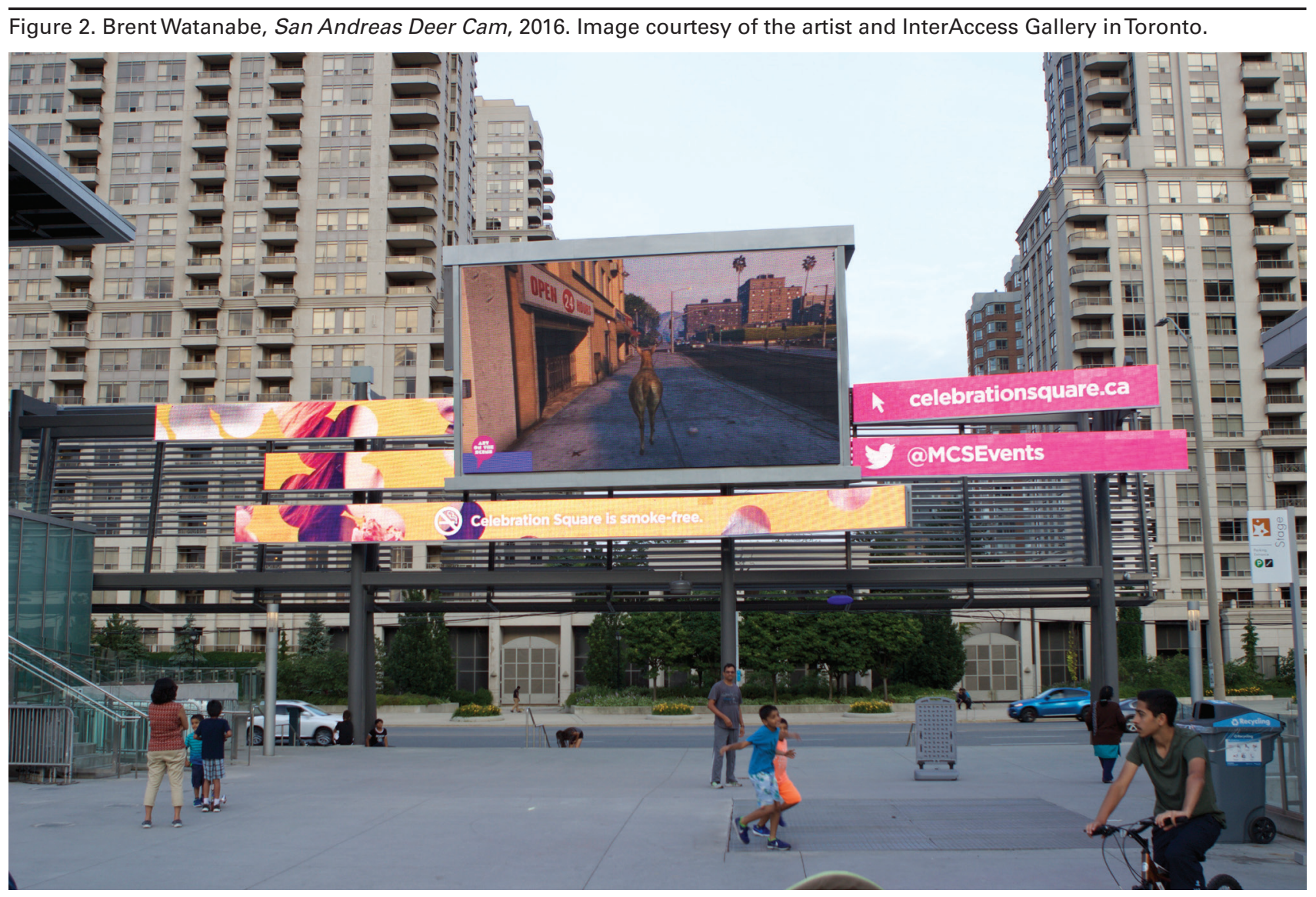


been uncertain whether or not the deer was controlled, its actions performed by a human player, it seemed clear that the real performance consisted of the deer's quasi-autonomous interpolation of a resistance to the algorithmically enforced violence and the constant cycle of virtual dying that characterizes GTA. While the game footage was still violent in its depiction of countless attacks on the deer, death remained conspicuously absent. Even to viewers unfamiliar with GTA, it was clear that the algorithmic substrate framing the deer's activities, as well as the performance's human audiences, remained incapable of making logical sense of its presence. The perceived liveness and realtime-ness of the roaming deer functioned both as an extension and as an incarnation of its inviolate survival skills. In the context of the public event, San Andreas Deer Cam ultimately provided an immersiveness and immediacy approximating an experience traditionally associated with performance art.

On a final note, Joseph DeLappe's recently completed Elegy: GTA USA Gun Homicides (2018) offers a good example of this kind of immersive performance art experience. ${ }^{14}$ Created in collaboration with Albert Edwin (coding) and James Wood (consultant), DeLappe's piece is designed to stream on Twitch, and is conceived as a critical data visualization tool that transposes statistical data on US gun violence into the virtual environment of Grand Theft Auto. Like San Andreas Deer Cam, the real-time GTA machinima Elegy critically reworks established performance art conventions against the backdrop of explicitly visualizing violence and survival data. Restarting at midnight every day and set to run for a full year until July 4, 2019, DeLappe's mod shows a first-person view of the GTA $V$ game world, with the viewer's vantage point tracking backwards slowly through the streetscapes of the game environment. What unfolds on the screen, day by day, is the killing of NPCs at the hands of an unseen shooter who appears to share the viewer's approximate position in the game space. The number of daily shootings of NPC inhabitants corresponds to daily updated statistics on US gun-related deaths. ${ }^{15}$

Importantly, viewers cannot interfere with the action, nor can they escape the gruesome spectacle. Viewers are forced to inhabit the video game first-person perspective generally associated with the ability to assume agency, controlling interactions in the game world. In Elegy, this ability is removed at code level, forcing the viewer to witness these mass shootings. Like San Andreas Deer Cam, Elegy plays itself, a key aspect of the piece that is further reinforced in the daily repetition of the mass shootings occurring across the US every year. I would argue that this factthat the artwork plays itself and is repetitive-is among Elegy's most powerful aspects. While Elegy is disturbing even if seen simply as a visualization of raw, statistical data, contextualized in a video game frequently invoked in discussions of violent, and supposedly violence-inducing, games, it is in the artwork's self-playing and repetitive nature that its critique fully unfolds. In Elegy, gun violence is experienced as inescapable and unpreventable. Like the first-person perspective assumed by the viewer, the seeming inescapability is algorithmically enforced, building on pre-existing affordances of the GTA game world-namely its ability to enforce violent behavior. Elegy thus achieves more than merely 


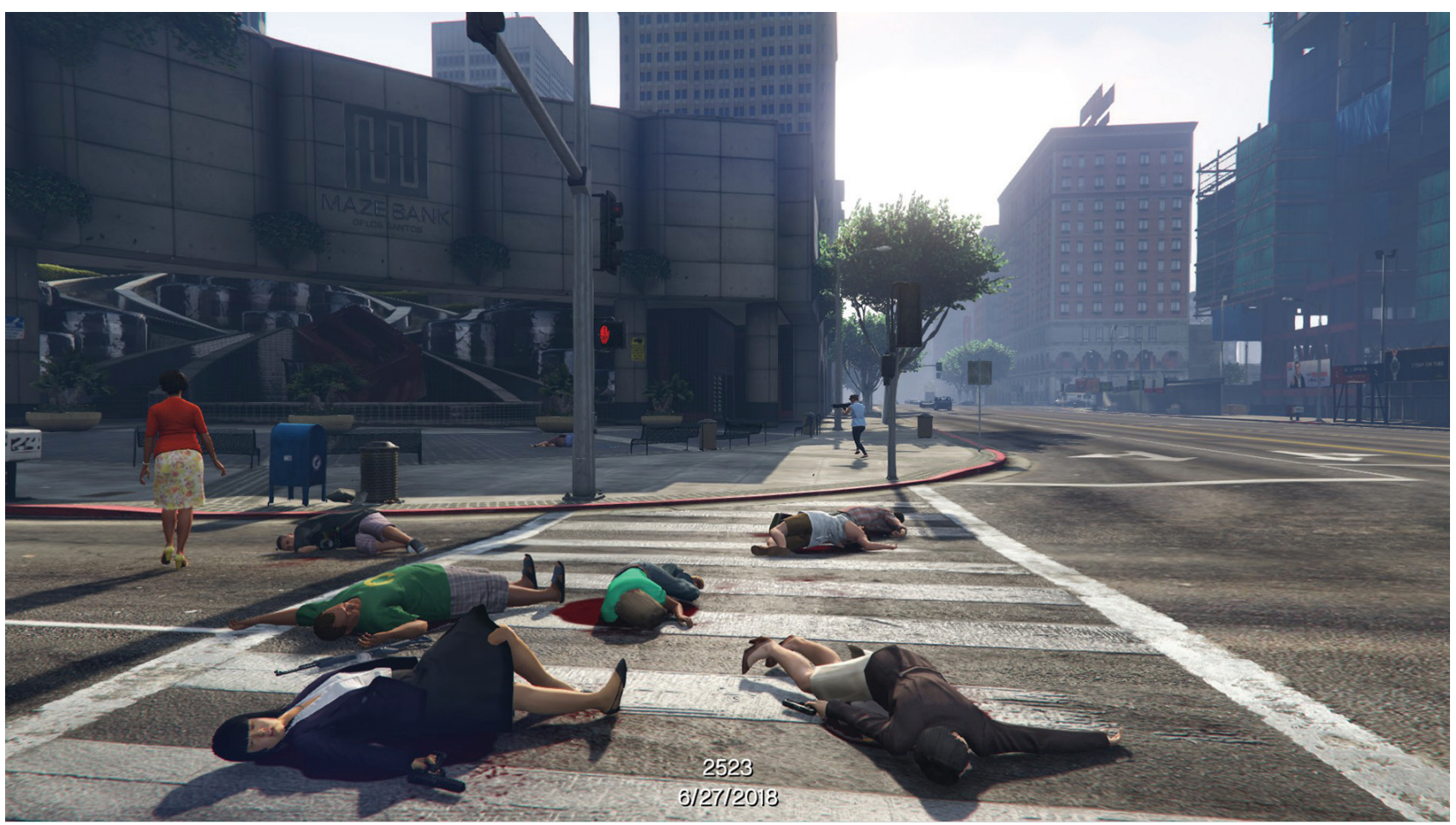

Figure 3. Joseph DeLappe, Elegy: GTA USA Gun Homicides, 2018. Image courtesy of the artist.

visceral, immersive visualization of statistical data. The deadly algorithmic system designed by the artist should be read as a complex, extended analogy critiquing the very rule systems that enable gun violence in the real world-laws and policies put in place to ensure that guns can be bought, traded, concealed, and used. Like the algorithmic system of Elegy, these laws and policies can (but should not!) be experienced as insurmountable and inviolable, an insight made powerfully clear in DeLappe's piece. Because its computational logic executes shocking and undesirable events without allowing for human interference and agency, Elegy functions brilliantly as a contemporary piece of performance art that challenges preconceived assumptions regarding our ability to survive gun violence in the US.

As I suggested above, "embodied" virtual performances that are enacted by human performers for algorithmic environments can be problematic because they generally cannot transgress the computational rule systems functioning as their frame and stage. In the artworks I discussed, such embodied performances appear successful only insofar as they critically emphasize and foreground this limitation, effectively addressing the futility of certain attempts at communicative, critical human-computer interaction. By contrast, the focus of San Andreas Deer Cam and Elegy is not simply to simulate a human-controlled intervention in the violent simulated environment of GTA. Instead, nonhuman agents here act autonomously to engender algorithmic behaviors which fork and deviate from established expectations in unexpected ways. In San Andreas Deer Cam, this serves to frame a meditation on algorithmic agency and survival that defies the personal experiences of player-audiences. The seeming alive-ness of the deer, paired with the unusual live-ness of the 
artwork itself, allows for a powerful performative quality to reemerge. In Elegy, the self-playing nature of the artwork forms an analogy to what is sometimes perceived as the "inevitability" of real-world gun violence, which is, in truth, a function of human-designed legal rule systems and policy conventions that enable gun violence in the first place. As Elegy powerfully reminds us, the lack of agency we as individuals experience in the face of rampant gun violence, expressed here through the seemingly inviolable algorithmic agency of DeLappe's mod, is not at all inevitable.

I would argue that works such as San Andreas Deer Cam and Elegy, because they deviate so strongly from preconceived assumptions regarding the conventionally embodied and live nature of performance art, constitute a new type of virtual performance art. Thanks to their focus both on survival in "hostile" virtual environments and their exploration of algorithmically driven, quasi-autonomous virtual interactions, the traditionally embodied nature and liveness of the performance work has extended to the (re-)coding of an algorithmic matrix that serves to not only render a representation of the "performer" (the simulated deer, the simulated shooter), but also bring the virtual performer to life. In this sense, the cultural and computational logic within which GTA operates becomes both object and subject of artworks that thematize survival as such while also rethinking the conceptual survival of performance in virtual environments. If the computational environment of a game world restricts or makes impossible effective critical intervention, as suggested with regard to some of the examples discussed in this essay, then virtual intervention may have to expand traditional parameters of performance to include disruption of the algorithmic logic of the performance environment itself. The protagonists of Watanabe's San Andreas Deer Cam and DeLappe's Elegy_deer and invisible shooterbecome new kinds of performers: by encoding novel and unforeseeable interactions within virtual environments, these virtual performers help us reconsider virtual survival and the virtual violence as well as conventional assumptions regarding "embodiment" in performance art. What we can glean from these new kinds of performance works is that in algorithmic contexts, "survival" must not be approached as an achievement (to use the conventional terminology of gamification), but rather as a kind of chronic condition, evident both in the stoicism with which Brent Watanabe's wandering deer endures the violence inflicted upon it, and in Joseph DeLappe's NPCs who endlessly respawn only to be shot to death again. 


\section{Bio}

Martin Zeilinger, PhD, Senior Lecturer in Media at Anglia Ruskin University, is a new media and digital culture researcher, practitioner, and curator based in London/UK. Martin's work revolves around the experimental use of digital technology in contemporary art-making, with a particular focus on intellectual property issues, generative art, and artistic critiques of emerging financial technologies. Since 2013, he has been co-curator of the Toronto-based Vector Festival, showcasing the use of video game technologies in experimental media art. Martin's research has been widely published in books and journals including Artists Re:Thinking the Blockchain, MoneyLab Reader 2, Philosophy \& Technology, and Computer Music Journal, and he is co-editor of a forthcoming special issue of Media Theory titled "Rethinking Affordance." $\mathrm{He}$ is currently completing a monograph on the concept of artistic practices of appropriation in digital contexts. // @ mrtnzlngr / http:// marjz.net/ / http://vectorfestival.org/ 


\section{Notes}

1. VTape, "My Trip to Liberty City," accessed July 27, 2018, http:/ / www.vtape.org/video?vi=6496.

2. Ian Bogost, Unit Operations: an Approach to Videogame Criticism (Cambridge: MIT Press, 2006), 156-157.

3. Georgie Roxby Smith, Fair Game [Run Like a Girl] (2015), credit notes, accessed July 27, 2018, https: / / www.youtube. $\mathrm{com} /$ watch? $\mathrm{v}=\mathrm{e}$ 7dyWORknnE.

4. Matteo Bittanti, “Interview: Georgie Roxby Smith," Gamescenes: Art in the Age of Videogames, June 13, 2016, http:/ / www.gamescenes.org/2016/06/interview-georgie-roxby-smith.html.

5. Smith, Fair Game.

6. Daniel Cottom, “To Love to Hate," Representations 80, no.1 (November 2002): 119-138.

7. Email correspondence with the author, March 7, 2018.

8. See, for example, their series The Fregoli Delusions, a machinima video installation that trains its attention on the NPCs of Forza Motorsports 2 (https: / / vimeo.com/153661614). Non-narrative racing games rely on NPCs for their simulations of realistic game environments. However, little attention seems to be paid to designing NPC behavior. The Fregoli Delusions focuses on "the behaviours of algorithmic beings that are never meant to be observed," and shows us that "they seem plagued with an existential boredom, their legs twitching impatiently when they sit down, the trajectories of their short strolls [caught] in endless repetitive circles." See Martin Zeilinger and Skot Deeming, "Rendered Visible: Exploring the Limits of Algorithmic Agency," curatorial essay, Vector Festival 2016, July 14-17, 2016, https: / /www. academia.edu/28331116/Rendered_Visible_Exploring_the_Limits_of_Algorithmic_Agency.

9. Among many other incidents and troublesome encounters, William Pope.L was famously arrested when an AfricanAmerican pedestrian complained about the artist's improper behavior to a police officer (and insisted on his complaint even when the artist attempted to explain). In Liberty City, no such response could occur.

10. Brent Watanabe, San Andreas Deer Cam (2016), accessed July 27, 2018, http:/ / www.sanandreasanimalcams.com/.

11. The Twitch stream is now offline. Additional footage and documentation is available through the artist's website: http: / / bwatanabe.com/GTA_V_WanderingDeer.html. Coverage ranged from sites like Hyperallergic and Wired to BBC News and New York Magazine: Michael Rundle, "Watching an AI Deer Wander GTA V is Strangely Hypnotic," Wired, March 21, 2016, http: / / www.wired.co.uk/article/ ai-deer-wandering-gta-5; Daniel Gerwin, "The Immortal Deer an Artist Set Loose in Grand Theft Auto," Hyperallergic, March 29, 2016, https:/ / hyperallergic.com/286837/ the-immortaldeer-an-artist-set-loose-in-grand-theft-auto/; "Grand Theft Auto deer causes chaos in game world," BBC Online, March 24, 2016, http:/ / www.bbc.co.uk/news/technology-33521984; Brian Feldman, "Hundreds of People Are Watching a Deer Run Around a Video-Game City, and It's Mesmerizing," Nymag.com, March 25, 2016, http:/ / nymag.com/ selectall/2016/03/grand-theft-auto-deer-cam-is-mesmerizing.html.

12. I was co-curator of the events with Skot Deeming. See vectorfestival.org, and the Vector Festival 2016 curatorial essay cited in note 8: Zeilinger and Deeming, "Rendered Visible."

13. Celebration Square is a large, well-used public space in Mississauga, one of Toronto's most populous suburbs. Information about Celebration Square can be found at https: / culture.mississauga.ca/ celebration-square.

14. See Joseph DeLappe, Elegy: GTA USA Gun Homicides (2018-2019) http:/ / www.delappe.net/ play / elegy-gta-usa-gunhomicides/

15. The piece has quickly received significant amounts of critical and popular attention: Matteo Bittanti, "Game Art: Joseph Delappe's Elegy: GTA USA Gun Homicides (2018)," Gamescenes: Art in the Age of Videogames, July 4, 2018, http: / / www.gamescenes.org/2018/07 / game-art-joseph-delappes-2018.html; Brock Wilbur, "Joseph DeLappe uses GTA to call attention to gun violence statistics," Rock Paper Shotgun, July 8, 2018, https: / /www.rockpapershotgun. com/2018/07/08/joseph-delappe-uses-gta-to-call-attention-to-gun-violence-statistics/. 


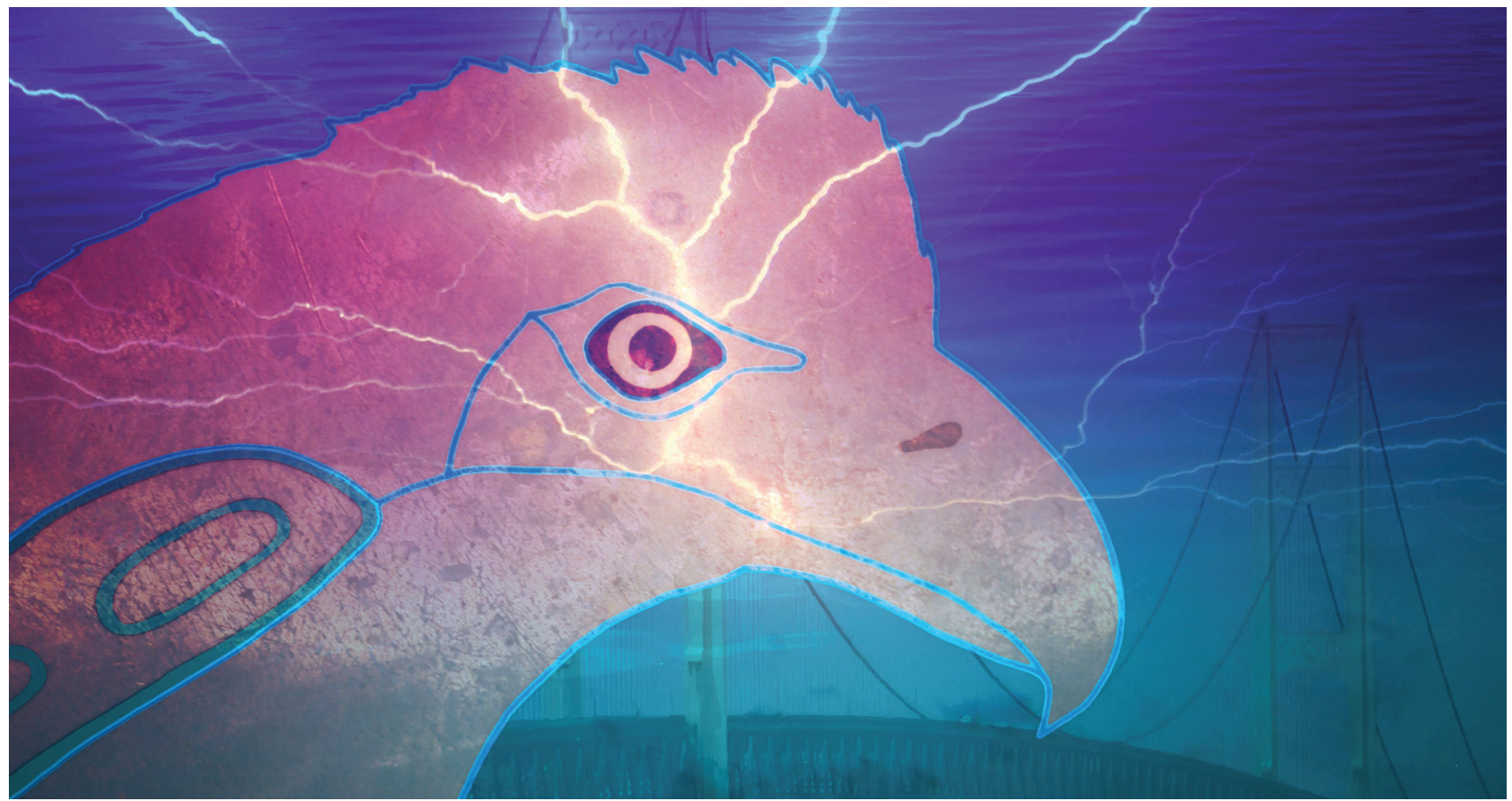

Figure 1. Thunderbird Strike, 2017. Image courtesy of Elizabeth LaPensée.

\section{Thunderbird Strike: Survivance in/of an Indie Indigenous Game}

\section{Elizabeth LaPensée}

Assistant Professor of Media \& Information and Writing, Rhetoric \& American Cultures, Michigan State University

\section{Abstract}

Thunderbird Strike, a 2D side-scroller developed by Elizabeth LaPensée, allows a player fly from the Tar Sands to the Great Lakes as a thunderbird protecting Turtle Island with searing lightning against the snake that threatens to swallow the lands and waters whole. The game encouraged players to learn about the indigenous culture, reflect on water protection and alternative energy sources, and gain awareness of risks posed by oil pipeline construction for the conveyance of tar sands.

Thunderbird Strike was developed through residencies including $O$ k'inādās Residency, The Banff Musicians in Residence Program, and Territ-Aur(i)al Imprints Exchange thanks to the 2016 Artist Fellowship grant from the Arrowhead Regional Arts Council. 


\section{INTRODUCTION}

Games-with their unique layering of design, code, art, writing, and audio-can be acts of survivance when developed from Indigenous perspectives for the purpose of Indigenous expression. An act of survivance is a form of selfdetermination. Anishinaabe scholar Gerald Robert Vizenor defines survivance as "an active sense of presence, the continuance of native stories, not a mere reaction, or a survivable name. Native survivance stories are renunciations of dominance, tragedy, and victimry." ${ }^{1}$ Survivance goes beyond survival-specifically, the survival of Indigenous peoples in the face of colonization, victimization, and attempted dominance by settlers-it is about nourishing Indigenous ways of knowing.

The two-dimensional mobile game Thunderbird Strike (2017) is one such act of survivance. It adapts Anishinaabe stories about thunderbirds into gameplay, and it unexpectedly became the inspiration for legal discussions regarding freedom of expression in games and games as art. The story of its design, development, and reception is one of survivance, meaning that it expresses an active Native presence, both in aesthetic and legal ways. ${ }^{2}$

Aesthetically, Thunderbird Strike uniquely brings Anishinaabe Woodlands-style art to stopmotion animations and side-scroller game design (fig. 1). The levels represent the lands and waters of Turtle Island (North America) in the midst of the continuation and expansion of pipelines that intrude on Indigenous territories. The gameplay reflects the hope that lands, waters, and all life on the island thrive, despite damage by oil operations.
The game's very existence is also an act of survivance in legal terms, since oil lobbyists and an affiliated government official attempted to shut the game down with accusations that it encourages "eco-terrorism." ${ }^{3}$ As the artist and designer, I along with the game endured a media smear campaign that involved Fox News, online harassment, and an audit on an arts fellowship I received. ${ }^{4}$ In the midst of proving that I honored the conditions of the fellowship, the game was also used to propose a new bill to control artistic expression. ${ }^{5}$

Despite this extreme reaction, people who actually played the game-in contrast to government representatives who admitted they had not played it-had positive interpretations. ${ }^{6}$ Players of Thunderbird Strike have described the game as humorous, and called it "cute" or even "adorable." 7 In three levels-made of around 80 unique backgrounds with hand-drawn sprites textured using modified photos of lands, waters, copper, birch bark, mining equipment, and oil-the player guides a thunderbird, a figure recognized by many nations. Thunderbird Strike uniquely comes from Anishinaabeg and Michif thunderbird stories. Jim LeBlanc, an Anishinaabe elder from Bay Mills Indian Community in Michigan, tells a version of the story in which the Crane Clan is foundational to the restoration of balance. All birds come from thunderbirds, who once walked among us. They return as the lands and waters are split and poisoned by hands that are always reaching, now removing layers of Aki (Earth) that are vital to wellbeing. As ongoing toxicity and environmental changes become more troubling, Crane Clan people lead by listening and bringing together communities around their shared concerns. 


\section{MOTIVATION}

The world is imbalanced. I grew up with the worldview from my mother that we are already living in a post-apocalyptic world. ${ }^{8}$ For Anishinaabeg, the world as we knew it has already ended due to the onslaught of colonization. With that perspective, the question is not "when will the world end?" but "what can we learn from before and what can we do now and for future generations?" Tłıcho musician and artist NÀHGA, a.k.a. Casey Koyczan, created the music, sound effects, and voice-overs for Thunderbird Strike, and he experiences the impact from mining toxins buried in the Northwest Territories day to day. He was motivated to collaborate on the game because he also cares deeply about informing people of Indigenous perspectives on resource extraction.

Through Thunderbird Strike, I am doing my best to pass on stories from my communities, animating the vital symbolism of thunderbirds in a new medium, as well as imagining an Indigenously-determined future. There are many versions of these stories from many nations. Since I am settler-Irish, Anishinaabeg from Sugar Island in Baawaating with relations from Bay Mills Indian Community as well as Métis, Thunderbird Strike reflects primarily Anishinaabeg and Michif voices.

"Thunderbird Woman," brought into form by Anishinaabe artist Isaac Murdoch, makes an appearance in a game cutscene (fig. 2). I appreciate how Mordoch recognizes Thunderbird Woman as her own autonomous figure who is meant to be shared with as many people in as many ways as possible. His perspective as an artist parallels the way I approach games-I strive to make my work as accessible as possible, which means releasing it for free. Thunderbird Woman is iter-

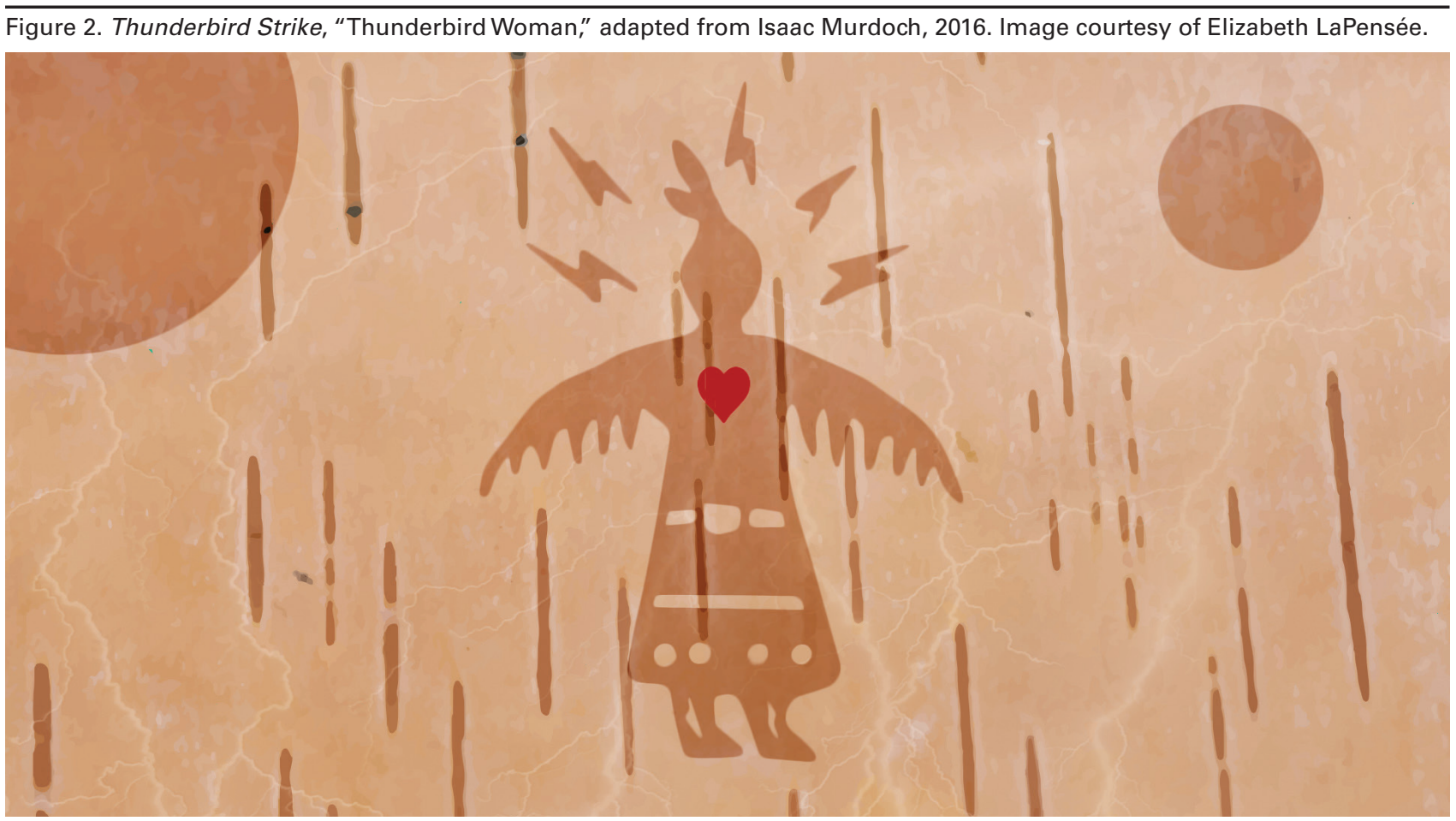




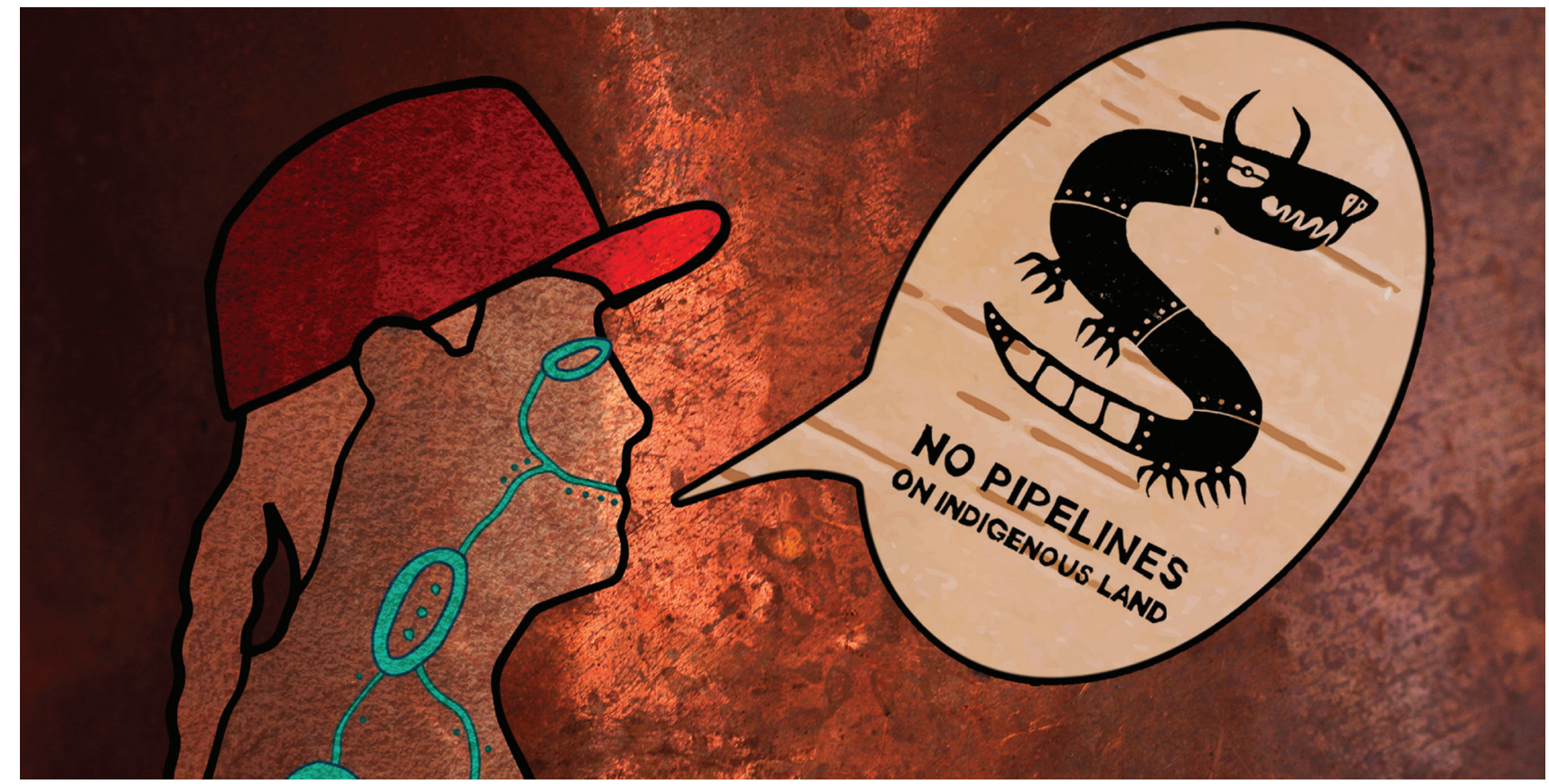

Figure 3. Thunderbird Strike, “No Pipelines on Indigenous Land," adapted from Dylan Miner, 2016. Image courtesy of Elizabeth LaPensée.

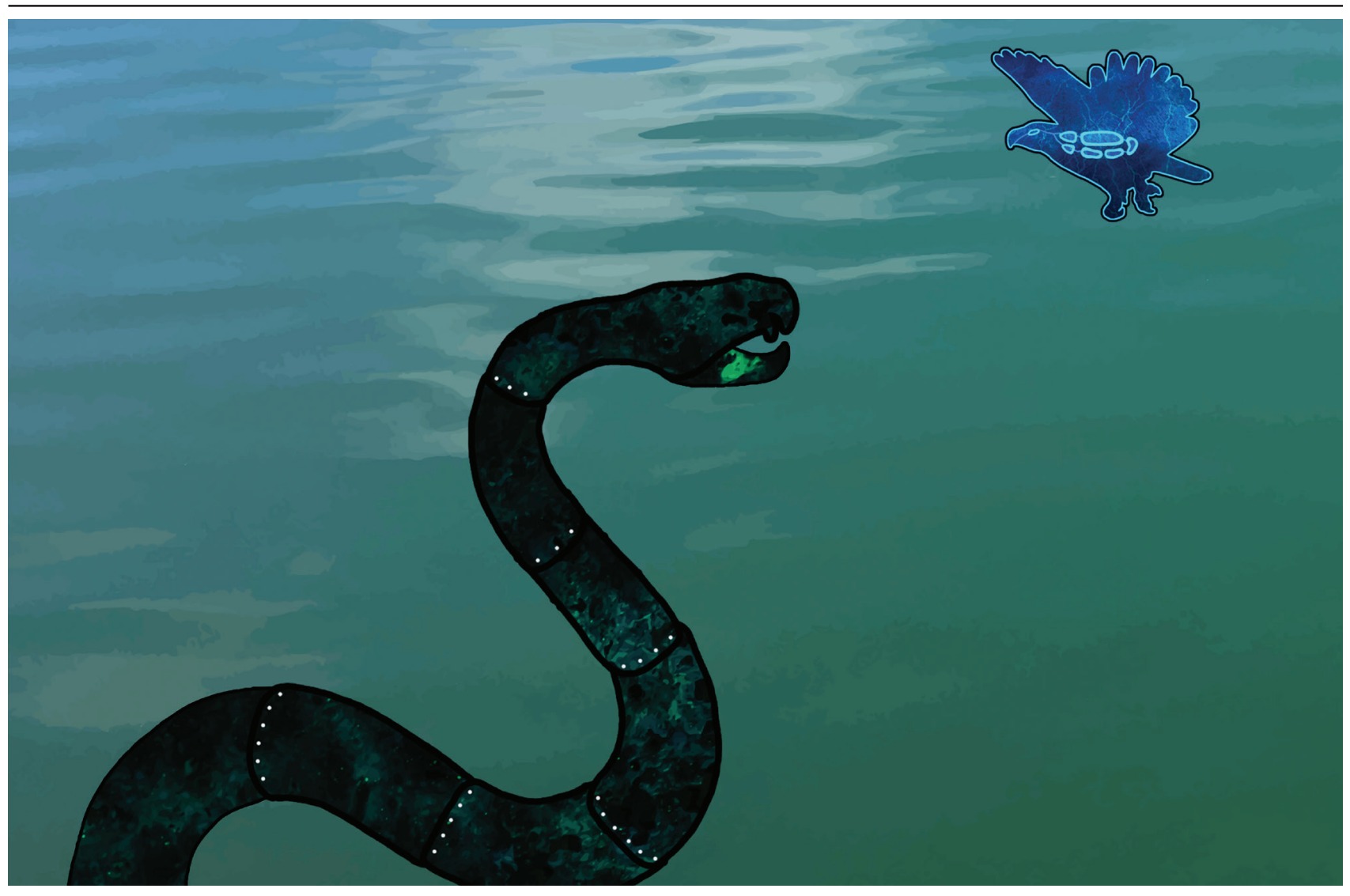

Figure 4. Thunderbird Strike, "Snake Boss," 2016. Image courtesy of Elizabeth LaPensée. 
ated in the game as an homage to her presence in art prints, posters, banners, community art, jewelry, and clothing. She also quite literally walks among us as a life-sized hand-held figure during gatherings regarding issues with pipelines, including the Dakota Access Pipeline (DAPL) at Standing Rock Indian Reservation, Line 3 which stretches across lands in Saskatchewan and Minnesota, and Line 5 in the Straits of Mackinac in Michigan, all of which put balance at risk. ${ }^{9}$

Notably, the only text in the game other than the title and instructions comes from Michif artist Dylan Miner's “No Pipelines on Indigenous Land" print, which has been used in screen printing gatherings for posters, banners, and shirts (fig. 3). He came to this representation through offering asemaa (tobacco), a teaching I also follow. I integrated his representation into Thunderbird Strike, which inspired the way the boss battle is depicted as a pipeline snake in the final level (fig. 4). Importantly, Michif artist Christi Belcourt cautions us to remember that snakes are not unilaterally representations of evil. There are snakes that help us, just as there is a snake that threatens to swallow the lands and waters whole. All life can be honored, and all greed must be recognized, reiterating the value of balance, which carries through Thunderbird Strike's mechanics.

\section{GAMEPLAY}

In Thunderbird Strike, the player takes on the responsibilities of the Crane Clan people by actively guiding the thunderbird player character from the Tar Sands in Alberta, Canada to the Straits of Mackinac in Michigan. The game scrolls in the opposite direction of conventional side-scrollers-moving from right to left, instead of left to right, in recognition of Anishinaabeg worldview, which looks at the Great Lakes to the South, and therefore envisions the journey from the Tar Sands to Line 5 as West to East (fig. 5).

The player can strike lightning to revive animals and activate people for Restoration points, and/or dissipate oil infrastructure for Destruction points. The meaning of the game is for the player to determine, since the gameplay weighs Restoration and Destruction the same for a total high score and does not actually require striking anything to reach the credits. The mechanics are based on balance, rather than the good vs. evil dynamic seen in most games. The design reflects what I hope for the lands, waters, and all connected life-balance.

In recognition of balance, in the first level players can choose to focus on the revival and survival of animals by striking lightning at the bones of caribou, buffalo, and wolves to reanimate them (fig. 6). Caribou reference the threat of extinction to animals in the Boreal Forest due

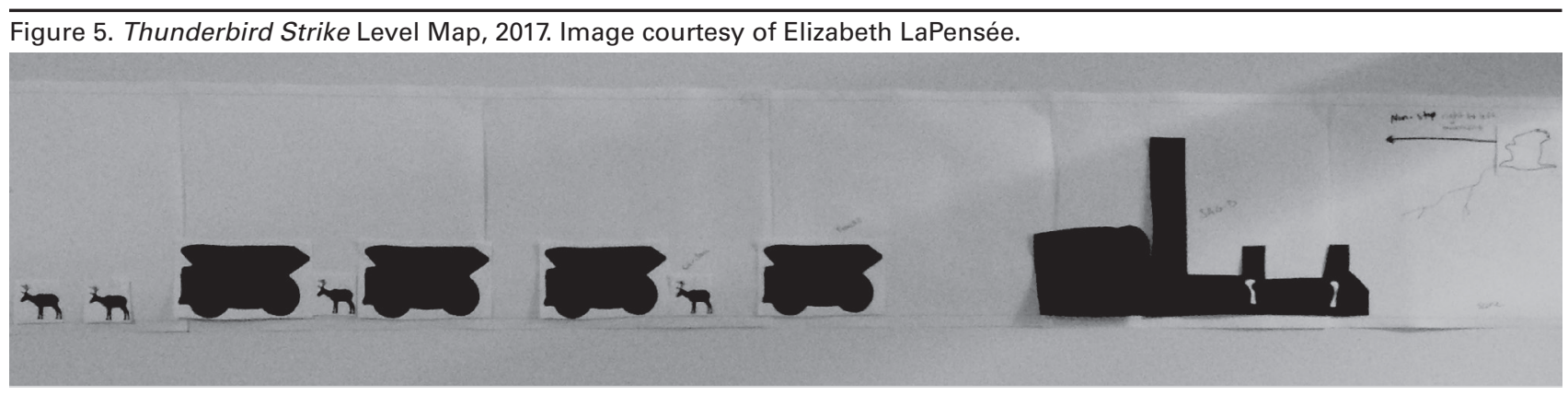




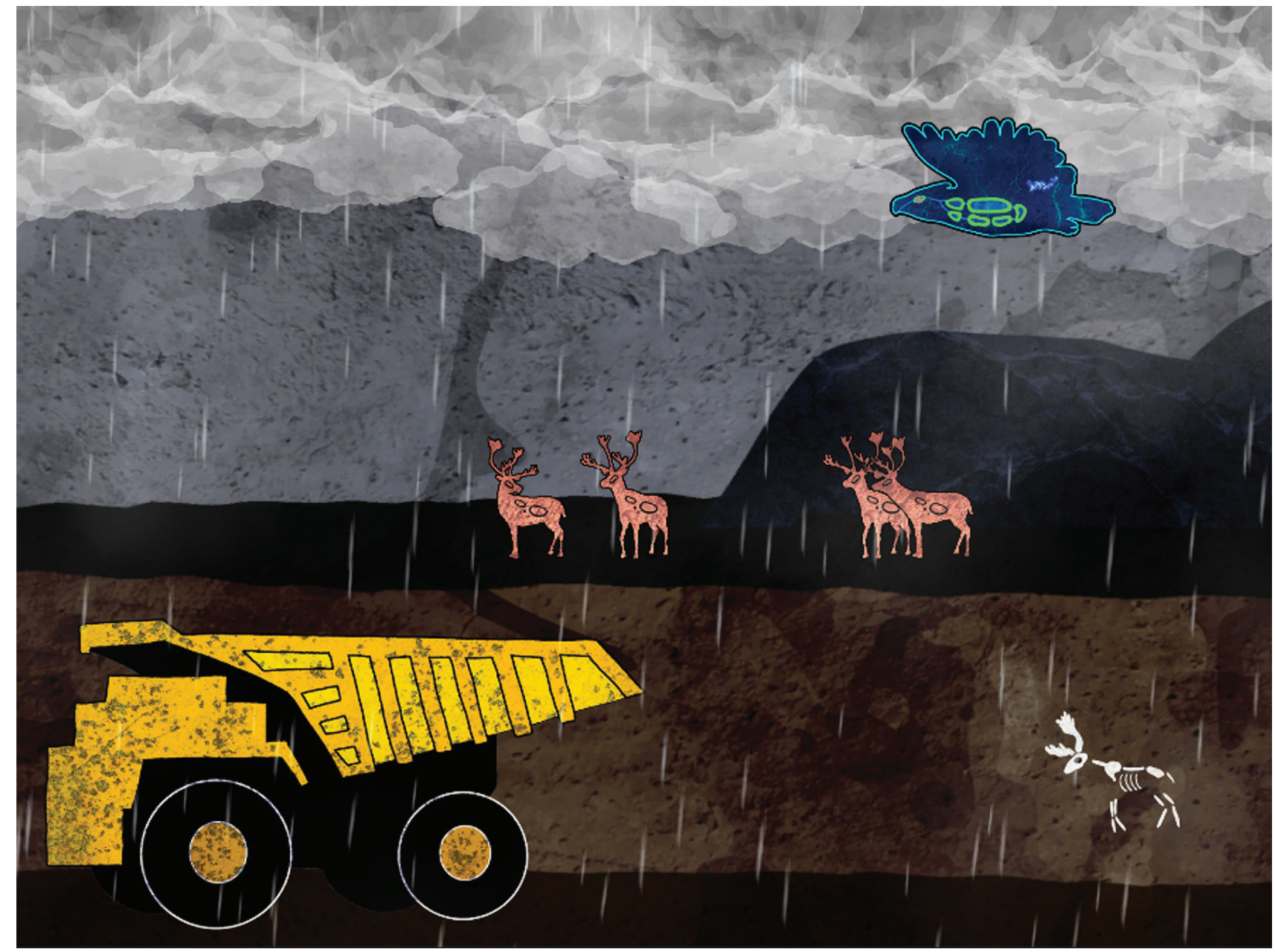

Figure 6. Thunderbird Strike Level 1, 2016. Image courtesy of Elizabeth LaPensée.

to the toxicity of the Tar Sands operations in Alberta, while wolves represent the loss of animals due to fading natural food sources, and buffalo signify the ongoing impact of colonization on Indigenous ways of life that were disrupted by the greed of overhunting during the fur trade era. ${ }^{10}$ Players can also collide with caribou in the background, who become lightning and contribute neutral points towards the total high score.

Similarly, in the second level, players can activate people who stand among pipelines and equipment used to haul and place pipelines in the ground (fig. 7). The figures are made from the silhouettes of community members in Nkwejong ("Where the Rivers Meet" or "where one body of water flows into the next") in Michigan, an Anishinaabeg trading territory also known as Lansing, where I am now living. Their activation contributes to Restoration points, while gathering up protectors walking with "No Pipelines on Indigenous Land" posters in the background add to neutral points. Notably, there are many opportunities for balance in the gameplay.

\section{IMPACT}

Poignantly, media attention sparked by an oil lobbyist (and later a senator in Minnesota) chose only to depict lightning striking at oil infrastructure and completely overlooked the overarching gameplay. Initially, the oil lobbyist called for the complete deletion of Thunderbird Strike with accusations that the gameplay trains 


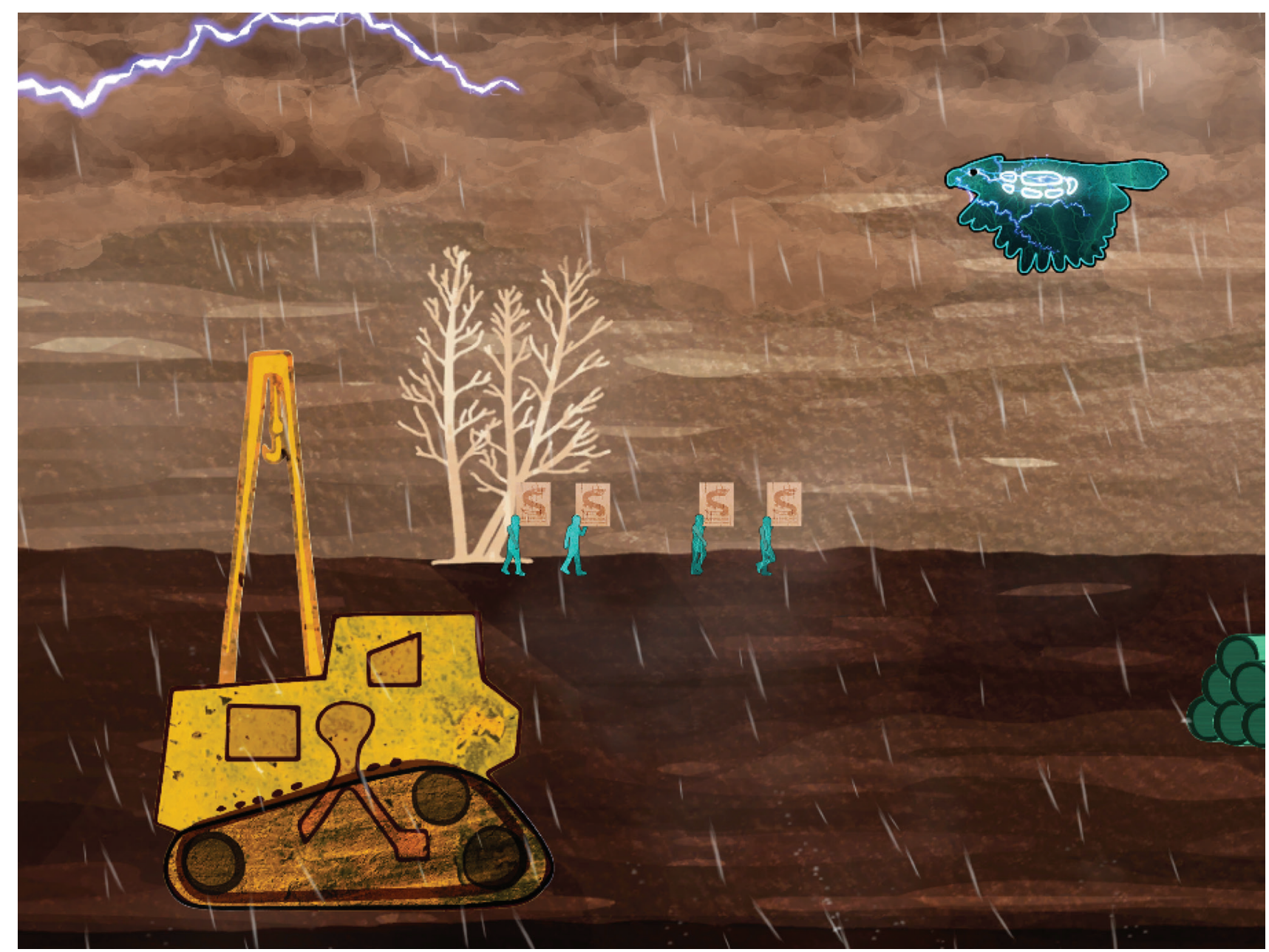

Figure 7. Thunderbird Strike Level 2, 2016. Image courtesy of Elizabeth LaPensée.

"eco-terrorists," a serious allegation referring to criminal violence against people or property for environmentalist ends. ${ }^{11}$ The press release also publicized misinformation that the game was developed at the Games for Entertainment and Learning Lab at Michigan State University, even though it was created independently and only involved my own equipment. The intention of drawing such a connection was to threaten my position at Michigan State University as well as shut down the game. I was barraged by media and oil infrastructure supporters looking for legal implications behind the motivation of developing Thunderbird Strike, about which I was very clear: I am Anishinaabekwe, an artist and a mother raising my children with hope for the next generations.

When a social media outcry declared the attack as a threat to freedom of speech in games, a Minnesota senator was alerted by the oil lobbyist, because Thunderbird Strike was funded by an artist fellowship from the Arrowhead Regional Arts Council. A series of meetings with government officials ensued, along with an audit of the artist fellowship. The Arts Council was in support of my work and pointed out that I completed the work as detailed in the proposal. With letters of support as well as paperwork, I showed that I substantially completed the game before moving from Minnesota to Michigan for a position at Michigan State University (residency in Minnesota was a proviso of the fellowship) 
and proved how the game related to Minnesota, since Line 3 is included, and the textures came from Anishinaabeg lands and waters in and around Fond du Lac reservation. I had delayed the release of the game so that it would premiere at the imagineNATIVE Film and Media Arts Festival in October 2017, just as I said I would in the fellowship application. In fact, Thunderbird Strike went on to be awarded Best Digital Media Work, an unanticipated and quite meaningful honor.

Despite being in the process of proving myself, the accusations by oil lobbyists and the senator were aired on national news, includ- ing claims that Thunderbird Strike incites and even trains eco-terrorists. ${ }^{12}$ In the midst of all of this, I was hit with threatening emails, attempts to break into my online accounts, and strange phone calls from hidden numbers at odd hours. Thankfully, I had support from colleagues aware of cybersecurity strategies and took steps to ensure my safety. Survivance is a stance that moves us beyond victimhood into denouncing the dominance of a colonial system responsible for the displacement and genocide of Indigenous peoples. ${ }^{13}$ Since then, contributors to this system continue to attempt measures to control free-

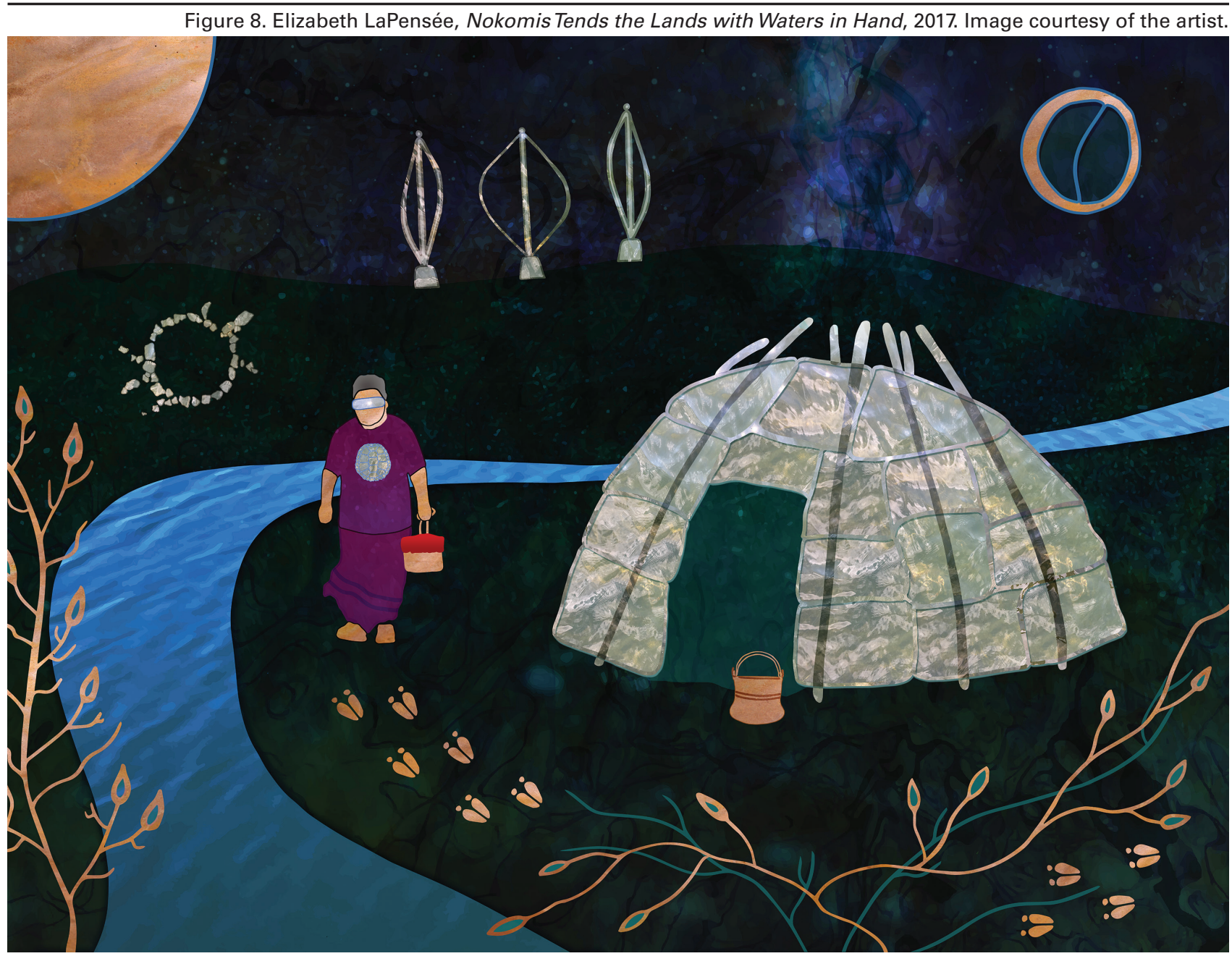


dom of expression in art, specifically referencing Thunderbird Strike as the catalyst. The latest attempt is a proposed bill that would implement a civil penalty for any artist who receives government-generated grant funding if their work is deemed to encourage "domestic terrorism." 14 The artist could be charged a fine of up to ten times the amount of their award. A bill such as this could silence artists whose works relate to similar themes as Thunderbird Strike. However, such a bill could also encourage work to be supported through independent means, which in turn could further emphasize sovereignty in game development, leading to more self-determined games.

\section{FUTURE WORK}

Despite the pushback and struggles, I continue to act from a position of sovereignty, as exemplified by Anishinaabe elder Carol Nadjiwon at Batchewana First Nation in Baawaating. She frames reservation operating structures as sovereign, meaning self-determined in power, both in terms of leadership and more recently and more literally, in regards to energy power. Her community diversifies its energy sources with both wind turbines and solar panels, as well as participates in testing water cleaning devices that use sound technology. This hope for the present and the future is reflected in Thunderbird Strike and compendium art (fig. 7) that will continue on with hope for generating discussion around the wellbeing of lands, waters, and all connected life. To this end, next steps for Thunderbird Strike include festival circulation as well as gallery exhibitions of the game, paired with art that depicts alternative energy sources and draws attention to Indigenous perspectives on pipelines. Regardless of attempts to silence Thunderbird Strike, the game continues on, with hope for the future. $\rightarrow$

\section{Bio}

Elizabeth LaPensée, Ph.D. is an award-winning designer, writer, artist, and researcher who creates and studies Indigenous-led media such as games and comics. She is Anishinaabe from Baawaating with relations at Bay Mills Indian Community and Métis named for Elizabeth Morris. She is Assistant Professor of Media \& Information and Writing, Rhetoric \& American Cultures at Michigan State University and a 2018 Guggenheim Foundation Fellow. 


\section{Notes}

1. Gerald Robert Vizenor, Manifest Manners: Narratives on Postindian Survivance (Lincoln, Nebraska: University of Nebraska Press, 1994), vii.

2. Vizenor, Survivance: Narratives of Native Presence (Lincoln, Nebraska: University of Nebraska Press, 2009).

3. Jacob Dubé, "Oil Lobbyists: Thunderbird Strike Video Game 'Promotes Ecoterrorism'." Motherboard, October 27, 2017, https://motherboard.vice.com/en_us/article/xwawq3/oil-lobbyists-thunderbird-strike-videogame-promotes-ecoterrorism.

4. Caleb Parke, "Eco-terrorism? Anti-Pipeline Video Game Under Fire for Putting Lives at Risk, Group Says," Fox News, October 26, 2017, http:/ / www.foxnews.com/us/2017/10/26/eco-terrorism-anti-pipeline-video-game-under-fire-forputting-lives-at-risk-group-says.html.

5. Matt McKinney, "Minn. Lawmaker Wants to Tighten Arts Grant Rules after Video Game Labeled as 'Ecoterrorism'," Star Tribune, October 28, 2017, http:/ / www.startribune.com/lawmaker-wants-to-tighten-arts-grant-rules / 453656383/; Leadership of the Minnesota House of Representatives, "Bill Approved to Prevent Legacy-funded Art Projects from Promoting Domestic Terrorism, Criminal Activity," Leadership of the Minnesota House of Representatives 2017-2018, https: / "www.house.leg.state.mn.us/SessionDaily/Story/13126.

6. Dubé, "Oil Lobbyists."

7. Kim Scorcher, "Oil Lobbyist Says Environmental Video Game is 'Ecoterrorism'," NerdAlert. November 28, 2017, https: / / www.youtube.com/watch?time_continue=1\&v=MXle9hY0Ig0.

8. Grace L. Dillon, Walking the Clouds: An Anthology of Indigenous Science Fiction (Tucson: The University of Arizona Press, 2012).

9. Winona LaDuke, "Pipelines" Honor The Earth, http:/ / www.honorearth.org/ pipelines.Honor the Earth.

10. Jennifer Huseman and Damien Short, "'A Slow Industrial Genocide': Tar Sands and the Indigenous Peoples of Northern Alberta." The International Journal of Human Rights 16, no. 1 (2012): 216-37; Tasha Hubbard, "The Buffaloes Are Gone' or 'Return: Buffalo'? - The Relationship of the Buffalo to Indigenous Creative Expression," The Canadian Journal of Native Studies 29, no. 1/2, (2009): 65-85.

11. Energy Builders, "Michigan State Univ. Prof Uses School's Taxpayer-Funded Lab to Create \& Launch Video Game to Blow Up Pipelines and Block Energy Infrastructure," Energy Builders, December 26, 2017, http:/ / energybuilders.org/michiganstate-univ-prof-uses-schools-taxpayer-funded-lab-create-launch-video-game-blow-pipelines-block-energy-infrastructure/.

12. Parke, "Eco-terrorism?"

13. Gerald Robert Vizenor. Native Liberty: Natural Reason and Cultural Survivance (Lincoln, Nebraska: University of Nebraska Press, 2010).

14. Leadership of the Minnesota House of Representatives, "Bill Approved." 


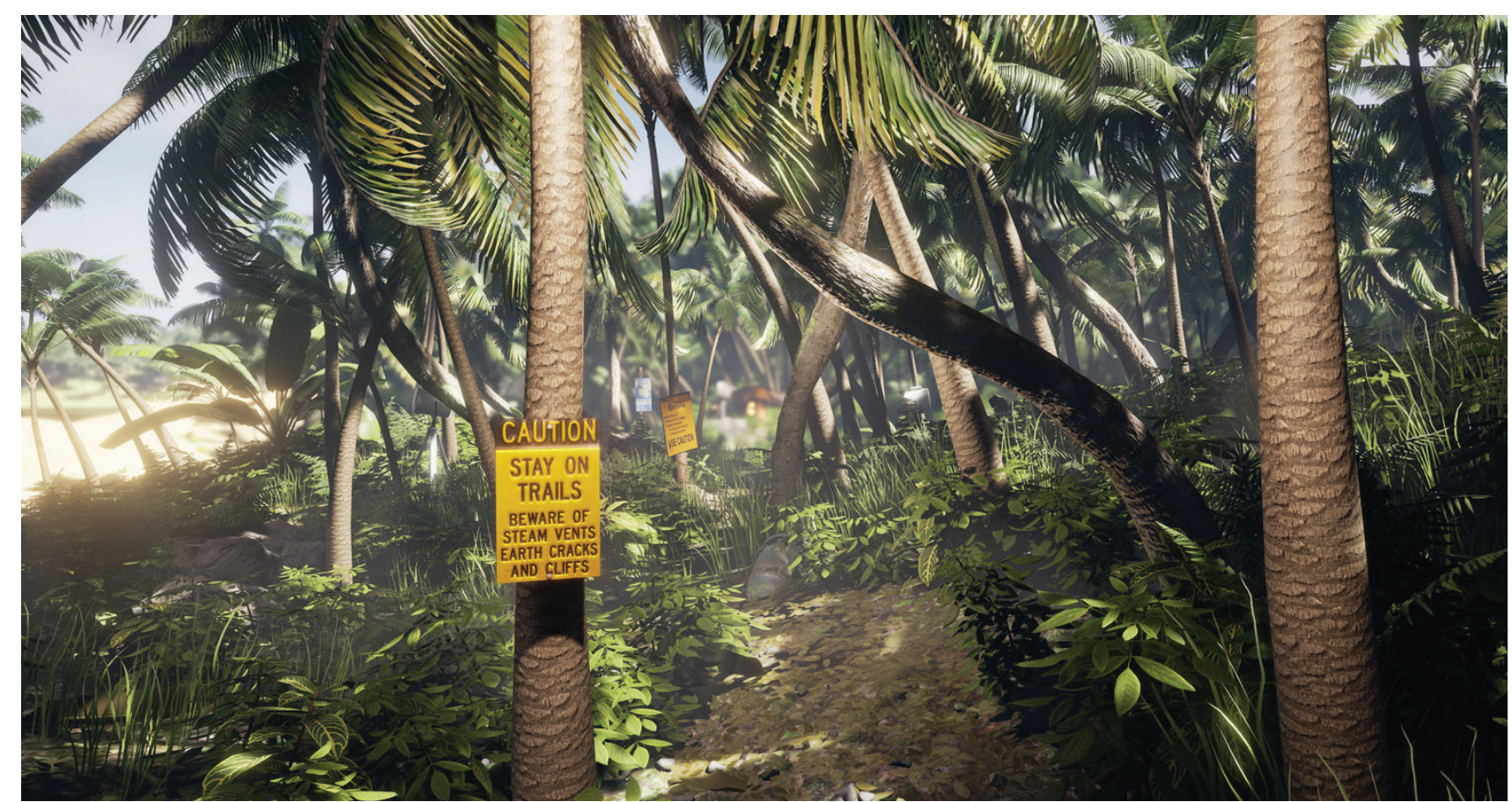

Jakob Kudsk Steensen, PrimalTourism: Island, headset view, 2016. Image courtesy of the artist.

\section{Fantastic Places and Where to Find Them: Pseudo-Indexical Realities Within Video Games and Game Art}

\section{Andrew Bailey}

PhD Student, Visual Culture and Art History, York University

\section{Abstract}

This paper examines the early text-based game Colossal Cave Adventure (1975) by William Crowther alongside the VR art installation Primal Tourism (2016) by Jakob Kudsk Steensen. By analyzing these works through an interdisciplinary lens of art history, visual culture, and game studies, this paper shows how depictions of real spaces within game environments can transform our conceptualizations of travel, exploration, and the unknown. I argue that the virtual spaces constructed by
Crowther and Steensen both strongly communicate the way that technologies such as remote access, computer simulation, and satellite imagery affect our understanding of the world and how we navigate it. After comparing both works and their pseudo-indexical relationships with reality, I conclude that game art is a critically productive tool for those seeking to deconstruct skewed or compressed representations of real-life spaces within video games or other digital media. 


\section{COLOSSAL CAVE WALKTHROUGH}

In 1975, William Crowther finished writing the code for a computer game that would go on to have a revolutionary effect on the recently formed video game industry. The text-based game was called Colossal Cave Adventure and was crafted by Crowther in an attempt to share his hobbies of cave spelunking and tabletop roleplaying games with his young daughters. ${ }^{1}$ To achieve his goal of writing a program that could be enjoyed by his children who had no technical knowledge of computers, Crowther chose to make it so that the software could be controlled with natural language. This meant that his daughters would have the game's cave systems described to them entirely through textual prose; they could then explore the caves using typed input such as "go west," and make site-specific actions such as "attack troll" (fig. 1). Additionally, instead of creating these virtual environments from scratch, Adventure was heavily inspired by Crowther's real-life experiences exploring and mapping the underground tunnels of Mammoth Cave National Park in Kentucky, USA. ${ }^{2}$ Together, Crowther's methods of crafting his personal experiences into Adventure's navigable game space, along with using non-technical, narrative prose to address the player, combined to create a completely novel and highly immersive interactive experience.

Eventually, Crowther chose to share Adventure with the public by making it available to download on an early version of the ARPANET (the Advanced Research Projects Agency Network, the technical foundation of the Internet).

Figure 1. "Colossal Cave Adventure running on a PDP-11/34 displayed on the VT100 console," by Wikimedia Commons user Autopilot, licensed under CC BY-SA 3.0. ${ }^{3}$

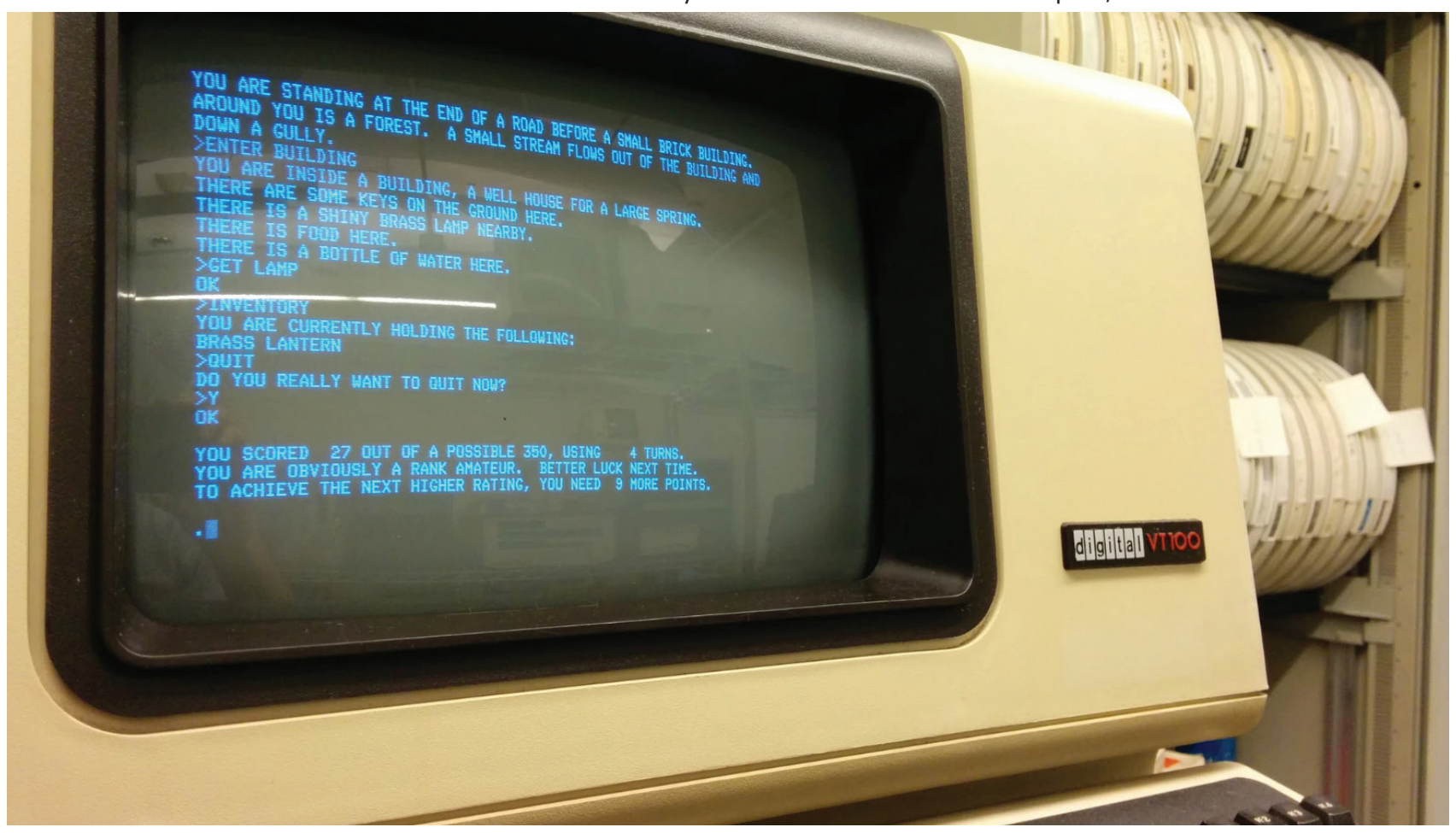


Due to the limited accessibility of the network, the game did not initially see widespread popularity; however, with help from Stanford researcher Don Woods, Adventure was ported onto more consumer-friendly machines. Over time, Adventure became increasingly popular, and even inspired many players to travel to Mammoth Cave National Park to experience the underground adventure for themselves. In a paper on environmental storytelling in video games, Alenda Y. Chang surveys the various accounts and travel logs of these players-turned-spelunkers, stating that "the extensive lore around $A d-$ venture includes numerous testimonials from avid Adventure players who, upon visiting the real cave system, were purportedly able to use their detailed knowledge of the game to navigate underground." ${ }^{4}$ Chang argues that Crowther's conflation of fantasy and real-world experience allowed significant exchanges between virtual experience and real-life space. She elaborates on this by drawing comparisons between the form and function of a typical Adventure game walkthrough and the Mammoth Cave travel logs she is examining, stating that "walkthroughs need not remain confined to any single realm of experience, and game environments cannot consider themselves impervious to correspondence with real-world environments, whether they are based on known places or not." ${ }^{5}$

Despite this confluence of game walkthrough and travel log, Chang also points out that there are many tensions that can arise during the construction of game environments meant to mimic real places. She observes how many designers will often abandon any extensive attempt at regional specificity for pre-patterned and ultimately generic scenes. Even when games do present more accurate depictions of real-life locations, due to the goal-oriented nature of most titles, these spaces often remain functionally inert with the only actionable parts commonly falling into two simple categories: either a collectable tool to aid the player's progress, or a destructible object/entity that would hinder it. ${ }^{6}$ In her book on interactive fiction, Janet Murray partially accounts for this oversimplification of place that Chang argues is all too common within game design. Murray states that "A game is a kind of abstract storytelling that resembles the world of common experience, but compresses it in order to heighten interest." ${ }^{\prime 7}$ Although these compressions of reality are usually necessary when constructing a functional and fun game, the "heightened interest" that Murray highlights can also have broader effects that reach beyond the borders of virtual space into reality.

\section{EXAGGERATING REALITY}

Henry Geddes Gonzales provides an example of how these compressions can affect the source material they reference. In a paper on the visual culture of the Greater Yucatán Peninsula, he explains how exaggerated images of ancient Mayan culture frequently found within film and video games recontextualize the reality of the place as extraordinary or fantastic. Gonzales argues that these images have been specifically constructed to produce a feeling of spectacle, and thus have more in common with theme park design rather than cultural accuracy or lived experience. Gonzales cites the convergence between tourism and the culture industry and their combined effect of enticing desire for spectacular travel imagery. As communication and image technologies continually advance, media consumers have an an 


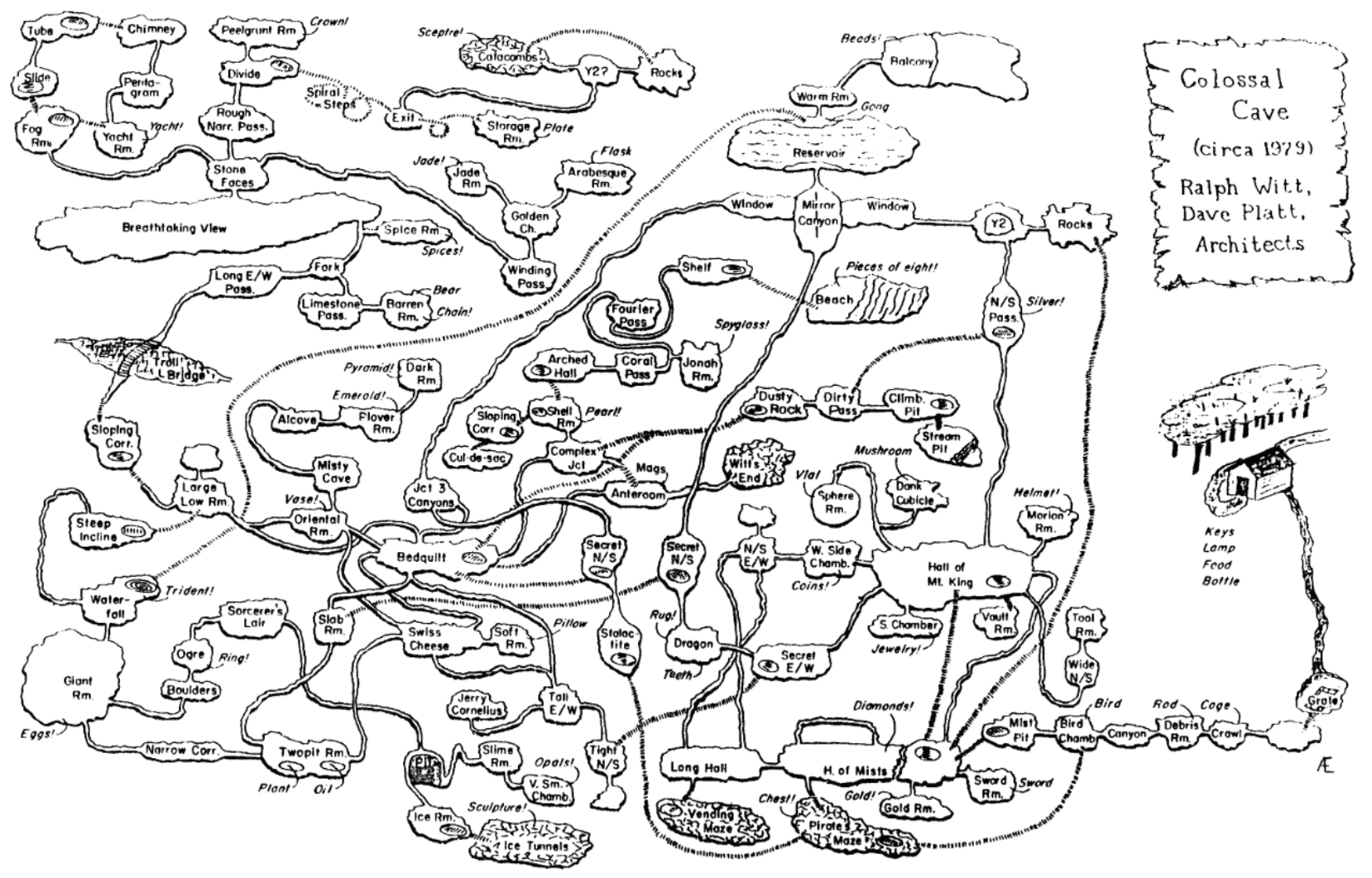

Figure 2. "Map of Colossal Cave," drawn by Dave Platt, via The Colossal Caves Adventure Page, http://rickadams.org/adventure/.

ever-escalating amount of options to experience distant places with the visceral quality of actually being there. Digital imagery, depth of field, and surround sound have taken mimesis to yet another level: the embodiment of world travel can be simulated in commodity experiences such as virtual reality, video games, and movie theatres. ${ }^{8}$ Gonzales concludes by postulating that this growing desire for immersive, virtual travel is connected with a longing for exoticism, mystery, and the unknown-an urge he feels has strong roots in the history of colonial exploration and adventure narrative. ${ }^{9}$

Although both rework reality into virtual depictions, Adventure differs from Gonzales' description of exaggerated images in that it does not attempt to represent any real world peoples or cultures. Unlike the Yucatán, the Mammoth
Cave system is an enclosed and mostly empty space, inhabited by a minimal collection of subterranean life and the occasional spelunker. Instead of hyperbolizing the real history of the caves to achieve the heightened narrative interest that Murray describes, Crowther drew upon his interest in fantasy storytelling when crafting Adventure. Additionally, Adventure may not contain any of the contemporary audio-visual tools Gonzales refers to when describing virtual travel, but the game's natural language interface allows for the same type of immersion that he connects to these experiences. Rather than providing surround sound, virtual reality, or depth of field, the simulated world travel that Gonzales speaks of is achieved textually through Crowther's accurate and navigable renditions of the Mammoth Cave system (fig. 2). Even though 
they may be full of fantastical monsters and treasures, as Chang points out, mastery of Adventure's caverns affords easier navigation for those players who are curious enough to travel out to the game's real-life counterpart.

This transition between virtual and real-life adventure not only serves to underline Gonzales' arguments on simulated travel, but also resonates with games scholar Roger Caillois' work in connecting play to the longing to master the unknown. Caillois states that "Without doubt, secrecy, mystery, and even travesty can be transformed in play activity, but it must be immediately pointed out that this transformation is necessarily to the detriment of the secret and the mysterious, which play exposes, publishes, and somehow expends. In a word, play tends to remove the very nature of the mysterious." ${ }^{10}$ Through the mental mapping, careful exploration, and navigational commands needed in order to complete the game, Adventure reveals the Mammoth Caves' secrets to Chang's players-turned-spelunkers. As we are increasingly exposed to the far reaches of the world through travel advertising, blockbuster films, or the latest adventure game, more and more of the mystery that Gonzales and Caillois argue we long for is being slowly expended, or removed. As the world becomes more heavily networked and intensely connected, these kinds of unknown or mysterious spaces will in turn become increasingly rare. In this fully mapped world, everything will be made at least virtually accessible, with no known unknowns left unknown.

PRIMAL TOURISM

As has been argued above, video games represent a nexus where the relationships between place, exploration, and knowledge can be uniquely explored. It is for this reason that I argue that digital art made using game development tools affords an especially salient perspective on these topics. In his book on game art and technoculture, Brian Schrank draws comparisons between Crowther's experimental narrative and the history of avant-garde art, categorizing Adventure as a formalist work of narrative art even if it was never the programmer's intention. According to Schrank, avant-garde game artists such as Crowther are able to re-imbue our world with a sense of "mysterious luminousness," breaking free from the patterns that have been imposed on it through the repeated exploration and colonization of the unfamiliar and unknown. ${ }^{11}$ Placing this argument within the context of the authors listed above, Schrank's mysterious luminousness can easily be compared to Murray's "heightened interest" and Gonzales' "immersive exaggeration." Crowther is able to imbue the Mammoth Caves with a luminousness through his use of a fantasy roleplaying lens-even as its spatial mysteries are expended through explorative gameplay.

Similar to Adventure's mimetic relationship with the Mammoth Caves, contemporary digital artist Jakob Kudsk Steensen's new media installation project Primal Tourism (2016) is accurately modelled after Bora Bora, a tropical island in the South Pacific Ocean. Like the avant-garde methods that Schrank ascribes to Crowther, Steensen playfully combines a fantastical narrative into the spatial reality of a remote place within our world. Through this process of reconstructing the real, Steensen works to simultaneously produce and expend the mysteriousness that Caillois and Gonzales connect to play, and that 
Schrank defines as a key aspect of successful game art.

\section{GUIDED TOUR OF THE ISLAND}

Primal Tourism is divided into two separate components, both constituted from a three-dimensional rendition of Bora Bora that Steensen constructed using the Unreal Engine. The first and most heavily exhibited of these two portions is Primal Tourism: Island, a VR installation in which the player steps into a wooden prism adorned with photos, pages of travel journals, maps, and other historical, geographic, and cultural ephemera relating to the island (fig. 3). On the ground within this minimally crafted structure is a layer of sand that the player feels underneath their feet as they put on the headset hanging from above. Once immersed within the work, players are free to explore the island's empty buildings, jungle, and beaches (fig. 4). Although in reality there are still active hotels and resorts open on Bora Bora, due to lukewarm tourist flow in combination with a slew of destructive cyclones, there are also many empty, overgrown buildings scattered across the islands. It is this aspect of ruin that Steensen has chosen to solely focus on-depicting an island seemingly abandoned at a moment's notice with a slew of objects, vehicles, and detritus littering the landscape.

The second half of Steensen's project is also

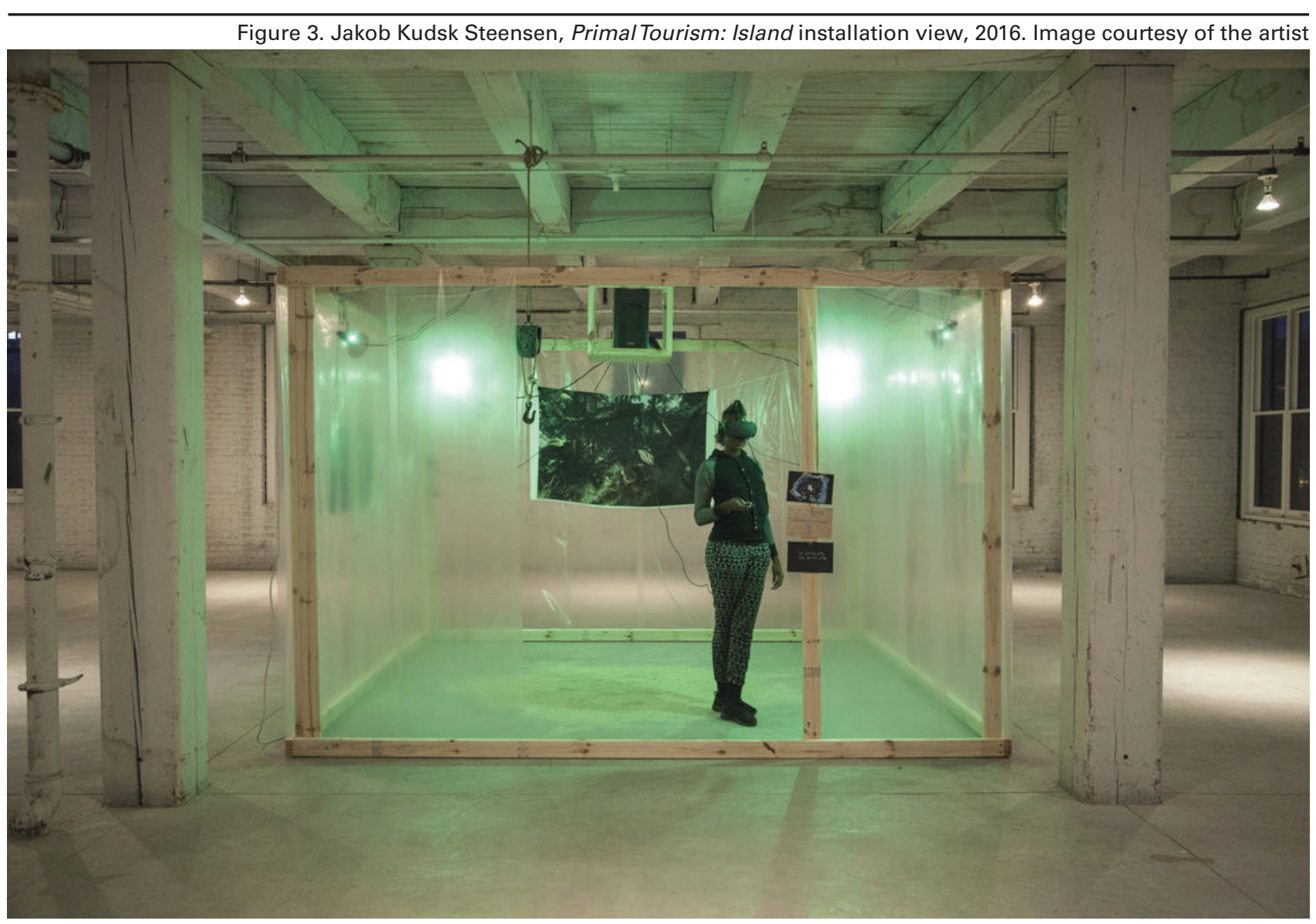




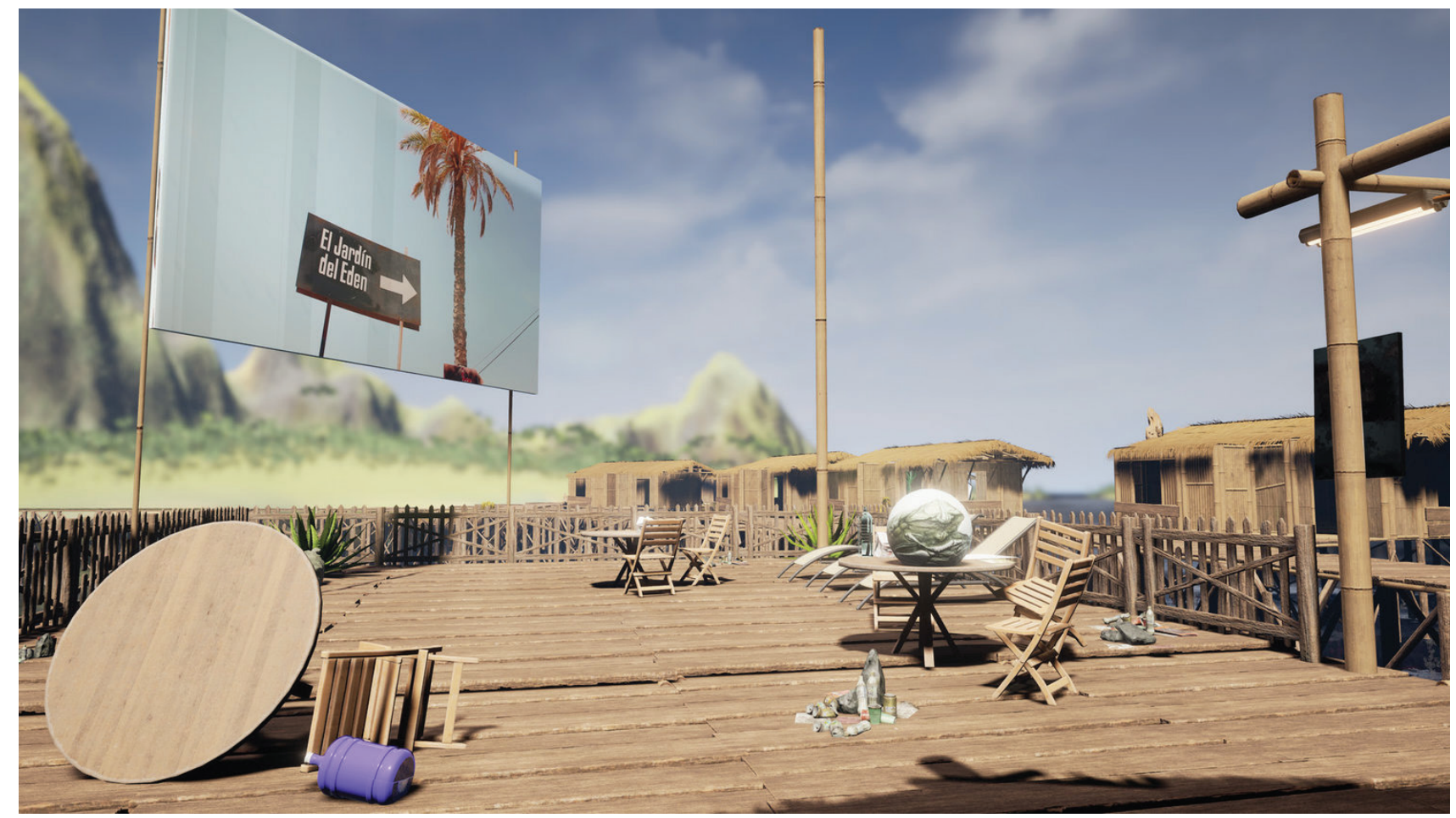

Figure 4. Jakob Kudsk Steensen, Primal Tourism: Island headset view, 2016. Image courtesy of the artist.

constructed as an installation work, except that it features a noninteractive video projected onto a blank wall in front of a group of white lounge chairs (fig. 5). The video features the same digitally rendered version of Bora Bora, but follows a linear path through the island that is narrated with an assemblage of monologues from a variety of unseen sources. In a way that links his efforts to Chang's connection between Adventure gameplay notes and Mammoth Cave travel logs, Steensen has named this more directed portion of his project Primal Tourism: Walk-through. This video work acts as a guided tour of Steensen's virtual island that highlights key locations with commentary, revealing the history of the island and its connections to colonial exploration.

In addition to this scripted audio, Walk-through also differs from the VR installation through an introductory sequence set in a lavishly decorated urban apartment. While moving through the space, the camera briefly slows to focus on a desk displaying a small collection of objects. One of these is a copy of the novel The Comical History of the States and Empires of the Worlds of the Moon and Sun by Cyrano de Bergerac [fig. 6]. This text represents one of the earliest notable forays into the genre of science fiction. In it, the protagonist attempts to travel to the moon using a variety of foolishly constructed devices. Along the way, he travels around the world before eventually flying to meet the aliens who reside on the sun and the moon. All of these encounters between the protagonist and other people-be they human or extraterrestrial-are satirically hyperbolic with the authorial intent being to critique dominant colonial ideologies. ${ }^{12}$ For Steensen, these aspects of the The Comical History allow it to work as a metaphorical reference to the travel journals of Jacob Roggeveen, an explorer working for the East India Trading Company who first discov- 


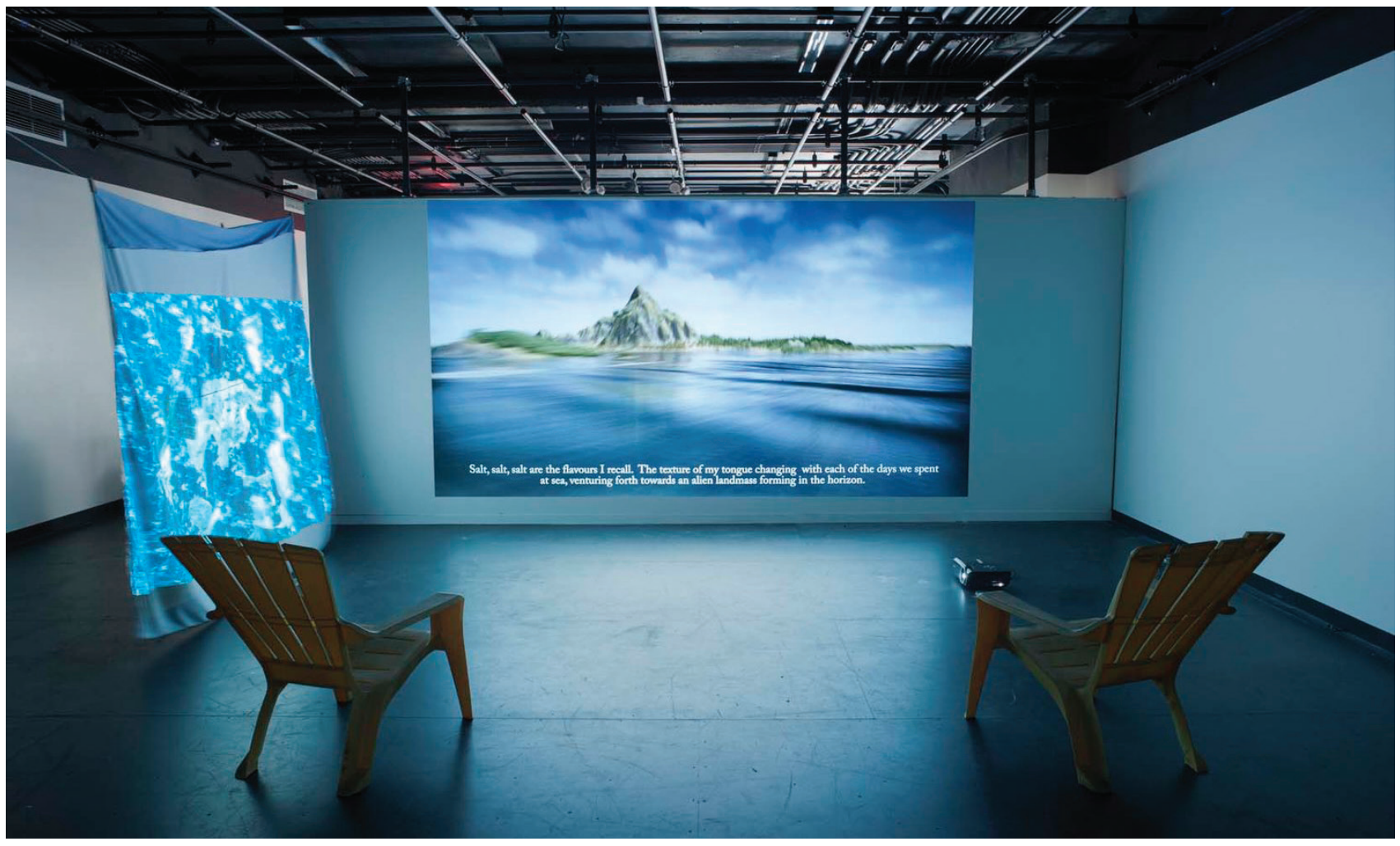

Figure 5. Jakob Kudsk Steensen, Primal Tourism: Walk-through installation view, 2016. Image courtesy of the artist.

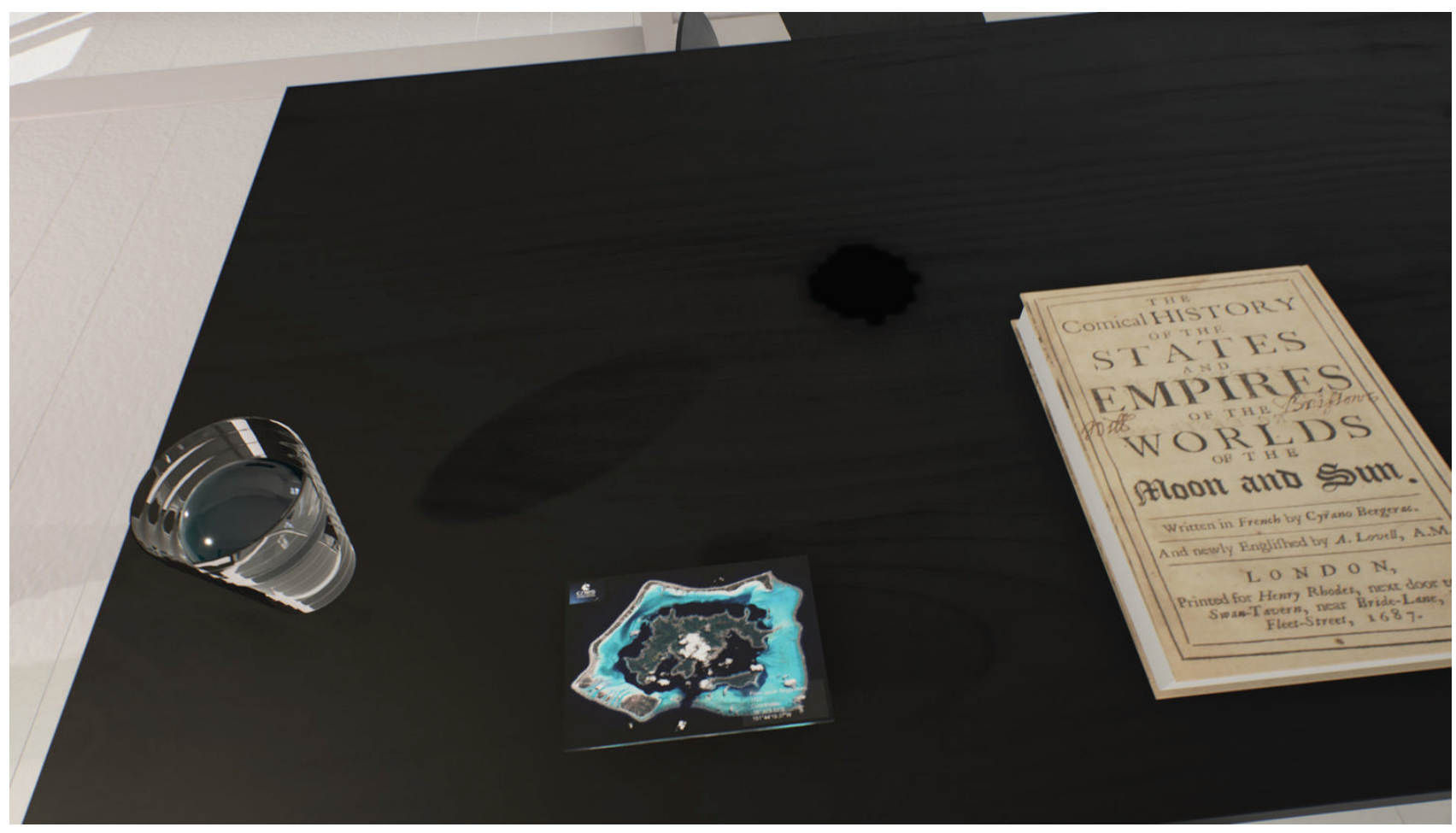

Figure 6. Jakob Kudsk Steensen, Primal Tourism: Walk-through, desk contents detail, 2016. Image courtesy of the artist.

Fantastic Places and Where to FindThem: Pseudo-Indexical Realities Within Video Games and Game Art | 45 
ered Bora Bora in 1722. Steensen has repeatedly cited these journals as a source of inspiration for Primal Tourism, as Roggeveen's encounters with the Polynesian natives were notoriously mishandled and represent a prime example of the destructive effects of colonial exploration. ${ }^{13}$

Another object of significance displayed on the desk alongside The Comical History is a satellite photograph of Bora Bora (fig. 6). When it comes into view, the camera slowly zooms in on this image before piercing its surface and transitioning to an aerial perspective of the simulated island. This dimensional shift from orbital to horizontal view of the island acts as a reversal of the journey to space found in The Comical History, but also acts to reference the importance of the horizon line within oceanic exploration. In an essay comparing the histories of linear and vertical perspectives, Hito Steyerl muses on the possi- bilities enabled by satellite technologies, stating, "Gazes already became decisively mobile and mechanized with the invention of photography, but new technologies have enabled the detached observant gaze to become ever more inclusive and all-knowing." ${ }^{14}$ Within Walk-through, the detached "observant gaze" that Steyerl describes is exemplified by the scripted movements of the camera and the way it slowly floats through the island showing audiences the secrets Steensen has hidden within. As the video moves through these various spaces, the audio narration changes in such a way as to imply the perspective of various animals, such as a snake or a mosquito. Each of these inhuman perspectives comes with an ambiguously poetic monologue that muses on the island's missing human inhabitants and potential reasons for their absence.

Figure 7. Jakob Kudsk Steensen, Primal Tourism: Walk-through, satellite photograph of Bora Bora detail, 2016. Image courtesy of the artist.

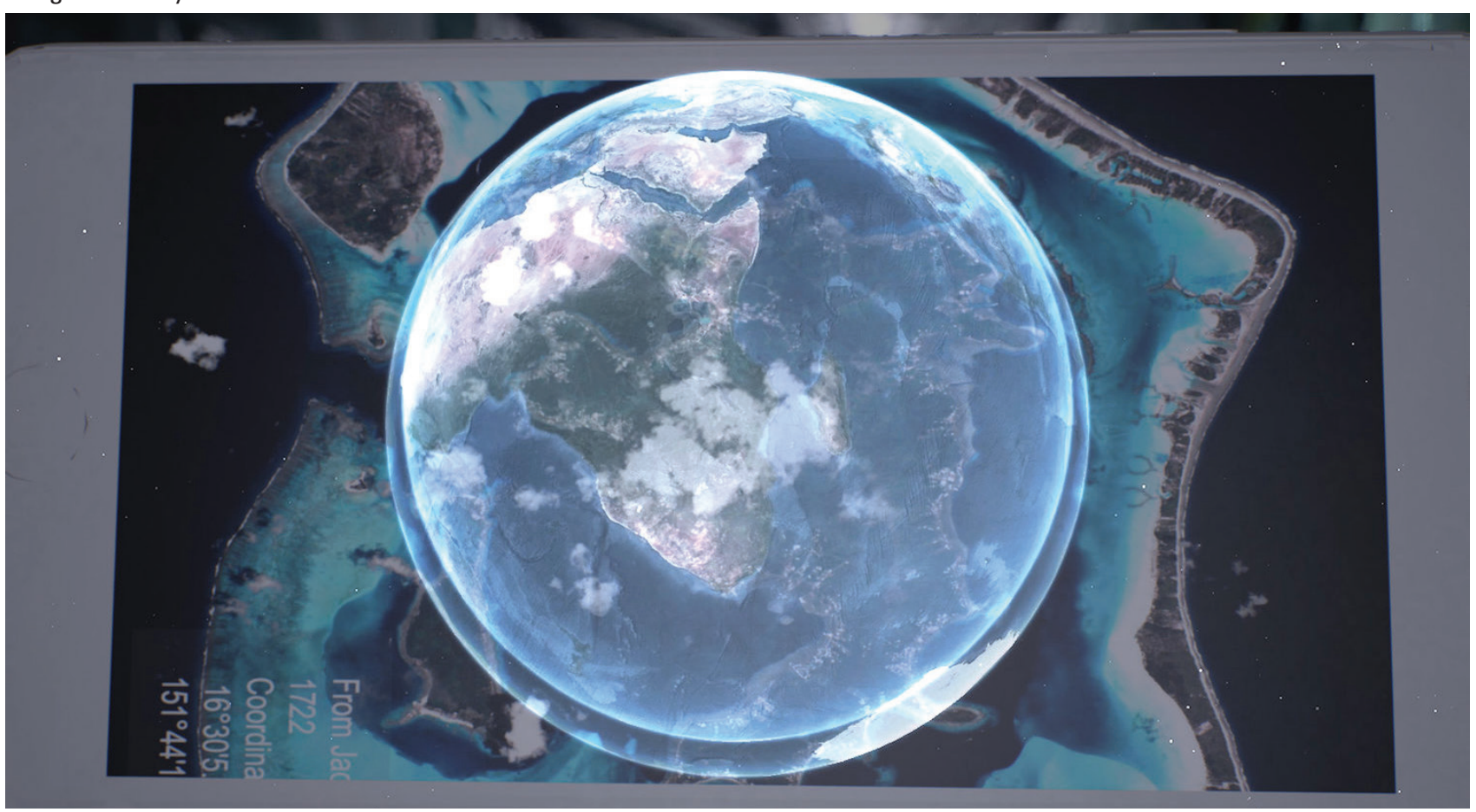




\section{THE OBSERVANT GAZE}

Although the inhuman perspectives delivered through the Walk-through video are not present within the interactive VR configuration of Primal Tourism: Island, the all-knowing and technological aspects of Steyerl's "observant gaze" still are. By affixing print media to the work's real-life wooden housing such as aging travel log pages, satellite photographs, and GPS coordinates, Steensen is giving audiences an extra layer of historical and geographical information to help contextualize their journey through his virtual island. As you move through the abandoned resorts and empty jungles of Primal Tourism: Island armed with the external knowledge that Steensen has provided, you take on the detached omniscient gaze that Steyerl describes. Through the combination of print objects, satellite photography, the Unreal engine, and VR technology, Steensen has constructed an experience that is contradictorily both enlightening and mysterious. In exploring the island, you become more spatially familiar with its terrain and observe the material history of its past hurricanes and failing tourist industry; however, the stark absence of people is also eerily intriguing and prompts many questions that Steensen leaves unanswered.

This combination of knowledge and mystery is what most directly connects the contemporary 3D aesthetics of Primal Tourism back to the early textual descriptions of Adventure. Like Crowther, Steensen used his own personal research and travel experiences to help inform the mapping of game art project; also like Crowther, Steensen filtered his selected portion of reality through a fantastical lens in order to create what Murray calls "heightened interest" for himself and his audiences. ${ }^{15}$ Whereas Crowther did this by creating Adventure as a nod to the monster-laden narratives of tabletop role-playing, Steensen achieves this through his references to the history of science-fiction literature, satellite imaging, and the use of inhuman perspectives. Additionally, although most of the island is constructed to mirror the real life islands of Bora Bora, Steensen also occasionally places an overtly futuristic piece of architecture or technology throughout the island to help emphasize his chosen sci-fi themes. By focusing only on the areas of Bora Bora that have been abandoned, Steensen is compressing reality in order to create a space that seems mysterious and full of secrets waiting to be uncovered by his audiences.

In combination with his playful use of science fiction, this exaggeration of Bora Bora's ruined and empty state creates a work of art that mirrors Chang's description of Adventure in that it produces significant exchanges between fantastical virtual experience and real-life space. Although Crowther was able to achieve this effect in the 1970s using textual description and natural language command prompts, technology has advanced considerably since then, and Steensen takes advantage of this through $3 \mathrm{D}$ rendering and virtual reality toolsets. When further explaining her theory of the "detached observant gaze," Steyerl specifically cites these kinds of methods as strongly affecting the reality which they are used to depict or simulate:

Recent 3D animation technologies incorporate multiple perspectives, which are deliberately manipulated to create multifocal and nonlinear imagery...The tyranny of the photographic lens, cursed by the promise of its indexical relation to reality, has given way to hyperreal representations-not of space as it is, but of space as we can make it. ${ }^{16}$

Crowther may not have used 3D animation 
when he programmed Adventure, but his pioneering work of interactive fiction used the tools available at the time to remake the reality of the Mammoth Caves in concert with his interest in fantasy roleplaying games. Similarly, Primal Tourism is connected to this same kind of pseudo-indexical interpretation of reality through Steensen's empty, dystopian version of Bora Bora.

\section{REACHING THE WORLD LIMITS}

Although both of these works were made with real locations in mind, due to their inherently artificial nature there are obviously limits to what each attempts to simulate. Crowther only chose to map out a small section of the interconnected Mammoth Cave system, and Steensen limited Primal Tourism to depict only the abandoned areas of Bora Bora. Additionally, both works actively reinforce the notion of remote and enclosed realities through the isolated nature of the places which they reference: Adventure is set within an underground cave cut off from the surface world, and Primal Tourism is set on an island, the allegorical definition of a place disconnected from the rest of the world. Not only do these locations serve to reinforce the compressed nature of Crowther and Steensen's creative efforts, but they also function to comment more broadly on video game culture in general. Caves and islands are relatively common settings for video games as they allow for believable narrative reasoning for the uncrossable world limits that are necessary to level design. Slavoj Žižek's interpretation of game design through the lens of the cosmic is helpful here in that there are noticeable parallels between these pixelated edges of game environments and the blurry quarks at the edge of particle physics. It is at both of these distant zones where all detail becomes hazy and unrendered. ${ }^{17}$ Referring back to Caillois and Gonzales and their arguments on secrecy, knowledge, and exploration, these hazy world limits can be connected to the way that both Adventure and Primal Tourism work to simultaneously produce and expend the mysteries of the places they were built to reference.

Echoing Schrank and his description of avantgarde game art, Steyerl argues that purposely diving into these kinds of hazy virtual spaces allows for one to see contemporary social and political landscapes from new vantage points. ${ }^{18}$ Although their creators may have differing goals and audiences in mind, both Adventure and Primal Tourism allow participants to travel to these types of enclosed liminal worlds. Both Steensen and Crowther subversively experiment with digital culture-a field that excels in crafting compressed exaggerations of reality-in order to re-instill elements of the unfamiliar into environments long ago thought fully explored and mastered. Contrary to Gonzales' exaggerated images of the Yucatán, this is not done with a longing for the Other or the exotic, but rather as an attempt to guide audiences away from the well-worn paths they might otherwise take. $A d-$ venture and Primal Tourism are united by their efforts to push audiences adrift into empty spaces outside of recorded networks of travel, and free fall into a hazy, compressed nonplace, removed from the influence of known reality and the compulsive need for complete understanding. Similar to the black void of space surrounding the satellites that so definitively map our globe or the sunless depths of the subterranean tunnels where Crowther found his inspiration, these kinds of nonplaces are not always easy to access. 
However, game art such as Adventure and Primal Tourism can act as odd kinds of travel guides for those seeking such empty nonplaces, mysterious walkthroughs that will take you outside of where you thought you ever wanted to go in the first place. $\rightarrow$

\section{Bio}

Andrew Bailey is a scholar, artist, and curator who lives and works in Toronto, Ontario. Andrew holds a MA in Art History \& Curatorial Studies from York University, and a BFA in Printmaking from OCAD University. Currently he is in the process of completing a PhD in Art History \& Visual Culture at York University with research centered around how history and materiality relate to both game art and game studies. 


\section{Notes}

1. Alenda Y. Chang, “Games as Environmental Texts," Qui Parle: Critical Humanities and Social Sciences 19, no. 2 (2011): 61.

2. Brian Schrank, Avant-Garde Videogames: Playing with Technoculture (Cambridge: MIT Press, 2014), 139.

3. “Colossal Cave Adventure on VT100 Terminal," Wikimedia Commons, accessed July 25, 2018, https: / / commons.wikimedia.org/wiki/Category:Colossal_Cave_Adventure\# / media/File:Colossal_Cave_Adventure_on_VT100_terminal. jpg; Attribution-ShareAlike 3.0 Unported, https:/ / creativecommons.org/licenses/by-sa/3.0/.

4. Chang, "Environmental Texts," 68.

5. Ibid., 69 .

6. Ibid., 58-60.

7. Janet Murray, Hamlet on the Holodeck (Cambridge: MIT Press, 1998), 142; quoted in Schrank, Avant-Garde Videogames, 137.

8. Henry Geddes Gonzales, "Tourism, Mass Media, and the Making of Visual Culture in the Greater Yucatan Peninsula, Journal of Film and Video 60, no. 2 (2008): 56.

9. Gonzales, "Tourism," 57.

10. Roger Caillois, Man, Play and Games (Champaign: University of Illinois Press, 1961), 4; quoted in Alexander R. Galloway, Gaming: Essays On Algorithmic Culture (Minneapolis: University of Minnesota Press, 2006), 95.

11. Schrank, Gaming, 139, 156.

12. "Cyrano de Bergerac," The Encyclopedia of Science Fiction, last modified April 04, 2017, accessed August 18, 2017, http:/ / www.sf-encyclopedia.com/entry/cyrano_de_bergerac.jaco.

13. Jakob Kudsk Steensen, "Primal Tourism: Walk-through," personal website, last accessed August 18, 2017, https: / / jakobsteensen.squarespace.com/\# / primal-tourism/.

14. Hito Steyerl, "In Free Fall: A Thought Experiment on Vertical Perspective," e-flux, Number 24 (2011), accessed August 18, 2017, http:/ / www.e-flux.com/journal/24/67860/in-free-fall-a-thought-experiment-on-vertical-perspective/.

15. Steensen. "Primal Tourism."

16. Steryel, Free Fall.

17. Slavoj Žižek, "The Reality of the Virtual," Youtube video, 39:33, posted by Casper Børretzen, August 20, 2012, https: / / www.youtube.com/watch? v=RnTQhIRcrno.

18. Steryel, Free Fall. 

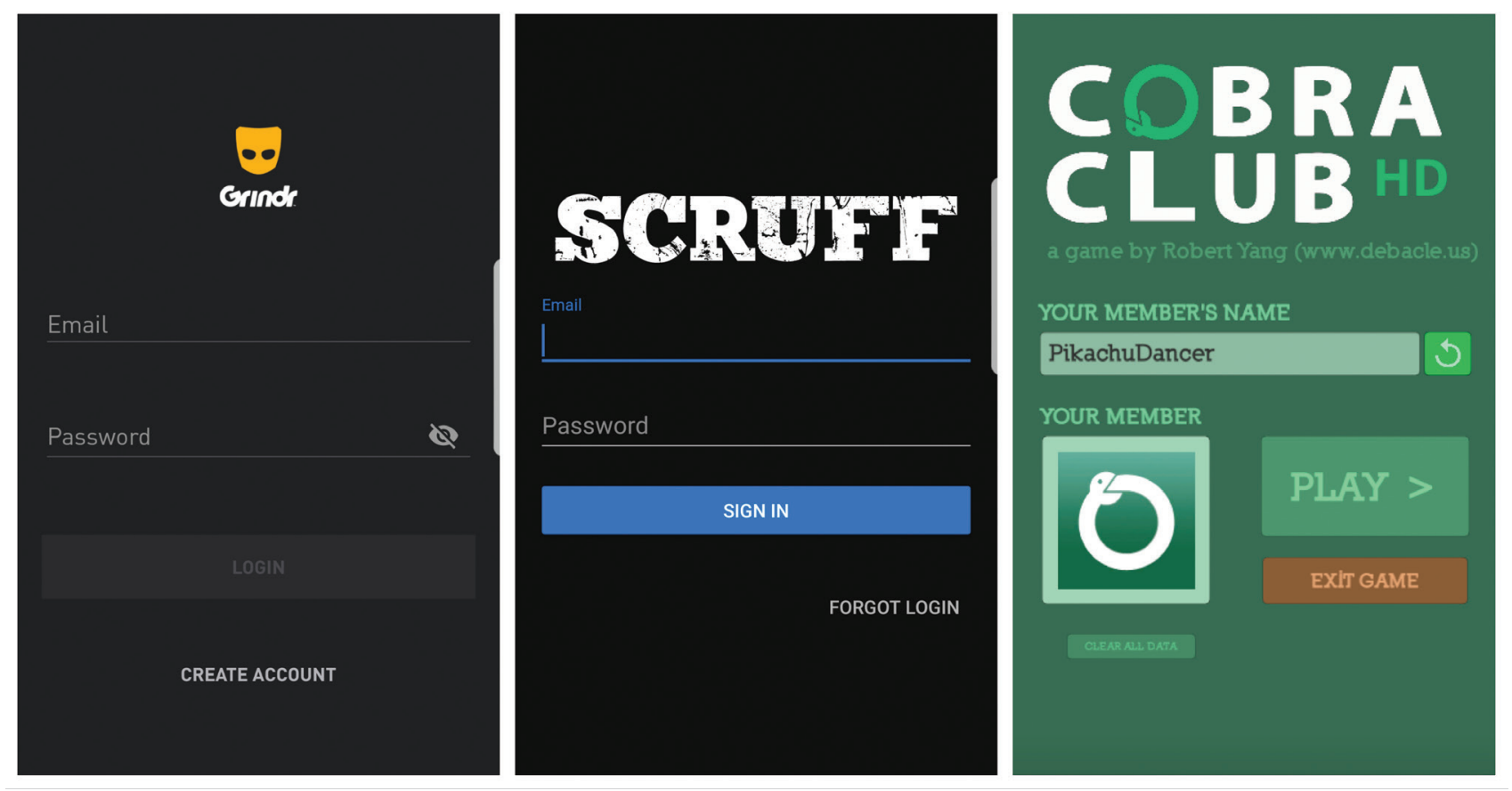

Figure 1. Left to right, login pages for Grindr, Scruff, and Cobra Club, 2015.

\section{Playing with Dick Pics: \\ Networked Technologies and Digital Closets}

Michael Anthony DeAnda

PhD Candidate, Technology and Humanities, Illinois Institute of Technology

\section{Abstract}

Robert Yang's free photo studio video game Cobra Club poses as a fictionalization of location-based mobile "hookup" applications marketed toward gay men. This "free artistic dick pic" simulator provocatively comments on body image and online surveillance. $\mathrm{Co}$ bra Club's game design successfully reflects queer experience by articulating how networked devices and surveillance technologies digitize the Closet. As video games provide spaces for considering how lived experiences engage present and future technologies to shape our communities and values, $\mathrm{CO}^{-}$ bra Club allows players access to a gay lived experiences and the continued problematic intersections of gay sexuality, surveillance, consent, and body image. 


\section{INTRODUCTION}

“Lets see some pikachu!" a message reads. Scrolling through your album, you select a picture of your cock in a flaccid state: you like the sepia filter and the angle of the picture that crops out the rest of your body because you feel insecure about the extra weight you've gained. You send this picture to him. "Artistic," "Inspired," "Postmodern," he responds before asking if you want to see his "soldiertool." As you are about to take him up on his offer, your mom knocks on the door. "Honey, are you okay? You've been in there quite a while," she asks. You don't answer. Instead, you reply to your chat partner and he sends you a picture of what he's packing: he has a brown, chubby belly, a long, thin erection with a Prince Albert piercing on the head of his penis, and large testicles.

This is a bit of what I experienced when playing Robert Yang's free photo studio video game Cobra Club. ${ }^{1}$ The game recalls location-based mobile applications like Grindr and Scruff marketed toward gay men, most often used to find nearby hookups (fig. 1). This game, which Yang bills as a "a free artistic dick pic" simulator, comments on body image and online surveillance. Recent public concern regarding surveillance resulted from the 2013 reports that Edward Snowden, a former United States Central Intelligence Agency (CIA) employee and National Security Administration (NSA) contractor, leaked a large corpus of information collected by global surveillance programs run by the NSA and the Five Eyes Intelligence Alliance with the cooperation of telecommunication companies and world governments. In designing Cobra Club, Yang drew inspiration from comedian and political commentator John Oliver's blend of comedy and activism in re- sponse to the Snowden leaks. On his show Last Week Tonight, Oliver took to the streets to gauge public opinion of the matter. As depicted in a segment of this show airing April 5, 2015, people he encountered only started thinking deeply about online surveillance once he framed the issue as the NSA having access to each person's nude photos; the camera zoomed in on the faces of Oliver's respondents as they paused, reflected, and stumbled over their words when trying to articulate their concerns and frustrations.

Yang began this project as a "dick pic generator" to flood the internet with a bunch of dicks as a form of protest. However, his initial prototype lacked nuance, as it only created a nude photo of an avatar and anonymously posted it online. ${ }^{2} \mathrm{He}$ then developed Cobra Club to comment on how people take dick pics privileging certain bodies over others, and explore how mobile applications can become tools for political activism. In this article, I argue that Cobra Club is important for its approach to game design, reflecting queer experience by articulating how networked devices and surveillance technologies digitize the Closet. Video games, as forms of unique storytelling, provide spaces for considering how lived experiences engage present and future technologies to shape our communities and values. Through its gameplay, Cobra Club presents a queer approach to game design that centers around gay lived experiences and the continued problematic intersections of gay sexuality, surveillance, consent, and body image.

\section{COBRA CLUB AS A CYBORG GAME}

Elise Vist defines cyborg games as games that resist normalized conceptualizations of game design, play, and audiences by affirming the expe- 
riences of people often pushed to the margins of representation. ${ }^{3}$ Vist locates cyborg games at the theoretical intersection of Donna Haraway's "A Cyborg Manifesto" and Sarah Ahmed's Queer Phenomenology: she applies Haraway's framing of irony and blasphemy to Ahmed's discussion of disorientation to discuss how cyborg games defy traditional tropes to subvert players' expectations of gaming technologies and genres to emphasize affectual play. ${ }^{4}$ Ahmed focuses on "orientation" and "orient" in terms of "sexual orientation" and the "orient," analyzing what it means for bodies to be situated in space and time; being "orientated" means feeling at home, recognizing the familiar and comfortable. Vist invokes Ahmed in articulating genre deviations and trope subversions as disorientaters for players of normalized and privileged identities and bodies. For example, the video game Gone Home (Fullbright, 2013) uses horror tropes to create an uneasy atmosphere as the player-character searches her childhood home uncovering narrative remnants detailing her sister's lesbian experiences, but the jump-scare moment common to horror games is never realized. As Vist argues, cyborg games emphasize the experiences and affects of players at the margins and challenge privileged bodies and identities. ${ }^{5}$

Because of the emphasis on gay eroticism, Cobra Club fits into Vist's category of cyborg games as well: using first-person perspective, the game focuses on self-objectification and eroticizing a fat, male avatar as opposed to the well-worn adventuring or killing gameplay common to first-person shooters. The first-person perspective in Cobra Club suggests the player is looking through their phone at the reflection of the nude avatar standing in front of a mirror, iden- tifying this as the player's own body. Furthermore, the chubby avatar serves to disorient the player's desire; instead of offering traditional masculine beauty for the player-the muscular, broad-shouldered, slim-waited avatar with the requisite v-shaped inguinal crease-Cobra Club requires that the player sexualize a soft, chubby, and hairless body (fig. 2).

\section{THE RESTROOM AND DISCIPLINING SEXUAL DEVIANCE}

Cobra Club specifically, and much of Yang's design work generally, comments on the collective experiences of gay men in ways that both affirm the identities and existences of gay men as well as challenge problematic and internalized values of homophobia, racism, and heteronormativity. Cobra Club marks an interesting moment in Yang's design where he diverted from using metaphors and symbols for penises: Succulent (January 2015) focuses on shooting a music video of a man eating a corn dog, simulating fellatio; in Stick Shift (April 2015), the player masturbates the stick shift of a car. Cobra Club, originally released in May 2015, differs in that the avatar's penis is now exposed, and the character's face is blurred. Commenting on the inspiration for this design choice in a postmortem on his blog, Yang wrote, "In gay dating networks, your body pic / dick pic is a promise as to how great the sex is going to be, while your face pic is where you show how attractive and normal and safe you are. (Given the history of gay men being targeted for attacks via gay apps, safety is always a concern.) There's an implicit private life / public life divide." ${ }^{\prime 6}$ In an email to Patricia Hernandez, a journalist for Kotaku, Yang said, "As a gay dude, dick pics are mundane and funny to me... 


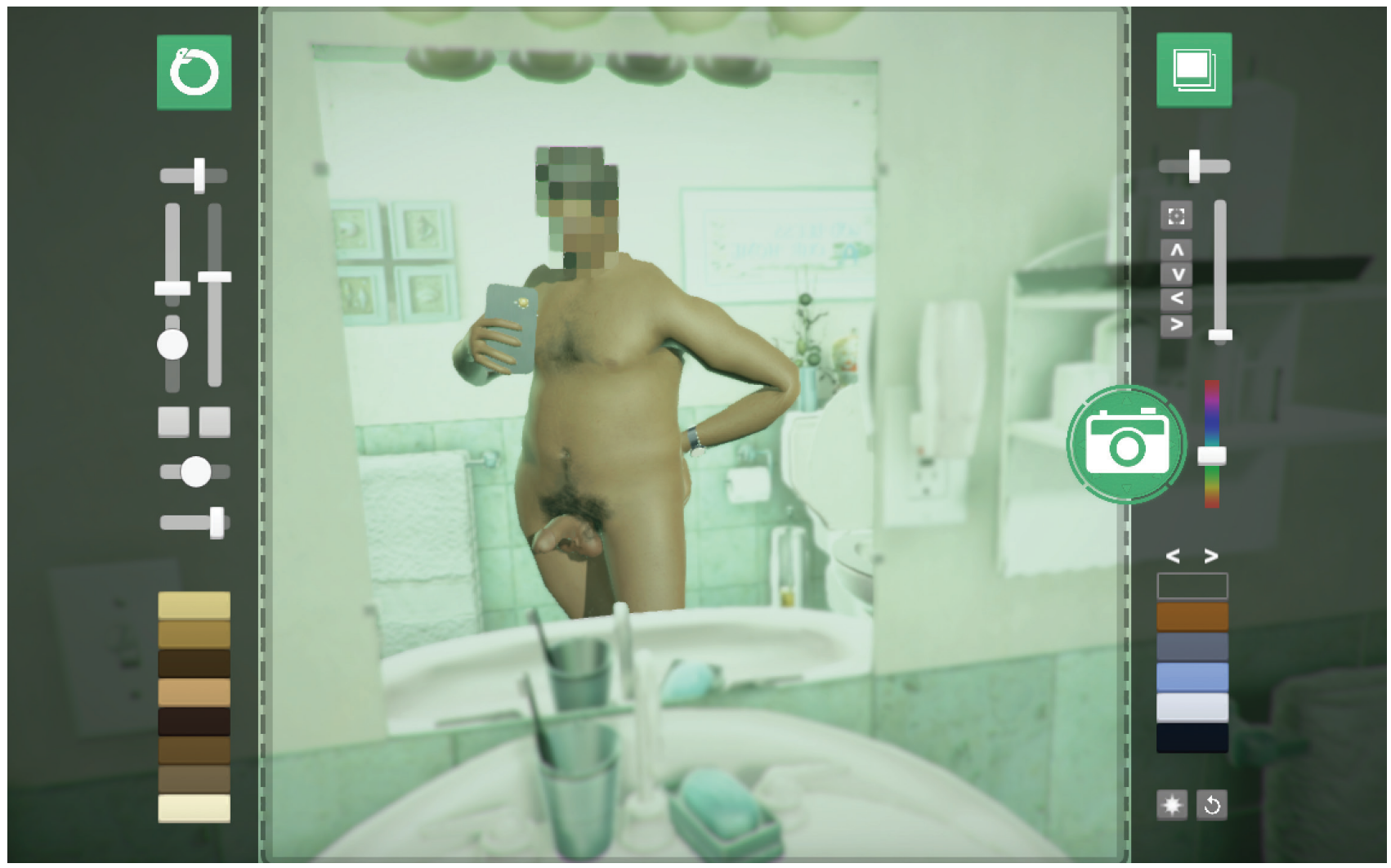

Figure 2. The interface and chubby male avatar, Cobra Club, 2015. Image courtesy Robert Yang.

It always fascinates me that so many dick pics are performed within bathrooms-there'll be a toilet and a dirty sink in the photo at the same eyeline as a cock, which is soooo not sexy, but at the same time it's important that those things are there because that's what makes it seem real and not staged." ${ }^{\prime 7}$ In these two comments, Yang highlights the import of authenticity-or the performance of authenticity-in the approach to both taking dick pics and sharing them. Yang's use of the restroom is an authenticating space for gay male desire, constructed through adverse dichotomies: abject/erotic, private/public, safe/ risky.

Lee Edelman's essay “Tearooms and Sympathy; or, Epistemology of the Water Closet" investigates the discursive construction of gay men in media reports; he analyzes how magazine and news reports scandalized the discov- ery of high-profile men engaging in sex with other men in semi-public spaces, particularly the restroom. ${ }^{8}$ The title draws on Eve Sedgwick's book title Epistemology of The Closet, and elaborates on Sedgewick's work in articulating the restroom, or water closet, as a materialized space of the Closet. As Sedgwick demonstrates, the Closet serves as a policing system serving to reify binary thinking. ${ }^{9}$ Edelman focuses on the 1964 scandal in which police surveilling a YMCA restroom frequented by gay men for public sex caught Walter Jenkins, President Lyndon B. Johnson's aide, engaging in homosexual activity; Edelman analyzes the spectacle of homosexuality in news reports about this event. Jenkins' arrest demonstrates the danger posed by government surveillance of sexual minorities, particularly as his outing by police led to public scrutiny and discursive construction of 
"the homosexual" in news reports and magazines. Edelman's analysis focuses on how these reports cite the Closet as a theoretical apparatus of social training to situate the homosexual as a deceptive figure who infiltrates the family unit by seducing married men in public restrooms; he highlights abjection in his analysis of reports, paralleling the restroom and the homosexual as exposed to the public eye, arguing that the tension imposed by authorities stems from the narrative that homosexuals threaten men by defacing their masculinity through seduction, and, by proxy, threaten women and families. ${ }^{10}$ Thus, the homosexual becomes an abject figure in his failure to perform masculinity, and must seduce other men into similar gender deviance.

Dharman Jeyasingham's study of the restroom as a spatialized Closet focuses on how heteronormativity informs the policing of public restrooms as a disciplinary measure for homoerotic behaviors. ${ }^{11}$ Using spatial syntax of public restrooms, he identifies that secluded public restrooms or public restrooms with many barriers (e.g. stairs, multiple doors, and hallways) enable sexual interactions as they provide just enough privacy. ${ }^{12}$ One particular example of heteronormative spatial syntax we experience in everyday life is how public restrooms are organized based on the model of the heterosexual family: the men's restroom is next to the women's, usually with a waiting area directly outside for people of opposite genders to wait for one another. Jeyasingham demonstrates how such a configuration serves as a panoptic disciplining of behaviors as the common area highlights an assumed heterosexual family unit: a user becomes aware of public surveillance when they encounter people waiting in the common area as they enter and exit the restroom. As a result, single gender restrooms that are secluded highlight the precarious boundaries between public and private spaces and lead to the eroticization of the restroom. ${ }^{13}$ Jeyasingham notes a clear correlation between abjection and sexual activity in the restroom: the dirtier and less kept restrooms were more likely to be used as locations for men to have sex.

While both Edelman's and Jeyasingham's studies focus on public restrooms, these analyses are still relevant to Cobra Club even though the game takes place in a home bathroom. Yang "attacks" this assumption of home bathrooms as private spaces through the inclusion of the mother non-player character (NPC), and later gameplay featuring the use of social media. ${ }^{14}$ In Cobra Club, the mother's random interruptions and interrogations underscore the precarious nature of the restroom as theorized by both Edelman and Jeyasingham: the presence of the mother NPC recalls Jeyasingham's argument that heteronormativity informs the policing of restroom spaces, "orientate" (to invoke Ahmed's usage of the term) the player within a heteronormative family unit. Such orientation serves to emphasize the affects of shame and transgression present in this dick pic simulator, particularly when the mom elicits embarrassment and aversion, admitting that she knows her son is "taking his little dick pics."

Cobra Club requires playing between the foregrounded nude figure and selfie interface and the background of the restroom, highlighting the water closet as a space of abjection and homoerotic experience. Sarah Ahmed calls for understanding the relationship between foreground, what we see and and how it informs our engagement, and background, the broader social and 
political contexts that inform the foregrounded figures. ${ }^{15}$ Applying Ahmed's methods to Edelman's analysis of abjection to gay eroticism in public spaces underscores how magazines and news reports foregrounded homosexual deviance against a background of a heteronormative context; as a result of this foreground/background juxtapositioning, the homosexual was interpreted as dangerous-not only because of his subversion of gender and sexuality strictures, but because he seduces "straight" husbands. Framing Jeyasingham's study through Ahmed's methods demonstrates homoeroticism as the clandestine foreground placed upon a background of heteronormativity; that is, both cruising men and those policing such behaviors placed semi-public sexual encounters between men within a heteronormative spatial syntax, thus reifying the abjection of gay eroticism. The affectual experience of Cobra Club derives from the play between the foregrounded homoeroticism-sharing dick pics—with the backgrounded abjection demonstrated in two ways: the obvious context of the game within the restroom, and the player's labor of sexualizing a body that deviates from typically desirable masculinity.

Within the game, occasionally some NPCs direct the player to click on various parts of the restroom in order to unlock more interface features. Some of these challenges include clicking on each lightbulb on the vanity in a patterned order, or clicking on the toothbrush a certain number of times. As a reward for each of these types of grinding, players receive more features that allow them to enhance the appearance of the cock, add different filters to the selfies, and gain more storage room for their own dick pics. Clicking the roll of toilet paper unlocks twenty extra spaces for the player to save even more photos to share over the chat function. Though the toilet paper in the game is clean-there is no sign of bodily waste at any point in the gameplay-to grind through clicking the toilet paper is an example of how the game forces the player to engage the loaded symbols of the backgrounded restroom in order to unlock features that eroticize the foregrounded body. Toilet paper clearly symbolizes the precarious nature of abjection and eroticism, as it is often used to clean the body by wiping up defecation and ejaculate. To invoke Ahmed, the toilet paper in Cobra Club orientates the player within the restroom, and recalls the very juxtaposition of abject and erotic Yang described in his inspiration for the game: the toilet is at the same level as the cock in a dick pic.

Yang bills Cobra Club as a dick pic simulator about body image and surveillance in which "all cocks are worthy of consideration."16 Yang uses Cobra Club to engage with several sites that society codes as abject, particularly flaccid penises and fat bodies. ${ }^{17}$ Yang resists coding, quite literally, the penis as phallus: the randomized state of the avatar's cock enables endless possibilities of penis configurations-between flaccid and erect, thick and thin, long and short. Susan Bordo examines the use of the phallus as an ideological rubric to judge masculinity, ultimately showing that this is an unachievable feat. ${ }^{18}$ Instead, Yang offers an experience that disorients players from this framework of masculinity: using the interface of gray checkboxes, radials, and sliders, the player has the option of changing the state of his erection, the girth of his penis, the length of his penis, and the balance and size of his testicles. The "Strap-on Mode," which colors the penis green and adds straps around the hips, invites 


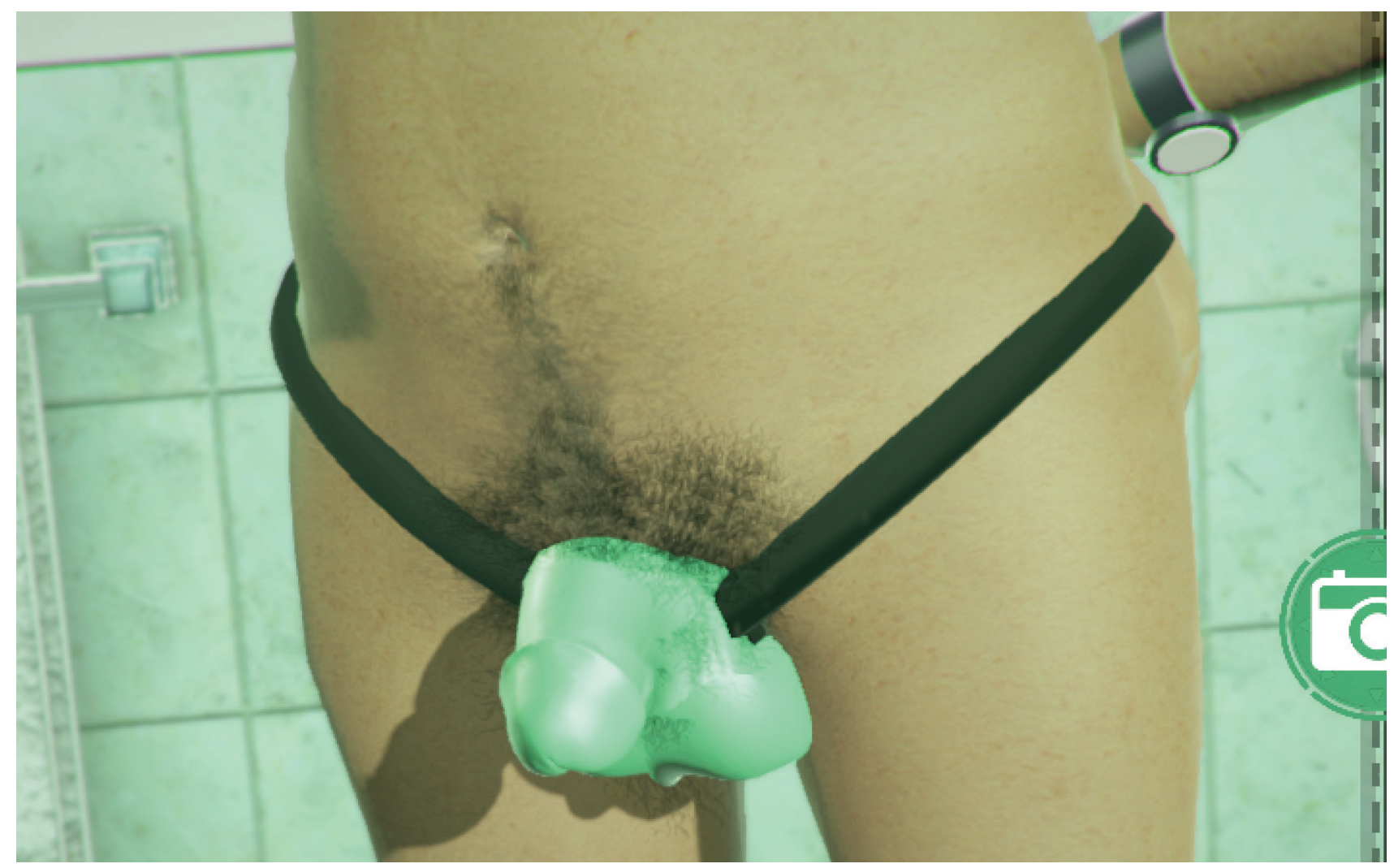

Figure 3. "Strap-on Mode," Cobra Club, 2015. Image courtesy Robert Yang.

the player to consider playing as a transman, ludically presenting the trans experience as worthy of erotic consideration within this context (fig. 3). The use of a chubby male avatar also offers a body diverging from the toned, muscled, and sculpted bodies that frequently circulate in advertisements, film, television, and games geared towards gay men. The avatar Yang chose for this game invites players to challenge internalized biases towards normalized beauty standards, and instead assert body-positivity by focusing play around eroticizing this chubby body.

Analyzing this procedural argument embedded in playful actions requires observing the player's labor in eroticizing the body. Beginning at the randomized configuration of skin color, penis size, shape, and erection state, the player is invited to adjust the body at will. While the randomization does not privilege hegemonic norms of masculinity and whiteness, players may adjust the avatar to reflect these values, although the avatar's body shape remains the same. The player may then use the interface of the game to adjust the camera angle of the selfie, zoom in or out on the body or different parts of the restroom, and add filters before clicking the button to take a picture. The picture is then stored in an inventory of pictures in the player's in-game gallery. When revealed by NPCs, the player then may grind to unlock additional features of the interface which provide more options for the penis and camera interface, allowing the player to play with how they eroticize the avatar; for example, they may offset the testicles, give the head of the penis a piercing, add filters or paint sparkles on the picture. While these actions may seem superficial, they direct the player's attention away from the picture mechanics for a few 
seconds of mindless clicking in order to level-up the gaming interface. In this way, the avatar is not already sexualized; this labor is given to the player. The description of the game as a "dick pic simulator" thus privileges and, to draw from Ahmed, foregrounds the dick pic as the goal of play, though the background forms the labor of play required to achieve that task.

\section{DIGITIZING THE WATER CLOSET}

In playing through the game, the player is able to consensually send and receive nude images with NPCs. Consent is built into the chat interface of the game; you must first consent to either send or receive nudes before you are given the ability to actually send pictures. Pictures are not constructed as a form of currency, meaning that you are able to receive nudes without being obligated to send nudes back to the NPC. However, once receiving the picture, the player must then respond to the image either positively or negatively. The language in-game is comical: what does it mean for a dick to be "zesty," "postmodern," or "baroque?" If, at the beginning, the player disables the web play option, they will continue to engage in this free-form play of sending and receiving dick pics with the occasional interruption from his mother. If, however, they enable networked play, the game collects the pictures they share with NPCs in a database and leaks some of them onto a public, IRL Tumblr blog. The player receives a link and a silly-worded alert from an NPC that their dick pics have been leaked. "I think this is your cheeta sword." "Your jealous johnson is on the internet." "The government has your dick!" When clicked, the link opens up a browser out-of-game, and directs the player to a live post on a Tumblr blog entitled "COBRACLUB v2.21; totally not illegal surveillance" containing the player's username, a nude picture they sent, and a chat log of the conversation he had with an NPC (fig. 4). [19] The artist's statement on COBRACLUB v2.21 explains that this serves as the page for the fictitious government team, Cobra Club, that surveils the internet for dick pics.

The system of leaking the player's picture onto the online Tumblr blog serves the in-game representation of government surveillance and simultaneously outs the player by both sharing their cock shot and the transcript with the NPC. Here, Cobra Club demonstrates how networked technologies and surveillance work in tandem to digitize the Closet. Cobra Club transgresses the confines of Johan Huizinga's "magic circle," a space of play within safe confines where we may come to understand and enact culture. ${ }^{20}$ Huizinga's theory of the magic circle complements Edelman's discussion of the restroom as a private space men uses for public sex, particularly in how high-profile men would have sex with other men in these clandestine spaces and then return to their families and heterosexual lives. The assumed privacy of the restroom in Edelman's essay parallels the assumed safety of play spaces; thus, COBRACLUB v2.2.1, as an in-game surveillance of the corpus of dick pics circulating the Cobra Club app, disciplining players alludes to the very real history of men being outed for participating in sexual activities with other men, as Walter Jenkin's outing is exemplified in Edelman's article. This adds to the affectual experience by disorienting the player, taking them from a ludic context in which they labor to share sexual images, to an online context where they have no agency to remove the artifacts of their 
gay networked encounter.

The difference between sharing dick pics ingame and having the same dick pic on a publicfacing Tumblr embodies a similar structure to Robert Payne's discussion of promiscuity and virality ${ }^{21}$ In his project, Payne discusses how popular discourse of spreadable media and online participation requires a separate understanding of "transmission" than the one we often associate with viruses. Developing the term virality 2.0, Payne argues how viral media is specifically post-viral, meaning that spreadable media made to go viral privileges the transmission and spread but divorces from the discursive constructions of viruses as dangerous, fearsome, and unsanitary or reflecting poor hygiene. ${ }^{22}$ The tension Edelman points to among heterosexuals in regards to homosexuality eerily aligns with the anxieties of the public Payne describes: while sodomy might have been a concern, the main point of fear Edelman discusses in reports is the possible virality of homosexuality-that gay men somehow seduce, or "infect," straight men into also being homosexuals by desecrating their masculinity. He compares how the goal of "going viral" contrasts from transmissions of viruses that are often used to demonize and discipline marginalized communities for example, how gay people are widely marked as sexual deviants, especially those living with HIV. Payne demonstrates how viral media focuses on transmission while undermining the ways society constructs viruses, hosting bodies, and transmitters as abject. Using HIV as a contrasting example to "going viral," Payne demonstrates the marked history of the black, hispanic, and gay communities as vulnerable to HIV resulting from many socio-political power structures, and how narratives spin this vulnerability as a way to demonize these communities for spreading HIV. Society imposes immoral, unethical, and savage readings upon the transmission of HIV and promiscuous sexual behaviors, whereas cute puppy videos are celebrated for going viral.

Framing Cobra Club through Payne's concept of virality 2.0, gameplay moves from the experience of laboring to take dick pics in the restroom to the Tumblr blog, disorienting the player's sense of agency over the representation of their nude avatar. In a similar way to the virus, the game gestures to discourses used to shame players exchanging nudes. As a single digital artifact on the fictitious surveillance database, the

Figure 4. "Leaked" post on COBRACLUB v2.21, Cobra Club, 2015. Image courtesy Robert Yang.

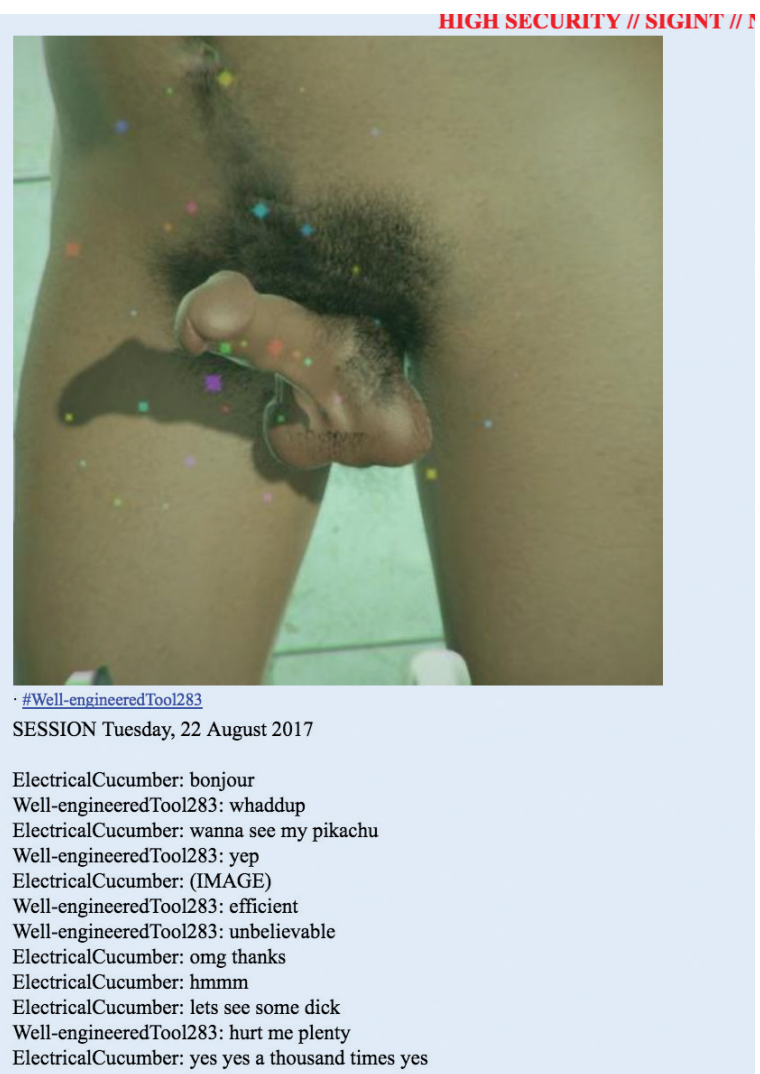


dick pic, once exchanged between two sharing subjects, now exists as a digital artifact on a surveillance website, suggesting that a surveillance agency is targeting this application specifically and men sharing nudes with other men generally. Jasbir K. Puar argues, "queerness is always already installed in the project of naming the terrorist; the terrorist does not appear as such without the concurrent entrance of perversion, deviance." ${ }^{23}$ As Puar demonstrates, the queer bodies are always already under surveillance because of how society codes them and their behaviors as deviant. Cobra Club reflects Puar's argument as it has a function that collects the dick pics shared by players quite literally "always already installed" in the coding of the game. So when the game appropriates the player's pictures and posts them onto the Tumblr, it is suggesting that the surveillance agency castigates the player for violating social conceptions of modesty, "outing" the player. An NPC first informs the player about this breach of privacy, ludically suggesting that the picture has been sent to others aside from the NPC; the in-game picture has already gone viral. Furthermore, Tumblr encourages the promiscuous sharing of media, so the player's picture has the potential to continue going viral. In the move from the confines of the ludic space of Cobra Club to the public-facing Tumblr blog, COBRACLUB v2.21 emphasizes the digital Closet as the player is publicly exposed within a discourse still structured and disciplined by normalized notions of decency and sexual deviance As Edelman suggests, COBRACLUB v2.21, the fictional government agency, disciplines online sexual behaviors because of the fear that straight men become targets of seduction by male sexual deviants. Edelman's discussion underscores the tension heteronormative power structures en- force to code gay men as deviant Others-or, to invoke Puar, as terrorists threatening heteronormative order.

Returning to the game, the player is notified several more times that his cock has been leaked on the same website. If he continues playing, he will get a notification that he has violated the terms of service he agreed to when he began gameplay. This results in the removal of the game interface, leaving only the naked, chubby avatar standing in the mirror. The player cannot move the camera, adjust the body, apply filters, or take pictures. After all their grinding and clicking on the restroom features, orientating himself to the game, and sending and receiving dick pics, the player no longer has access to the ludic features to continue playing. Yang explains that "the player is banned for some arbitrary reason," and is directed to the terms of use to which the player consented. Yang uses a similar lockout feature in Hurt Me Plenty (2014), a game where the player and NPC negotiate, and then engage in a spanking scene. Whereas in Hurt Me Plenty the player is banned from accessing the game if they violate the negotiated terms of the scene, thus having a clear understanding of the violation of terms, the ban from Cobra Club results from unknown reasons, only explained in terms vaguely outlined in the user agreement. By removing the interface, the player is left without the agency to play the game, left merely staring at the chubby avatar on the screen. If the player wishes to play again, he must erase all data of this current game and begin again, grinding through clicking the different spatial features in the restroom. Neither the networked game nor the dick belong to the player any longer: "the government has your dick." 


\section{CONCLUSION}

Cobra Club demonstrates how games can make use of subcultural knowledge and collective histories while it also challenges the embedded values of these subcultures. The game challenges the conflation of penis and phallus, and the dick pic as a symbol of male power. Instead, Cobra $\mathrm{Club}$ initially offers a space for considering the pleasures of consent and celebrating different body types and different penises by orientating the player in a space where they are supposed to enjoy sharing nude pictures. However, the game then enacts a Closet-like disciplinary measure by violating the player's privacy, disrupting his play, and then taking away player agency. The structure of play in Cobra Club depicts the vulnerability of queer bodies existing under surveillance networks wielded by agencies with the power to not only code people as queer, but also dangerous, and it ultimately punishes them by revoking their agency.

Blogger Todd Harper criticized Cobra Club for being a campy, distilled experience of taking a dick pic "without risk, without vulnerability, and it is the very danger of being judged as your person, in total, merely by the qualities of your cock that makes gay men so cagey about the relationship between their dick and their face that Yang mentions in his artist statement." ${ }^{24}$ Harper understands the risk of sharing dick pics with the "level of this knowledge being used to hurt or judge you that is critically important. It's the fear that: 1) They know that dick is yours, 2) That dick is found wanting, 3) Having a dick that is found wanting removes your worth as a person." ${ }^{25}$ Harper feels that without any vulnerability, there are no real stakes for the player, so the surveillance system lacks impact. To this extent, the game provides a magic circle for the player to experience sharing dick pics without having to actually share their own anatomy. However, Harper's critique fails to engage the removal of agency from the queer body under surveillance. In developing "dick pic simulators" maybe a proper one, as Yang developed, needs to account for surveillance. Perhaps between Yang's initial quest to develop a "dick pic generator" to flood the internet with dick pics and the dick pic simulator called Cobra Club, he created, to paraphrase Payne, a dick pic 2.0, one that foregrounds nude photos as spreadable media, casting the vulnerability and affect of sharing your cock with others to the background.

Despite this criticism, Cobra Club points to an important thematic development in Yang's design work. By using representation of an actual penis rather than the metaphorical stand-in, Yang challenges assumptions about private and public spaces through his configuration of a digital Closet, created through the use of networked technologies and social media in the restroom. Yang's more recent game The Tearoom (2017) returns to the space of the restroom, but this time within a dingy public restroom where the player fellates the guns-metaphorical penises-of other men, potentially exposing himself to brutal violence at the whim of an undercover cop. The water closet continues to be a location of interest in Yang's progression of game design. Apparent in these two games is the ongoing history of surveilling the sexual practices of gay men, forcing us to confront and critique the heteronormative power structures that code them as deviant. $\rightarrow$ 


\section{Bio}

Michael Anthony DeAnda is a PhD candidate in Technology and Humanities at Illinois Institute of Technology. His research focuses on how games built for gay male audiences encode gender identity and sexuality, interrogating the extent to which they envision healing from toxic heteronormativity. As a scholar-practitioner, he develops games that comment on sexuality and gender. DeAnda is involved with Different Games Collective, an organization that develops programming that celebrates diversity and inclusivity in games and gaming culture. 


\section{Notes}

1. Robert Yang, New and Improved Cobra Club HD [computer game], Radiator Yang, 2016, https:/ / radiatoryang.itch.io/ cobraclub.

2. Yang, "Cobra Club as ouroboros," Radiator Blog, May 28, 2015, https:/ / www.blog.radiator.debacle.us/2015/05/ cobra-club-as-ouroboros.html.

3. Elise Vist, “Cyborg Games: Videogame Blasphemy and Disorientation,” Loading... 9, no. 14 (2015): 56.

4. Donna Haraway, "A Cyborg Manifesto: Science, Technology, and Socialist-Feminism in the Late 20th Century," in The International Handbook of Virtual Learning Environments, eds.Joel Weiss, Jason Nolan, Jeremy Hunsinger, and Peter Trifonas (Dordrecht: Springer Netherlands, 2006), 117-158; Sara Ahmed, Queer Phenomenology: Orientations, Objects, Others (Durham: Duke University Press, 2006).

5. Vist, 60 .

6. Yang, "Ouroboros."

7. Patricia Hernandez, "A Game About The Complicated World of Dick Pics," Kotaku, May 29, 2015, https://kotaku. com/a-game-about-the-complicated-world-of-dick-pics-1707644515.

8. Lee Edelman, "Tearooms and Sympathy, or Epistemology of the Water Closet," in The Lesbian and Gay Studies Reader, eds. Henry Abelove, Michèle Aina Barale, and David M. Halperin (New York: Routledge, 1993), 553-575.

9. Eve Kosofsky Sedgewick, Epistemology of the Closet (Berkeley: University of California Press, 2008).

10. Edelman, 557, 566.

11. Dharman Jeyasingham, "Closure, Affect, and the Continuing Queer Potential of Public Toilets," South Atlantic Quarterly 115, no. 4 (October 2016): 771-778.

12. Jeyasingham, “Building Heteronormativity: the Social and Material Reconstruction of Men's Public Toilets as Spaces of Heterosexuality," Social \& Cultural Geography, 11, no. 4 (2010): 311.

13. Ibid., 312.

14. Yang, "Ouroboros."

15. Ahmed, Queer Phenomenology: 37.

16. Yang, New and Improved Cobra Club HD.

17. Phil Powrie, "The Abject Object: Avatars of the Phallus in Contemporary French Theory, Literature and Film," French Studies: A Quarterly Review 61, no. 2 (April 2007): 244-245; Linn Sandberg, "The Old, the Ugly and the Queer: Thinking Old Age in Relation to Queer Theory," Graduate Journal of Social Science 5, no. 2 (2008): 117-139; C. Marie Harker, "Fat male sexuality: The monster in the maze," Sexualities. 19, no. 8 (2016): 980-996; Deborah McPhail, "What to Do with the 'Tubby Hubby'? 'Obesity,' the Crisis of Masculinity, and the Nuclear Family in Early Cold War Canada," Antipode 41, no. 5 (November 2009): 1021-1050; Lee F. Monaghan and Helen Malson, "'It's Worse for Women and Girls': Negotiating Embodied Masculinities Through Weight-Related Talk," Critical Public Health 23, no. 3 (January 2013): 304-319.

18. Susan Bordo, The Male Body: A New Look at Men in Public and in Private (New York: Farrar, Straus and Giroux, 2015$), 94$.

19. Yang, "COBRACLUB v2.21; Totally Not Illegal Surveillance," accessed December 31, 2017, http:/ / cobra-club.tumblr.com/.

20. Johan Huizinga, Homo Ludens: A Study of the Play-Element in Culture (London: Routledge, 1949).

21. Robert Payne, The Promiscuity of Network Culture: Queer Theory and Digital Media, (New York: Routledge, Taylor \& Francis Group, 2015).

22. Payne, "Virality 2.0: Networked Promiscuity and the Sharing Subject," Cultural Studies 27, no. 4 (2012): 1-21.

23. Jasbir K. Puar, Terrorist Assemblages: Homonationalism in Queer Times, (Durham: Duke University Press, 2007), xxiv.

24. Todd Harper, "Not Safe For Work (Or Anywhere Else)," Stay Classy, May 29, 2015, http: / / www.chaoticblue.com/ blog/2015/05/not-safe-for-work-or-anywhere-else/. 


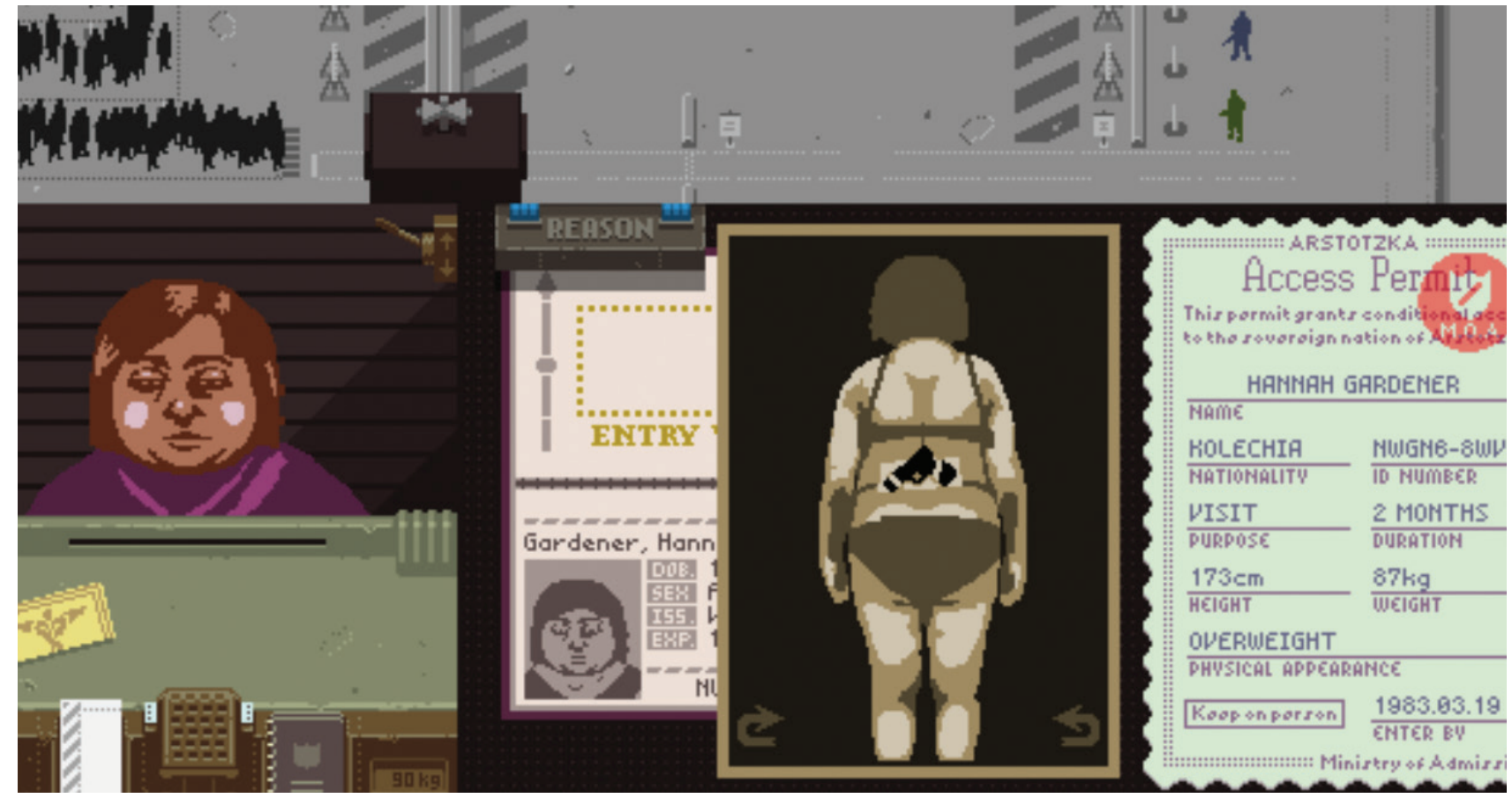

Lucas Pope, Papers, Please, 2013. Image courtesy of the artist.

\section{These Wars of Mine:}

\section{Why It Matters How Video Games Represent War}

\section{Luisa Salvador Dias}

MA candidate, Digital Humanities, University of Alberta

\section{Abstract}

The first genre that comes to mind when we think about war-themed video games is likely the AAA first-person shooter, but is this genre the best method to represent war? In recent years, the boom of indie titles has introduced new forms of immersive experiences for players, and some of these explore war through new perspectives. This paper proposes an analysis of two war-themed indie games-Papers, Please (Lucas Pope, 2013) and This War of Mine (11 bit studios, 2014) - using Jan-Noël Thon's theory of immersion. These games were selected because they explore war without resorting to violence as a core mechanic. The format of the study will be a "close play," in which significant details and patterns from both games are identified and analyzed, forming a better understanding of how their immersive dimensions combine to offer new ways to engage with video game representations of war. Games like Papers, Please and This War of Mine enrich our understanding of what it is like to live through war and its aftermath. 


\section{INTRODUCTION}

War-themed first-person shooters (FPSs), in which the primary action consists of shooting enemies, are an extremely popular game genre, boasting an enormous fanbase and some of the highest development budgets in video game production. They attempt to provide a series of challenges for the player, fostering a sense of empowerment through fighting in hyper-realistic, three-dimensional environments. Yet despite the sophistication of their graphics and the intricacy of their controls, most of these games are rather shallow when it comes to content, basing their stories on a simple enough premise: violencespecifically the violence inflicted by the playercharacter-is the primary experience within the context of the war-themed FPS. It is a reductionist portrayal that frames war as an immediate "us" versus "them," effacing the complexities of the topic and framing the nightmare of war in a mist of glorified, fast-paced adventure that places the player-character in a clear position of power.

The dynamics of FPS games are designed to test a player's dexterity, as well as how they manage their feelings of frustration in the face of challenges that defy their ability to think logically, act strategically, and move with efficiency in the virtual environment. Cole, Cairns, and Gilles call these trials functional challenges. They observe that:

When faced with games with a majority functional challenge component, reviewers are more concerned with technical and mechanical considerations such as how the character moves, what powers they have, what actions they perform, what weapons they can wield and, often, how powerful the game makes the player feel. The reviewers' focus is, "What can I do?," and the core pleasures obtained are that of power and "hard fun."1
The functional challenge stands in opposition to what is found in certain indie or "avantgarde" games, like Papers, Please (Lucas Pope, 2013) and This War of Mine (11 bit studios, 2014), where the player's focus is shifted toward narrative and theme. According to Cole, Cairns, and Gilles, these are called emotional challenges, and upon reflecting on the game:

(...) The reviewer's primary focus is, "How do I feel?" This is achieved by leaving parts of the experience ambiguous, confronting them with difficult material or by use of strong characters, story and good writing....This presents the player with an "emotional challenge" that is overcome not with skill and dexterity, but with a cognitive effort not dissimilar to Schopenhauer's notion of the aesthetic experience of the sublime. ${ }^{2}$

Although some of the most popular mainstream FPS franchises, such as Call of Duty (Activision, 2003-2017), have been trying to bring more nuance into their more recent titles, tentatively exploring issues like posttraumatic stress disorder (PTSD), they often do so in a superficial manner, never amounting to more than adding flavor and therefore doing little to defy the conventions of representing war in games. It can be argued that violence is embedded in the very core of FPS games: if the violent aspects were removed, the core game would become unplayable and any sense of immersion would be lost.

\section{GAMES AS A SINGLE STORY}

We should interrogate video games' representations of war given how our minds engage with narrative forms. George Lakoff and Mark Johnson suggest that "metaphor is central to human understanding" and that "our conceptual systems are fundamentally shaped by cultural constructions. ${ }^{\prime 3}$ In other words, the representations we engage with have a crucial role in forming our 
ideas about a subject. Narrative representations of war, however distorted or stylized, become a domain of experience that we unconsciously use to structure our thoughts about the actual phenomenon of war. It becomes worrisome, then, to consider how the glorified images and beliefs about war propagated by FPS games help constitute the terrain of popular conceptions (and misconceptions) about the experience of war.

Joyce Neys and and Jeroen Jansz also contribute to this discussion, quoting Liesbet Van Zoonen's argument that citizenship, like any other societal role, is a kind of performance. Van Zoonen's study of individuals' reactions to politically themed television demonstrates that media is a powerful resource for creating one's political identity. ${ }^{4}$ As these representations become ways through which one organizes the material facts in life (through a process of metaphor), they are internalized and become beliefs, which can then be used to support action. In presenting warfare as a fable that demonstrates how extreme violence solves problems, Call of Duty and other FPS games reinforce the idea that war is a necessary part of the human experience, perhaps even a fun one. Team bonding and the development of self-worth are core themes, as the player-character triumphs over greater and greater challenges with their comrades in tow. The problem with this representation is how it flattens war into a singular narrative. The Nigerian novelist Chimamanda Adichie, whose work often revolves around the complexities of common people living through moments of political conflict, would call this a "single story." Adichie's discussion about the long-term consequences of limited representations have been explored in her TED talk, in which she argues:
The single story creates stereotypes, and the problem with stereotypes is not that they are untrue, but that they are incomplete. They make one story become the only story. (...) [It] is impossible to engage properly with a place or a person without engaging with all of the stories of that place and that person. The consequence of the single story is this: It robs people of dignity. ${ }^{5}$

\section{THE INDIE ALTERNATIVE}

The tension between offering grim, truthful views of war in games and the imperative, common among AAA FPS titles, to produce enjoyable, glorified experiences of play, has received a different treatment in two indie titles developed and published outside the mainstream, AAA industry: the simulation game Papers, Please and the survival game This War of Mine. Papers, Please takes place in 1982, when the fictional country of Arstotzka re-opens its border with the neighbouring nation of Kolechia after six years of war. Tensions are still running high and the player, as the new inspector, is tasked with running the customs office. Apart from the bureaucratic work, the game presents a series of human dilemmas that involve the impact of war on ordinary people. It was created, developed, and published by Lucas Pope, an indie developer and former employee of Naughty Dog studio, responsible for the Uncharted franchise. In designing Papers, Please, Pope took direct inspiration from the totalitarian governments of early 1980's Eastern Bloc states and the dynamics of immigration during moments of high political instability.

This War of Mine is a survival game that places the narrative focus on the civilian point of view, simulating the dynamics of living in a besieged city. The player controls a group of randomly picked characters taking refuge at an abandoned 
house who must cooperate to find supplies, improve their shelter, and support each other emotionally. It is a brutal setting that demonstrates both the practical and personal struggles of life in a conflict zone. This War of Mine was created by 11-bit studios, a Polish indie company founded in 2010. The game was directly inspired by the Bosnian War, in particular the Siege of Sarajevo (1992-1996) that ead to the deaths of 13,952 people, half of whom were civilians.

Both games represent war outside the military bubble, demoting player-inflicted violence from its place as the primary game mechanic and replacing forms of immersion-building, like "realistic" narrative and aesthetics, with frustration.

I follow Jan-Noël Thon in defining immersion as "the different levels of computer game structure that players shift their attention to and construct situation models of," and the corresponding ways in which "these different kinds of structural properties lead to different kinds of experience." ${ }^{\prime \prime}$ Thon breaks down the phenomenon into four complementary dimensions that operate in conjunction: ludic, spatial, narrative, and social immersion. Building from Csikszentmihalyi's idea that immersion means a state where "all a person's relevant skills are needed to cope with the challenges of a situation [and] that person's attention is completely absorbed by the activity,"7 Thon defines ludic immersion as the player's ideal interaction with the game system and the construction of a situation model that encompasses both its elements and the possibilities for action within the game space. ${ }^{8}$ Spatial immersion comprises the aesthetic elements responsible for the shift of attention from the player's real environment to the game's spaces. These elements are multimodal—the game's im- ages, its soundtrack, etc.-but not interactive, which distinguishes it from ludic immersion. Thon states that besides the general components of a story, such as characters or plot, narrative immersion also encompasses the player's interaction with said story, and can be considered either temporal or emotional narrative immersion. For Thon, "temporal immersion refers to the experience of suspense, i.e. the shift of attention to the unfolding of the story," while "emotional immersion refers to the experience of empathy, i.e. the shift of attention to the fate of certain characters in a story" ${ }^{\prime \prime}$ The last category in Thon's definition is social immersion, which arises from players' interactions with other players, a phenomenon often found in FPS games in their multiplayer modes.

Taking advantage of Thon's categorization of immersion, it is possible to undertake a "closeplaying" of both Papers, Please and This War of Mine to form a better understanding of how these games create compelling alternatives to FPS depictions of war.

\section{PAPERS, PLEASE}

\section{LUDIC IMMERSION}

Papers, Please is organized into two periods: day, when the player-character goes to work in an inspection booth, and night, when the player character returns home. Each new day starts with a long line of travellers outside the inspector's booth that approach the front desk one-by one to have their papers checked. Inside the booth, the player has several tools to inspect documents and rules to approve or deny people, with the complexity of the process increasing as the game progresses. 
The requirements are very simple at first: only nationals of Arstotzka with a valid passport can enter. To evaluate potential entrees, there is a board for height measurements, a scale, a clock (marking date and time), the inspector's manual, two stamps (entry permit and entry denied), the daily journal and a "highlight discrepancy" button. As the days go by, the booth receives add-ons. The travellers' documents also become more sophisticated, going from only passports to an assortment of supplementary papers (there are tickets, permits, consular certificates, and IDs) that need to be processed as fast as possible. If there is anything wrong with the documents, the player must use the "highlight discrepancy" button to try and clear the person for entry. Among the tests implemented are fingerprint strips, X-Rays, and a transcription of the dialogue between the inspector and the traveller. Once all of the viable alternatives have been used, the inspector makes his decision of either allowing entry, rejecting the traveller, or pressing the "detain" button, which leads to the person being arrested.

Every denial must be justified by evidence, and entry is only permitted if there are no irregularities. If the inspector makes a mistake, the player will receive a notice declaring so, and from the third notice onwards, a payment deduction is implemented for each new mistake. The notice system can be exploited by the player to make room for "moral" infractions, allowing for a quota of mistakes that allow the player to ignore a person's lack of documentation out of mercy, self-interest, or to aid the resistance fighting against the Arstotzka government. Attention to detail, strategic thinking, and good organiza- tion are the core skills demanded by the mechanics of Papers, Please, since the number of elements the player has to manage is often overwhelming.

The second period of the game happens when the inspector returns home with his earnings at the end of each day; a total of five credits is given per person allowed in, minus the irregularity deductions (if any). At this moment, a user interface declares both the daily utilities bills and the inspector's total payment, and the player must manage household expenses. This makes money an important part of the game, since it is needed to both improve the customs booth and to keep the inspector's family alive, covering their basic needs such as food and medicine.

In general, we can define the mechanics of $\mathrm{Pa}$ pers, Please as highly conductive of flow through the repetition of a task with disruptive intervals of decision-making. It is a game where the mechanics also carry a sense of cause and consequence, enforced both by the logic of the tasks themselves and by the first-person perspective: the inspector's failures and successes are measured only by the player's skill.

SPATIAL IMMERSION

In Papers, Please, the scenario, soundtrack and interface elements characterize the game-world as reminiscent of the Soviet Union through an aesthetic inspired by constructivist art, architecture, and color palettes. The gray tones in particular transmit a sense of monotony that harmonizes well with the repetitive nature of the tasks the inspector must complete, while the visual elements are pixelated, evoking the time period in which the game is set. The same can be said for the format of the documents, which follow a 
clear pattern to facilitate inspection. No matter how fast the player moves, there will never be an end to the line, fostering a sense of desperate stress within an environment that is primarily static. Everything in Papers, Please seems to serve a procedural purpose, helping to foster the mindset of utilitarian order in the oppressive structure of a post-war period.

\section{NARRATIVE IMMERSION}

Papers, Please's narrative starts with the inspector acquiring their job by something called the labor lottery. The game is structured as a firstperson experience, which means everything happens directly to the player character. From the very first moment there is a contradictory sense of powerlessness: the inspector is forced by the government to change cities and take on a job regardless of his personal desires. When visited by "higher-ups," he is talked down to and almost insulted, but can do nothing about it. Yet on the other hand, the inspector is an authority figure to others: both at work (determining who will be allowed in the country) and as the sole provider for the family-an uncle, motherin-law, wife, and son-whose survival depends exclusively on the player-character. The game's division into either the office booth or the utilities management screen does not allow players to ever see the inspector's family through his eyes, which in its turn suggests that the character is somewhat detached from the household. At work, however, there's no shortage of faces, but the inspector is constrained to the booth, going through the motions of checking documents and stamping passports while the never-ending queue of impatient travelers awaits.
Amid the drudgery of the office job, traveler's stories come through: couples separated by war need the inspector to ignore their lack of documents, a woman being trafficked across the border begs for him to arrest her kidnapper, a father wants to illegally enter the country to avenge his daughter's murder, the list goes on and on. These dilemmas that appear between paperwork pose the humanity of the player against the underlying authoritarian rules of the game system, creating a constant tension. Perhaps the most iconic of these side narratives is the Ezic Order storyline. Agents of the Order plan to overthrow Arstotzka's corrupt and totalitarian government, but they need the inspector's help to infiltrate the country. From time to time, a hooded figure will come with new puzzling requirements that the player must complete to aid the revolution, though it is also possible to denounce the Order, or simply not cooperate with them. Importantly, there are always consequences: Papers, Please has twenty different endings triggered by the decisions taken during the game, ranging from the inspector's execution to the end of the dictatorship in Arstotzka.

Regardless of which side the player chooses to aid-the State or the Order-the inspector can only mildly influence these overwhelming powers, and often at the cost of the playercharacter's life. The world of Papers, Please might seem bleak or dystopian for some, but it presents a lifelike view of the challenges faced by individuals living in post-war states. History is filled with examples of dictatorships that took hold of a country by providing a sense of order in difficult times. 


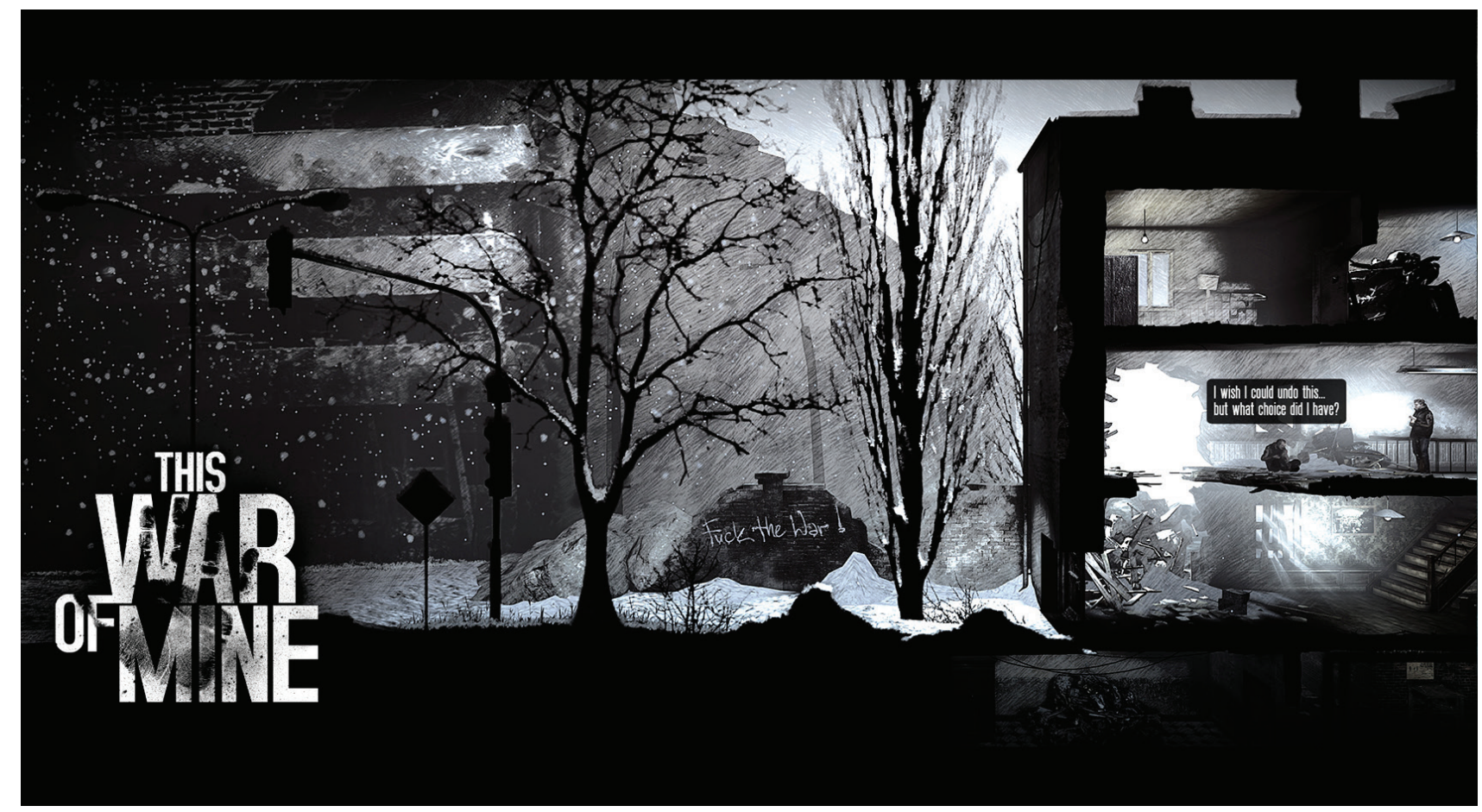

11 bit studios, This War of Mine, 2014. Image courtesy 11 bit studios.

THIS WAR OF MINE

\section{LUDIC IMMERSION}

The goal of This War of Mine is to have at least one of the characters in the shelter survive the war, but we do not know exactly how long the conflict will last (it is randomly assigned for each new playthrough, and is generally between twenty-five and fifty in-game days). Staying alive is no small feat in This War of Mine, and the permadeath mechanics ensure that once you lose one of the survivors, he or she will be gone for the rest of that playthrough. There is no safety net the player can rely on, fostering an intimate sense of loss even though the game is set in the third person, outside of any one playercharacter.

The gameplay is divided into two halves: morning and night. During the morning, survivors can eat, take medication, dress their wounds, craft improvements for the shelter, listen to the radio for news and sometimes trade with a travelling merchant. At night the player assigns survivors different tasks: one of the people in the house can go into a different area of the city to scavenge for supplies, while the others are told to sleep or keep guard. All alternatives present potential dangers.

Within the house, characters need to rest to function properly as lack of sleep might lead to illness. Yet if no one keeps guard, looters might come and steal the shelter's provisions, even harming some of the survivors in the process. Selecting the wrong person to stand guard can be disastrous, but there are no clear-cut indications of who should be chosen, since the game does not display the characters' attributes. In fact, the only clear data is the number of supply slots in each person's bag, which determine how many items he or she will be able to carry back home when scavenging. 
Going out for supplies is another world of trouble. Besides only being able to scavenge one location per night, characters will face different types of problems: physical blockades that require special equipment like shovels or crowbars, hostile armed individuals, scarcity of needed resources in the place the character is exploring, and the character's own limitations for carrying supplies. Any combination of these factors can prevent him or her from getting what the group needs. To overcome those barriers, the player must determine which problems can be surpassed, and which ones are beyond the selected character's scope. Outcomes of scavenging depend on both the player's skill, the character's aptitudes, and the resources at the location. As a result, one night's scavenging might wield many useful supplies, while other times the items retrieved might not meet the shelter's immediate needs. Sometimes, the character might be forced to return home empty-handed or, worst of all, die in the process of collecting supplies.

Another factor that complicates scavenging is time. If a character is still outside when the night is over, he or she will either be captured by the military and killed, or be stalled, forcing the player to complete incursions as fast and efficiently as possible. Resources in the game are also not renewable, so as time progresses, they become rarer, leading to an increase in moral dilemmas. Soon enough the player needs to decide between the group's survival and stealing from (or even murdering) people outside the shelter.

Criminal activity can have a significant effect in the overall mood, which is a crucial factor in This War of Mine. When a character's mood deteriorates they can become broken, leading to suicide, internal fights or desertion. Further, playthroughs that include children as survivors present four different layers of complexity to the game's mechanic: they are a potential source of distress to the player, they are not useful (they cannot trade, build, or fight), they are more sensitive than adults, quickly becoming depressed when bad things happen, and their emotional and physical state affects other survivors. Including the daily suffering of children in this war scenario sharply distinguishes This War of Mine from the "single stories" of most FPS games, viscerally presenting how war overwhelms all corners of social life. War is never simply an adults' game.

Other randomly generated challenges in the game include special events, like sudden drops in temperature and crime waves, that can significantly disturb the frail balance of the house. During those times, even previous preparation (like building a heating system or boarding doors) might not be enough, leading to characters falling ill or getting injured and having supplies stolen. This struggle between what players can accomplish and what is beyond even their best efforts creates a constant tension that captures one's attention, leading to an immersive type of play by posing an emotional challenge. The individual epilogues are the reward for surviving the ordeal, and there is a variety of possibilities for each character based on how the game was played.

\section{SPATIAL IMMERSION}

In many ways This War of Mine presents a scenario that is diametrically opposed to Papers, Please. The world in This War of Mine is in a state of chaos, and to transmit that, the game's aesthetics take a fragmentary approach: everything-the 


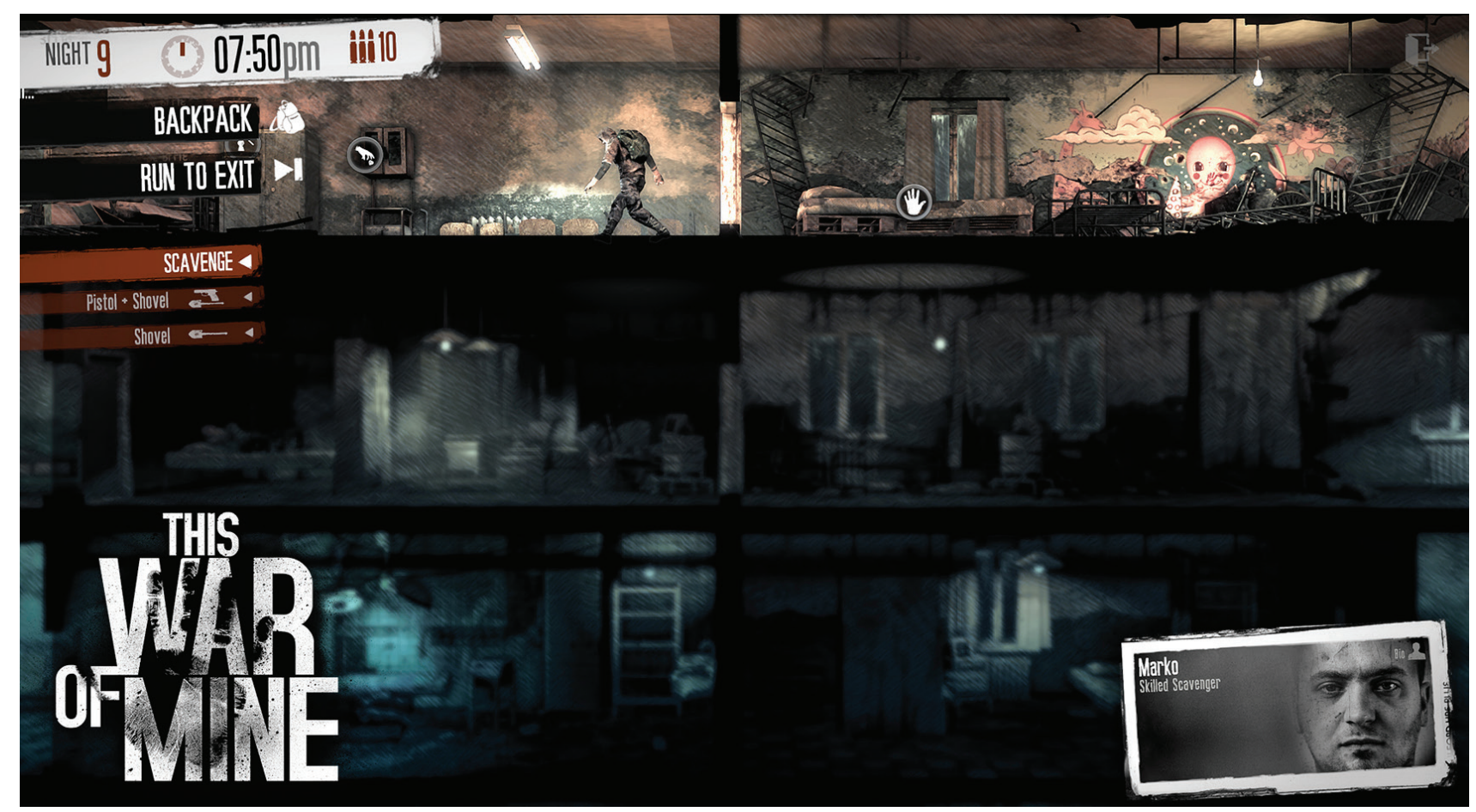

11 bit studios, This War of Mine, 2014. Image courtesy 11 bit studios.

sounds in the radios, the story of each character, the places they visit-is incomplete. Any new visual information is a reminder of a fractured nation that cannot be cleanly reassembled. The dark tones and granular effect of the view into the world simultaneously create a more dynamic and contemporary look, while limiting the player's ability to perceive the environment. This obscuration is particularly interesting when it comes to the characters. Their facial features are blurred in the game's third-person view, bestowing them relative anonymity for the exterior world. The player, however, has their portraits at the bottom of the screen, reinforcing their status as individuals within the personal realm of their improvised home.
NARRATIVE IMMERSION

This War of Mine's narrative, on the other hand, is less linear than that of Papers, Please. Since the game changes every time, the cast also shifts among a pool of twelve characters: Anton, the mathematician; Arica, the cat-burglar; Boris, the strong-man; Bruno, the star chef; Cveta, the school teacher; Emilia, the lawyer; Katia, the trades specialist; Marin, the carpenter; Marko, the emergency responder; Pavle, the star athlete; Roman, the deserting soldier; and Zlata, the music student. The DLC also adds the duos Iskra and Christo (father and daughter), Ivano and Henrik (grandfather and grandson), Lydia and Irina (aunt and niece), and the war orphans Kalina, Miska, and Sergei. Each character has his or her own unique backstory, personality, and quirks. Their age groups and emotional needs 
also vary widely. These traits combined are what determine how strong the character will be against the duress of war, or what type of event influences them the most.

Some characters have a low tolerance for immoral acts, while others are pragmatic enough to oversee criminal activity if it helps the group. There are characters who become violent with housemates when depressed, and others whose temperament makes them easily cheered up. A few will run away with the group's supplies as soon as they get upset, while others are experts at providing comfort. The only way to find out is by letting people reveal themselves through time and experience.

During the first days in the shelter, survivors have a lot to do: beds need to be built for the coming night, there are wardrobes to unlock for supplies, and doors to block in case of looters. The number of tasks transmit a sense of purpose, taking the player's mind away from the anxiety of violence outside. At this point in the game, we only have access to a one-line bio for each character and their photograph. As time goes by and narratives develop, the bio section expands, simulating the progressive building of trust among the group of strangers. As we learn more about these characters, it is easy to become invested in their stories and their future after the war. Because of that, when death occurs, there is a strong impact on the player, especially if it is ruthless and unexpected.

\section{CONCLUSION}

Combined, the immersive elements in Papers, Please form a story about routine and disruption, where individual power is limited in the face of institutional forces. It demonstrates the balance between needing to be a compliant and productive member of society, and the need to obey one's own moral compass in times of state violence. This War of Mine, on the other hand, challenges the player with emotional and empathetic dilemmas, particularly when children are included as survivors in a playthrough. The uncertainties one feels when playing This War of Mine and the desire to "get it over with" so that the characters can be safe contradicts the player's own enjoyment of being in the game, making This War of Mine a potent moral dilemma that dramatizes for players the real stakes of survival during violent conflict, and the impossible choices that life during wartime regularly presents. Both approaches significantly expand upon the variety of experiences war-themed video games, particularly FPSs, have been known to provide. These games create new ways for players to experience the kaleidoscope of ethical, emotional, and physical horrors of war, while remaining ultimately pleasurable activities. $\rightarrow$

\section{Bio}

Luisa Salvador Dias is a MA candidate in the Digital Humanities at the University of Alberta, specializing in Modern Languages and Cultural Studies. She is currently a Graduate Research Assistant in the Refiguring Innovation in Games (Refig) project, an initiative focused on promoting diversity and equity in the game industry and culture. 


\section{Notes}

1. Tom Cole, Paul Cairns, and Marco Gillies, "Emotional and Functional Challenge in Core and Avant-Garde Games," Proceedings of the 2015 Annual Symposium on Computer-Human Interaction in Play (2015): 121-126.

2. Ibid.

3. Jan-Noël Thon, Immersion Revisited: On the Value of a Contested Concept (Rovaniemi, Finland: Lapland University Press, 2008).

4. Mihaly Csikszentmihalyi, Flow: The Psychology of Optimal Experience (New York: Harper \& Row, 2009): 53.

5. Thon, Immersion Revisited.

6. Ibid.

7. Quoted in Ian Bogost, "Frame and Metaphor in Political Games," in Worlds in Play: International Perspectives on Digital Games Research, eds. Suzanne De Castell and Jennifer Jenson (New York: Peter Lang, 2007): 77-86.

8. Joyce Neys and Jeroen Jansz. "Political Internet Games: Engaging an Audience," European Journal of Communication 25, no. 3 (2010): 229.

9. Chimamanda Ngozi Adichie, “The Danger of a Single Story," filmed July 2009 at TED Global, Oxford, UK, video, 18:43, https://www.ted.com/talks/chimamanda_adichie_the_danger_of_a_single_story. 


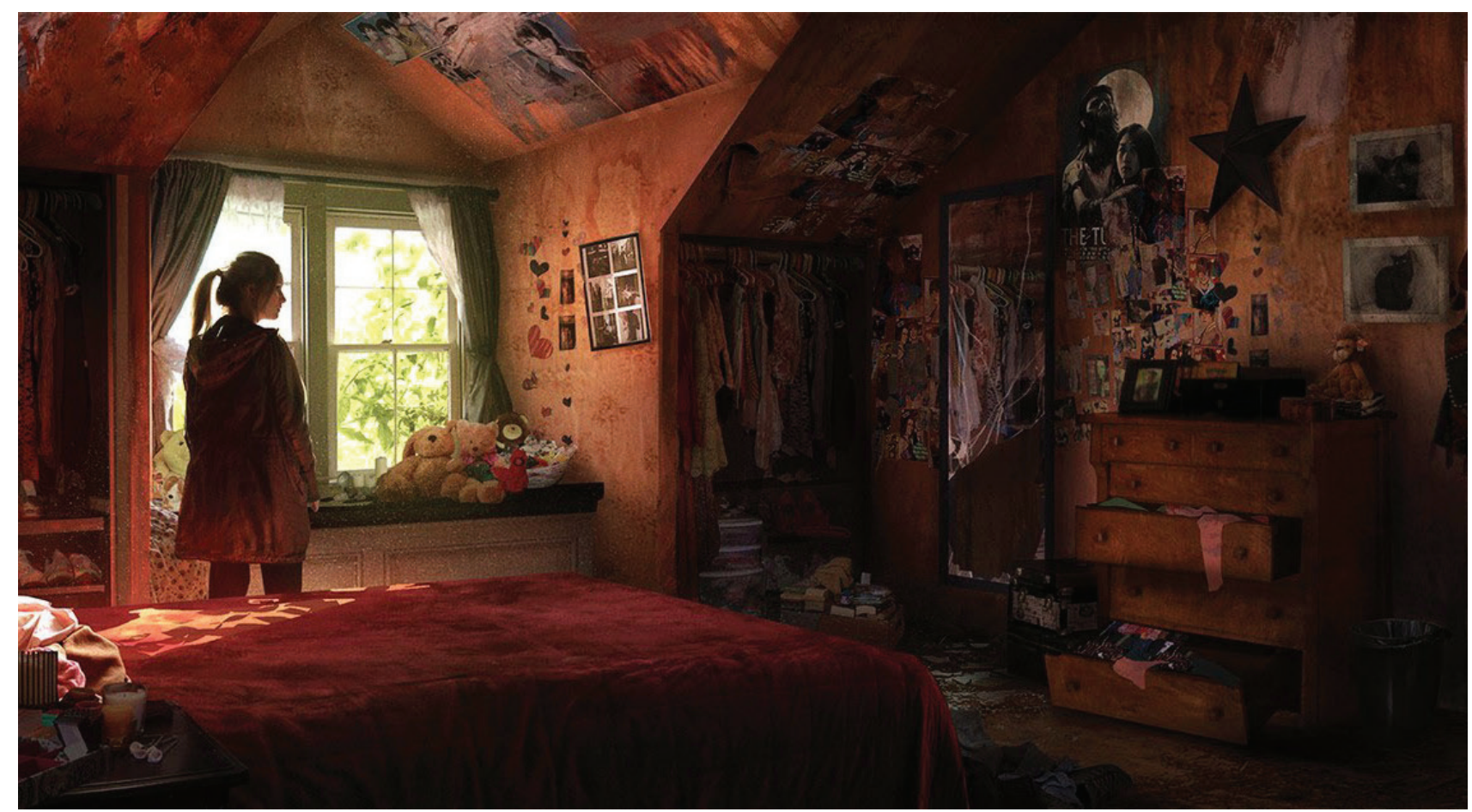

John Sweeney, Remembering, from The Last of Us (Naughty Dog), 2013. Image courtesy Naughty Dog.

\section{Virtual Intimacy and Queer Confrontations in The Last of Us: Left Behind}

\section{Michael Paramo}

\section{Graduate student in American Studies, California State University Fullerton}

\section{Abstract}

Video games can produce intimate bonds between the player and the game through interactive virtual roleplay. Players formed an emotional attachment with Left Behind through immersive storytelling, which opened space for confrontations to be experienced much more intimately, producing reactions of greater intensity. Controversy regarding the expansion's portrayal of queer love between main characters Ellie and Riley generated opposition from a toxic masculine gaming culture and support from queer and feminist players for several reasons. I argue that video games can function as progressive spaces for representation, empowering queer players to persevere in world that seeks to inhibit their survival. 
With the push of a button or the movement of a joystick, many video games allow players to control virtual bodies. The controllers in our hands are the tactile instruments that channel connections between the physical and the virtual-a bond between the human player and the character they are roleplaying as within the simulated world of the game. In return, video games generate reactions from players based on their interactions within its environment. Survival horror third-person shooter The Last of Us was a game that produced unusually intimate connections with players via its storytelling and characters. Released by Naughty Dog in June 2013 for PlayStation 3, the game sold over eight million copies. ${ }^{1}$ As a result, there was considerable anticipation for the release of its downloadable expansion The Last of Us: Left Behind in February 2014, which added a previously unseen narrative to the story as well as more intense survivalist gameplay. While it received acclaim, Left Behind was also met with opposition from a vocal subset of players who reacted negatively to the portrayal of queer love initiated by its protagonist.

In Left Behind, players control Ellie, a young teen, through two challenging moments in her life. Both narratives occur in a world where humanity has been overrun by a deadly cordyceps fungus that has transformed much of the population into zombie-like creatures known as "the infected." The primary plot focuses on Ellie's close relationship with Riley, another adolescent girl who has returned into her life after having unexpectedly disappeared, while the secondary acts as a link between two chapters in the main game's storyline. It is in the primary narrative, and what will be the focus of this essay, that players navigate Ellie on an adventure through an abandoned mall with Riley to rekindle their complex relationship. There is a playful intimacy between Ellie and Riley, represented in interactive experiences like dressing up in masks while perusing a deserted Halloween store, smiling together in a broken photo booth, and engaging in a water gun fight. These moments eventually culminate in an impassioned kiss between the two adolescent girls, shortly before they are overrun by a horde of the infected. As a survival game, the queer relationship of Ellie and Riley in Left Behind is portrayed against a backdrop of the chaos of its post-apocalyptic setting, within which their relationship is given temporary refuge-an opportunity to survive.

Similar to Naughty Dog's previous games, Left Behind's cinematic and immersive storytelling aided in the cultivation of intimate connections through virtual roleplay as playercharacter Ellie. This obligatory identification of the player with Ellie meant that her queerness, when overtly revealed late in the narrative arc, was both unexpected and unavoidable, unlike that of many other queer representations in gaming which often permit its optionality so as to avoid potential backlash. In the aftermath of Left Behind's release, this exposure spurred contention online, in journalistic outlets, discussion forums, and social media platforms. As I'll discuss in more detail, opposition materialized in the form of deflection and aggression, originating from a toxic gaming culture that upheld the status quo of the medium, represented in the masculine-focused heroism of The Last of $U s$ and Naughty Dog's preceding Uncharted franchise. These adversarial reactions existed as bigoted onslaughts launched against feminist and queer 
players, unraveling in the buildup to the 2014 hate campaign of \#GamerGate. Support largely emerged from feminist and queer gamers, who championed it as a step forward for the industry and particularly for empowering queer players. Amidst the controversy, Naughty Dog publicly affirmed Ellie's queerness, which legitimized the arguments of queer and feminist gamers and championed this representation as a step forward for the industry. Left Behind thus existed at a critical juncture in which reactions to its representation of queer love unveiled the underlying power, and effects, of an intimacy between the physical and the virtual, the player and the game, the controller in our hands and the characters on our screens. These bonds may shatter or solidify when confronted by what may be considered threatening or empowering, triggering intense emotive responses. Ultimately, the theme of survival frames the relationship of Ellie and Riley, as expressing their queer love for one another becomes more urgent in a world where their very existence is constantly under imminent threat, perhaps resonating with the experiences of queer players who endure the harsh realities of a queerphobic world.

\section{VIRTUAL INTIMACIES}

In Left Behind, players interact with the game through actions carried out via the PlayStation controller. Neil Druckmann, writer of Left Behind, commented that interactive gameplay is "something very unique to our medium, [because] through controlling a character you get to roleplay as that character," and the goal of the expansion was to allow players "to roleplay two teenagers and the bond that they form." ${ }^{2} \mathrm{It}$ is here that Druckmann indicates his objective to create intimate connections between player, player character Ellie, and NPC (non-playable character) Riley through virtual roleplay. Bonnie Ruberg describes how the interactive element of gaming may embody a ludic, even queer, intimacy "between player and game, between flesh and the controller in our hands." Ruberg references how intense physical contact and deep emotional connections between player and game allow for the manifestation of intimate bonds that may be interpreted as queer in their existence as "alternate visions of the control-freedom dynamic" of play. ${ }^{3}$ In Left Behind, players form an intimate connection with Ellie and experience her relationship with Riley through interactive gameplay and the genuine-feeling dialogue between the teens. This affiliation between player and character prompts what Robert Kolker refers to as "a deeply personal, emotional, relationship between player and game and the rules and methods of engagement" that is enhanced by the strength of the game's narrative. ${ }^{4}$ According to Jonathan Frome, "many people attribute the lack of emotional connection between most players and characters to poor writing." 5 In the case of Left Behind, Naughty Dog was able to produce emotional attachments between player and game by capitalizing on the interactive element of the medium through engrossing storytelling and strong character development.

Virtual intimacies with Left Behind were shared by The Last of Us. Several reviewers and players recognized its emotionality and ability to generate intimate connections. Eric Swain of PopMatters went as far as to critique the The Last of $U$ s as "emotionally manipulative," declaring that "everything in the game, every action, every design choice exists to facilitate an emotional resonance 
between the player and the game's characters and events and nothing else." ${ }^{16}$ Others were less critical, yet indicated similar sentiments, such as the blogger who claimed, "within the first ten minutes of the game" there were "tears in my eyes and I'm not really sure how they got there." ${ }^{\prime 7}$ Both perspectives acknowledge the emotional power of The Last of Us, which carries through to its expansion. Anthony Decicco of the gaming blog Just Push Start reported that Left Behind "emotionally... sets itself apart" as downloadable content (DLC) and will even exact an "emotional toll" on players, particularly with its tragic conclusion. ${ }^{8}$ Others reacted similarly. A reviewer for The Guardian wrote, "Naughty Dog has serious emotional range. Rarely have I played anything as powerful," ${ }^{\prime 9}$ while another for The Digital Fix affirmed that "the genuine emotional power that it carries is exceptional." 10 These accounts of virtual intimacy operate as testaments to the emotional bonds that players held with Left Behind. While they certainly reflect player attachment, this closeness simultaneously opens space for confrontations to be experienced much more intimately, producing reactions of greater intensity.

\section{QUEER CONFRONTATIONS}

Initially, as the game progresses, subtle cues arise that the relationship between Ellie and Riley may exist on a romantic level prior to their kiss. Forum user Zorskel emphasized, "I kind've started to suspect it after the photo booth scene" when "there was a brief period of silence while they just stared at each other." ${ }^{\prime 11}$ Ellie's queerness only becomes overt near the conclusion of Left Behind, when she initiates an impassioned kiss with Riley. The scene unfolds when we learn that Riley may again be departing from Ellie's life. Ellie, overcome with emotion, pleads to Riley: "don't go." Riley then gazes into Ellie's eyes and expresses to her that she will not be leaving after all. In response, Ellie kisses Riley. Although many players possessed a bond with Ellie via their playthrough of The Last of Us, her queerness was not revealed during its narrative, nor was it mentioned in Left Behind at the inception of play. In a video entitled, "The Kiss That Got People Pissed," YouTube user Luke Stephens asserts that some players may have been offended because they would "prefer not to see, or encourage, or participate in" homosexual activity. ${ }^{12}$ It is this unanticipated participation in queer virtual roleplay on an intimate level, in which players felt personally included in what they may ideologically oppose, that resulted in controversy unfolding rapidly and aggressively.

Queer representations often exist as uninvited confrontations in gaming, holding the potential to shatter emotional bonds between player and game. To the dominant heteronormative masculine gaming culture, queer representations are contaminants to the status quo that pervades mainstream video games. Ruberg describes how queer representations are positioned as "polluting the hetero safe space of queer-free play." ${ }^{13} \mathrm{In}$ the case of Left Behind, players had already been exposed to the masculine-focused heroism of Naughty Dog's preceding titles. Although Ellie is briefly a playable character in The Last of $U_{s}$, the game ultimately centers on the story of the straight, white-male protagonist Joel. The New York Times indicates that women in The Last of Us are portrayed in "frustrating" respects, as Ellie is largely cast in a "secondary, subordinate role" to Joel. ${ }^{14}$ At the time of Left Behind's release, Naughty Dog's Uncharted franchise had released 
three games, each of which portrayed the white male-focused heroism of Nathan Drake, with women similarly relegated to secondary, subordinate status. In reference to these normative portrayals, Katherine Cross asserts that "the gaming industry doesn't like risks, and it has fixated on the straight, white-male lead as safe."15 As a result, queer confrontations in mainstream games are overwhelmingly nonexistent or made optional due to threats of backlash. Since The Last of Us and Uncharted existed largely within the status quo of gaming in this regard prior to Left Behind, its portrayal of queer love may have been interpreted as largely unexpected and confrontational to players.

However, Left Behind was not the first mainstream video game to include queer representations in its storyline. In fact, The Last of Us already portrayed a queer character by the name of Bill, an ally to the player-character who was revealed in the game to be gay. In 2013, Bill was voted as one of the "most intriguing" new LGBT characters across all storytelling mediums by LGBT-focused media organization GLAAD. ${ }^{16}$ Despite this accolade, Bill remains a minor NPC whose queerness, although unavoidable, is also non-confrontational. Bill's partner committed suicide, and his queer love is only revealed when the player comes upon his corpse. Players then learn that Bill's partner despised him and had planned to desert him. After Bill's complex queer relationship is briefly acknowledged, the narrative immediately progresses onward. In a short review, Daniel Sipocz concurs that "almost immediately after the player is encouraged to sympathize with Bill's loss and see him as a complex individual, this sympathy is quickly pushed aside" in order to "neutralize Bill's threat of deviance" as a queer character. ${ }^{17}$ While Bill was lauded for representing complex queer representation in gaming, his minor role meant that virtual intimacies between player and game were not directly confronted, but rather, averted to cater to players who may find queer content offensive.

Popular video games in mainstream franchises, such as Dragon Age: Origins and Mass Effect by developer BioWare, have also incorporated queer characters prior to Left Behind. However, if not in the form of minor NPCs like Bill, this was primarily done through presenting a choice for the player to opt in or out of queer storylines and plot points through prompted settings. Adrienne Shaw highlights how selection-based queer representations are done with intention, to allow the "optionality of gay content to protect [game studios] from the ire of homophobic players." ${ }^{18}$ While these interfaces provide players with the agency to roleplay queerness, its optionality in the narrative also ensures that it may be minimally, if not absently, encountered. Contrastingly, in Left Behind, players are unable to avert Ellie's queer love and must therefore roleplay as a queer character to complete the narrative. The lack of optionality, combined with the unexpected nature of queerness in the narrative, resulted in some players deflecting its existence entirely, while others reacted with disapproval towards Naughty Dog, accusing them of promoting a feminist and queer social justice agenda in gaming.

Deflection of Ellie's queerness characterized a large subset of the oppositional responses to the game. These players labeled the kiss as originating from adolescent confusion, particularly in teen girls, rather than as a portrayal of queer 
love. One forum user argued that "either way, she's not a lesbian" since "the majority of girls are bisexual due to the amount of time they spend with their female friends." ${ }^{19}$ Another user claimed, "It's very normal for young girls to show more affection to each other then [sic] boys do..." further contending that "many women/ girls are attracted to other women / girls but prefer men and are not bi-sexual or lesbian." ${ }^{20} \mathrm{Re}-$ sponses such as these became so pervasive that Druckmann, in an interview with GayGamer.net, replied:

It is a little strange when I read stuff like "Oh girls are just confused at that stage." or "They're still finding themselves." (...) I think it's weird because if Riley was a boy this debate wouldn't be happening. No one would say "Oh maybe it's just a friendly kiss." No one would question that. I think even if it was two boys I don't think anybody would question it. ${ }^{21}$

Druckmann thus emphasizes the double standard at play for teen girl characters, asserting that displays of heterosexual affection would never be dismissed in such a way by players. A forum user echoed similar sentiments to Druckmann, stating, "what would it take for y'all to just accept that Ellie is gay/bi? Some people seem really invested in Ellie being straight..."22 These examples indicate how some vocal players were devoted to ignoring queerness in Left Behind and utilized gendered and age-based arguments in an attempt to avert their intimate participation in roleplaying queer love. Deflection may have been a common method for such players to mentally deny their unanticipated intimate connection with queerness.

The brunt of the backlash was initiated by those who interpreted queerness in Left Behind as belonging to a larger, more insidious "social justice agenda" that was encroaching upon gam- ing. Cross comments that "such gamers see our virtual world as a fragile and ephemeral one, perpetually under threat from outside forces," in which "women and LGBT people" are "constructed as invaders whose criticisms, or even just their very presence, herald the end of gaming as we know it." ${ }^{23}$ By early 2014, when Left Behind was released, Anita Sarkeesian's Tropes vs. Women series, which examined gaming from a feminist lens, had already become the focus of a "media spotlight" after "a campaign of misogynistic harassment" had begun, including "death threats" and "waves of hate-filled messages." ${ }^{24}$. The events of \#GamerGate, a movement aimed at defending gaming as a straight, masculine culture, proceeded to unfold in August 2014, continuing to assert "that feminists are actively working to undermine the video game industry." ${ }^{25}$ These attacks were represented in numerous criticisms of Left Behind's representation of queer love. In an article entitled "The Last of Us: Gamers Left Behind in Bigotry," Hannah Le explains how many players blamed this portrayal on feminist and queer social justice agendas, with one user stating, "the team was influenced by feminism, disgusting," while another expressed, "it makes me angry seeing gays trying to take over media now Games [sic]?!" 26 The backlash directed at Left Behind existed within a pre-existing toxic gaming culture and in the buildup to its most public and virulent exhibition. While its mainstream position, along with the compulsory and overt nature of queerness in its narrative, exposed the game to intense backlash, it also spurred support for queer narratives in gaming, propelling empowering representations forward. 


\section{QUEER EMPOWERMENT}

While queer representation in Left Behind spurred opposition, it was also empowering to many queer-identified players. Naughty Dog defended supporters by explicitly confirming Ellie's queerness amidst immense deflection and backlash, in addition to Druckmann's statements on the matter quoted above. Druckmann also revealed that queer representation in Left Behind was successful due to the diversity of Naughty Dog's development team, stating that he "asked someone who is gay on the team questions about experiences they've had, or what they would find offensive or not offensive" in reference to this portrayal. ${ }^{27}$ Druckmann's reference to the inclusivity of Naughty Dog's development team as critical to the success of portraying Ellie and Riley's queer love points to the ongoing need for developers to both hire and consult with team members who embody intersections of identity paralleling the characters portrayed in their games. At the same time, this clarification from the developer on Ellie's queerness was decisive in legitimizing the queer love portrayed in the game. One forum user put it simply, stating, "she is gay, Neil did say so" while another declared, "Neil Druckmann (who wrote the game and created the characters) has said that both Ellie and Riley are gay, so that's the official word on it." ${ }^{28}$ YouTube user kathleenmms expressed a similar perspective in her video entitled, "Is Ellie Gay? The Last of Us," which has garnered over 140,000 views. She addresses players who were "still in denial" regarding Ellie's queerness by directly citing how Naughty Dog had confirmed it was their intention to portray Ellie as gay. Her video received approximately four times as many people supporting or agreeing with her discussion of Ellie's queerness than those opposing or disagreeing. ${ }^{29}$ These responses exemplify how players have referenced statements from Druckmann to defend Ellie's queerness, demonstrating how developers who incorporate queer portrayals in their games should publicly legitimize the queerness of their characters amidst a queerphobic gaming culture to support and empower queer players.

Several players indicated the capacity of this portrayal of queer love to empower, solidifying their intimate connection with Left Behind. One user affirmed, "speaking as a gay teen girl, this was a beautiful, heartfelt moment not just ingame, but a moment of representation for those like me and others in the LGBTQIA+ community." ${ }^{30}$ An IGN article penned by queer writer Keza MacDonald emphasized the importance of this portrayal, stating, "Left Behind is not only the first mainstream game to depict an authentic friendship between two girls. It is the first mainstream game to depict a friendship between two girls that could be something more." MacDonald also indicated the importance of player engagement in this kiss, stating "It's active, not passive. It is also the first mainstream, big-budget game I've ever played that's done it, and that feels really significant to me. This is a moment I didn't even know I'd been waiting for until it happened." ${ }^{31}$ Left Behind succeeds as a mainstream portrayal of queer love that explicitly involves the player character. It was a case of unavoidable queer love, in which the virtual intimacy of the video game medium was able to deeply connect players to a queer adolescent girl expressing her affection, with players remaining unaware of its presence until it unfolded before their eyes. This rare opportunity to roleplay as a queer charac- 
ter was entering rather unfamiliar territory for mainstream gaming, in which millions of players of a prominent franchise experienced queerness through the controllers in their hands, whether expected and desired or not.

\section{CONCLUSION}

Video games may serve as ideal spaces to hold controversial discussions in media through virtual intimate roleplay. Regarding the power of video games to allow players to reimagine or garner a differing worldview, Shaw questions, "If we conceptualize representation as important because it provides us with a chance to imagine the world differently, why can't that difference ever include a more open acceptance of gender and sexual diversity?" ${ }^{32}$ As the queerphobic reactions to Left Behind reveal, video games hold the power to construct deep emotional bonds with an audience who may be opposed to experiencing queer narratives. However, incorporating queer narratives that cannot merely be opted out of or avoided entirely, as in the case of Left Behind, may prove valuable in altering how gamers perceive their own individuality as well as the identities of others. Michael Salmond refers to this as "the sense of experimentation," in which "video games enable players to (...) also experience other aspects of their personalities (male or female, good or evil, etc.) through role play." ${ }^{33}$ Forging an empathetic connection to a player character whose queerness is revealed in the narrative, as it is with Ellie, provides opportunities for reflection and, perhaps, growth and change. At the same time, for many queer gamers, it not only further solidifies their emotional bond to the player character and virtual world that recognizes them, but also may further em- power them to push onward in a queerphobic world that often seeks to stifle and prevent their very survival. Samantha Allen states that queer representation in "mass market titles" can be incredibly important to the "young, closeted queer people playing them," by enabling them to "find vocabulary and community in young adulthood that help you understand who you are." Allen emphasizes that incorporating queerness in mainstream games is important because "some queer people are subsisting on them, even if they don't know they're queer," affirming that they may be "a lifeline to lost gamers." ${ }^{34}$ In this sense, queer representations in mainstream gaming may serve as powerful forces that can initiate reflections on queer identity while also empowering queer people to survive and persevere in a queerphobic world through virtual roleplay. a

Naughty Dog appears committed to grappling with controversial issues that many mainstream video games shield queerphobic and bigoted gamers from confronting. With The Last of Us Part II on the horizon, in which Ellie is positioned to be the main character, threats of backlash appear imminent once again. However, Druckmann has already indicated his intention to confront controversial issues through the game, replying to a social media user on Twitter who was disgruntled by representations of "race, gender, and orientation" that Left Behind and Uncharted 4: A Thief's End's expansion The Lost Legacy have openly confronted. The Twitter user urged for Druckmann to "please try to keep your personal politics out of Part 2." Druckmann replied with "no can do." ${ }^{35}$ A writer from Mic took this fan's request to mean "keep the characters white and male," and concluded their article by accentuating that "Black people, women and LGBTQ 
people exist in life, as they exist in games-even if they make you uncomfortable." 36 Ultimately, Druckmann indicated his defiant commitment to combating toxic gaming culture following the release of Left Behind, indicating that he receives "more hate tweets than I have ever before, but I'm kind of proud of those." ${ }^{37}$ In such a tumultuous political climate that seeks to silence and oppress people based on their race, gender, and sexuality, it is certainly an appropriate moment for mainstream video games, with their unique power to forge intimate connections with mass audiences through virtual roleplay, to be at the forefront of incorporating progressive representations in media. We should not be left behind.

\section{Bio}

Michael Paramo is a queer asexual Latinx graduate student in American Studies at the California State University of Fullerton. They created The Asexual, a journal and website for people under the ace umbrella to publish their writing and art. Their research interests include (a)sexuality, gender identity, queerness, and media representation.

mdparamo@gmail.com 


\section{Notes}

1. Jason Dunning, "The Last of Us Remastered Sales Cross 1 Million Worldwide," PlayStation LifeStyle, September 1, 2014, http: / / www.playstationlifestyle.net/ 2014 / 09 / 01 / the-last-of-us-remastered-sales-crosses-1-million-sold-worldwide/.

2. Laura Hudson, "Inside the Mind Behind the Brilliant New Last of Us DLC," Wired, February 18, 2014, https: / / www.wired.com/2014/02/last-of-us-dlc-interview/.

3. Bonnie Ruberg, "Playing to Lose: The Queer Art of Failing at Video Games," in Gaming Representation: Race, Gender, and Sexuality in Video Games, ed. Jennifer Malkowski and TreaAndrea M. Russworm (Bloomington: Indiana University Press, 2017), 201.

4. Robert Kolker, Media Studies: An Introduction (Chichester: Wiley-Blackwell, 2009), 26.

5. Jonathan Frome, "Video Game Sadness from Planetfall to Passage," in Video Games and the Mind: Essays on Cognition, Affect and Emotion, ed. Bernard Perron and Felix Schröter (Jefferson: McFarland \& Company, 2016), 169.

6. Eric Swain, “The Last of Us' is Emotionally Manipulative," PopMatters, July 22, 2013, https: / / www.popmatters.com/173815--2495737897.html.

7. Kenori, "The Emotional Connection to Video Games - The Last of Us," Giant Bomb, July 7, 2014, https: / / www.giantbomb.com/ profile/kenori/blog/the-emotional-connection-to-video-games-the-last-o/110188/.

8. Anthony Decicco, "The Last Of Us: Left Behind-The Emotional Toll," Just Push Start, February 20, 2014, http: / / www.justpushstart.com/2014/02/last-us-left-behind-emotional-toll/.

9. Keza MacDonald, "The Last of Us: Left Behind - review," The Guardian, February 17, 2014, https: / / www.theguardian.com/technology / 2014 / feb / 17 / last-of-us-left-behind-review.

10. Gareth Gallagher, "The Last of Us: Left Behind," The Digital Fix, March 17, 2014, https:/ / www.thedigitalfix.com/gaming/content/2298/the-last-of-us-left-behind/.

11. Zorskel, "About Left Behind DLC," The Last of Us Wiki, February 16, 2014, http:/ / thelastofus.wikia.com/wiki/Thread:24039\#7.

12. Luke Stephens, "The Kiss That Got People Pissed — The Last of Us: Left Behind," YouTube video, 38:14, November 1, 2017, https: / / www.youtube.com/watch?v=XiZ34kDA_5k.

13. Ruberg, "Playing to Lose," 199.

14. Chris Suellentrop, "In the Same Boat, but Not Equals," The New York Times, June 14, 2013, http: / / www.nytimes.com/2013/06/14/arts/video-games/in-the-video-game-the-last-of-us-survival-favors-the-man.html.

15. Katherine Cross, “Gaming the System: Are Women-led Games D.O.A.?," Bitch Media, May 20, 2013, https:/ / www. bitchmedia.org/article/gaming-the-system-female-video-game-characters.

16. “The Most Intriguing New LGBT Characters of 2013," GLAAD, December 26, 2013, https:/ /www.glaad.org/blog/ most-intriguing-new-lgbt-characters-2013.

17. Daniel Sipocz, "The Last of Us," 100 Greatest Video Game Franchises, ed. Robert Mejia, Jaime Banks, and Aubrie Adams (Lanham: Rowman \& Littlefield, 2017), 101.

18. Adrienne Shaw, Gaming at the Edge: Sexuality and Gender at the Margins of Gamer Culture (Minneapolis: University of Minnesota Press, 2015), 202.

19. Zorskel, "About Left Behind."

20. Fanofwiki, ibid., http:/ / thelastofus.wikia.com/wiki/Thread:24039\#11.

21. Sal Mattos, "Is Ellie Gay? Naughty Dog's Neil Druckmann Weights in on The Last of Us: Left Behind," PopQT, July 15, 2016, https: / / popqt.com/is-ellie-gay-naughty-dogs-neil-druckmann-weights-in-on-the-last-of-us-left-behind-d768a6c5c572.

22. MayonnEgg, "About Left Behind DLC," The Last of Us Wiki, February 17, 2014, http:/ / thelastofus.wikia.com/wiki/Thread:24039\#20.

23. Katherine Cross, "The Nightmare Is Over," in Queer Game Studies, ed. Bonnie Ruberg and Adrienne Shaw (Minneapolis: University of Minnesota Press, 2017), 181.

24. Chris Bratt, "Anita Sarkeesian Brings Tropes Vs. Women in Video Games to a Close," Eurogamer.net, April 28, 2017, http: / / www.eurogamer.net/ articles / 2017-04-28-anita-sarkeesian-brings-tropes-vs-women-in-video-games-to-a-close.

25. Shira Chess and Adrienne Shaw, "A Conspiracy of Fishes, or, How We Learned to Stop Worrying About \#GamerGate and Embrace Hegemonic Masculinity," Journal of Broadcasting \& Electronic Media 59, no. 1 (2015): 210.

26. Hannah Le, "The Last of Us: Gamers Left Behind in Bigotry," Amplify Your Voice, June 2, 2014, https: / / www.webcitation.org / 6XrGj5W6L?url=amplifyyourvoice.org/u/hannahology / 2014/ 06/ 02 / the-last-of-usgamers-left-behind-in-bigotry. 
27. Sal Mattos, "Is Ellie Gay?"

28. "Lesbian or Bisexual?," The Last of Us Wiki, April 21, 2014, http:/ / thelastofus.wikia.com/ wiki/Thread:27405\#3.; Klock101, ibid. http:/ / thelastofus.wikia.com/wiki/Thread:27405\#2.

29. Kathleenmms, "Is Ellie Gay? The Last of Us," YouTube video, 12:22, February 23, 2014, https: / /www. YouTube.com/ watch? $\mathrm{v}=\mathrm{xVWWi2}$ fHFs.

30. "Ellie and Riley Kissing 'Controversy,'” The Last of Us Wiki, February 22, 2014, http:/ / thelastofus.wikia.com/wiki / Thread:24692.

31. Keza MacDonald, "The Significance of The Last of Us: Left Behind," IGN, February 19, 2014, http: / www.ign.com/ articles / 2014/02/19/the-significance-of-the-last-of-us-left-behind.

32. Adrienne Shaw, Gaming at the Edge, 34.

33. Michael Salmond, Video Game Design: Principles and Practices from the Ground Up (London: Fairchild Books, 2016$), 87$.

34. Samantha Allen, "Closing the Gap Between Queer and Mainstream Games," Polygon, April 2, 2014, https: / / www.polygon.com/2014/4/2/5549878/ closing-the-gap-between-queer-and-mainstream-games.

35. Christopher Gates, "The Last of Us Part 2 Won't Shy Away from Politics," Looper.com, January 23, 2017, http:/ / www. looper.com/38232/last-us-part-2-wont-shy-away-politics/.

36. Tim Mulkerin, "Last of Us Part 2' Director Neil Druckmann Shuts Down Racist Comments on Twitter," Mic, January 23, 2017, https: / / mic.com/articles / 166326/ last-of-us-2-update-director-neil-druckmann-shuts-down-racist-comments-on-twitter\#.4MpERrxhU.

37. Sal Mattos, "Is Ellie Gay?" 


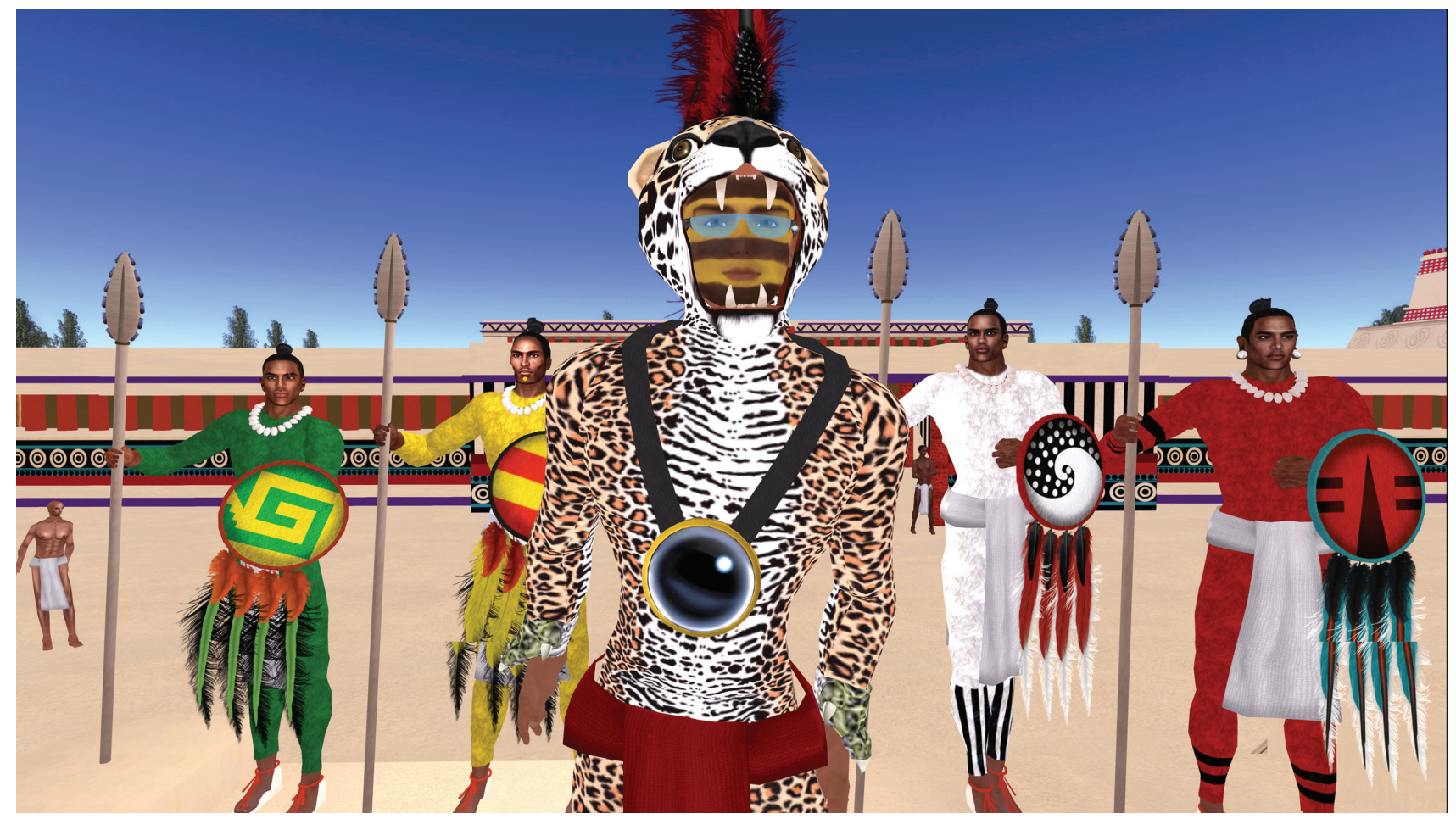

Figure 1. Skawennati, Hunter and Warriors, TimeTraveller ${ }^{\mathrm{TM}}, 2008-2013$. Image courtesy of the artist.

\section{Playing, Performing, Policing: Navigating Avatar Expression in Second Life}

\section{Treva Michelle Legassie}

PhD candidate, Communication Studies, Concordia University; Assistant Director of the Speculative Life Cluster at Milieux

\section{Abstract}

Avatars are visual representations of their users that can be navigated through virtual space, perform tasks, socialize, work, play, and "live" online. How does a user effectively create a visual representation of the self limited by the programming and design constraints of the virtual world? This article will look critically at the complex socio-political and economic constraints affecting the avatar creator and performer by examining the countercultural, activist, and artistic interventions explored in the existing complex cultural nexus of Second Life. 
The figure of the avatar is a malleable, movable, and customizable character you create to represent any version of yourself you choose to display online. To begin, I want to question: what opportunities can the avatar create, and what opportunities may be made inaccessible due to the policing of racialized, gendered, and otherwise marginalized avatar figures? This paper will address some of the possibilities and limitations of avatars, primarily as conducted through Second Life and its market economy.

Second Life, a software application originally called Linden World in its alpha testing phase, was created by Philip Rosedale, founder of Linden Labs. The beta version of Second Life was released in November 2002, and went live to the public on June 23, 2003. ${ }^{1}$ Second Life is an online, virtual world featuring 3D-based usergenerated content hosted on a grid of servers that run interactive simulations: one can visit fantasy builds such as tropical islands, elaborate Victorian-style sex dungeons, and amusement parks, as well as spaces that mimic the physical world, like the Ontario College of Art and Design University (OCAD U) Campus, the White House, and the Eiffel Tower in VR Paris. Though Second Life has existed for what may seem like an eternity-especially in the context of digital technologies and virtual worlds in particularit remains populated and active, a lively site of public encounter. Users are offered the opportunity to engage in a variety of virtual forms of social play, including sexual encounters, creative practices, and activist protest. Its open nature has made it an especially productive experimental tool for contemporary artists. Though Second Life presents a wealth of opportunities for social experimentation, providing what is largely considered a positive outlet for social interaction among humans-as-avatars, the platform is also commonly exclusionary. Despite claims to the contrary, expressions of racial, socioeconomic, and gendered violence are prevalent in its virtual world. Racialized and gendered avatars, as well as less-elaborate, and thus less-expensive, avatars, regularly experience marginalization, judgement, and harassment. These forms of policing are often constructed and implemented by other users who form cliques and social groups based on shared interests and identities, represented through the visual aesthetic of their avatars.

To take part in the virtual world of Second Life, users must create and play with avatar characters they select and modify. American humanities scholar Uri McMillan tracks the etymology of the term "avatar" concerning virtual environments:

"Avatar," a term from Hindu mythology, is derived from the Sanskrit word avatara; its translation denotes the descent of a deity to earth in order to be reincarnated in a human form... The word avatar was first used in 1985 to describe virtual persona, specifically a graphic representation of a person-a humanlike figure, usually—controlled by a person via a computer. Taken together, these two seemingly divergent meanings gesture toward how avatars both duplicate and displace the human. ${ }^{2}$

Duplicating and displacing the human form allows users to create a divergent persona that may represent an aspect of their identity unrestricted by their embodied selves. The avatar offers an opportunity for creative expression and freedom for many often-marginalized groups. Users may express identities and aesthetics unavailable to human bodies: for example, furries, individuals who identify as animals or wish to explore animal-like personas, have the ability to create anthropomorphic animal avatars to represent themselves. 
BUILDING AN AVATAR: ECONOMY, AFFECT, AND LABOR

Well-established inhabitants of Second Life may experiment with their online identities in productive and exciting ways. While Second Life furries may use animal-human hybrid avatars, robotics or steampunk enthusiasts might create robotic or mechanical characters. In their introduction to Women in Second Life, Dianna Baldwin and Julie Achterberg identify how Second Life also allows gender-bending: "Not only is diversity prevalent, but the possibilities to disrupt traditional norms and roles allow for the collapsing of normal hegemonic power structures that exist in most environments-both real life and online." ${ }^{3}$ Jessica Bennett and Malcolm Beith suggest that Second Life is "a potent medium for socializing -it provides people with a way to express, explore, and experiment with identity, vent their frustrations, reveal alter egos" through the visual look of the avatar. ${ }^{4}$

However, before an avatar can become an effective social tool, it must be built and customized. Upon entering the virtual world of Second Life, users will be offered a selection of prefabricated avatars. Users are then encouraged to personalize their avatar after navigating what is called "Orientation Island," the first stop when entering Second Life. Initial pre-fab avatars are ordered into three distinct categories: "New," "Classic," and "Vampires." Users are presented with a small variety of mostly able-bodied, thin, white or light-skinned characters, with the exception of a few zombie and werewolf avatar variations. Second Life does not suggest why this selection is offered to beginning users, though their limiting framework for selection suggests that the platform may not be as unrestrictive as it may initially seem.
Expressions of diversity are mainly communicated through the visual and cosmetic difference between "skins" and accessories of each avatar. However, the expanded wealth of customizations, or mods, for avatar embodiment come later; in most cases, options become available long after users have established a normative character, made friends, and built up status. In addition, even though avatars rarely reflect the appearances of their creators, socioeconomic diversity is often inscribed onto avatars very clearly. Though Second Life has become increasingly progressive in its selection of avatar bodies, these mods come at a price. Literal financial capital is filtered into the virtual world by the thousands, enabling users to build custom skins, outfits, accessories, and bodies for their avatars. Highly customized avatars are costly to build, accessorize, and house, and each aesthetically communicates the amount of money and time invested in-world. Though the economy rapidly fluctuates, the average price for an avatar outfit is usually between $\$ 3$ to $\$ 6$ (USD). Many users frequently purchase new clothing items multiple times each week from virtual fashion meccas like Last Call, whose designers are constantly building new clothing and accessories.

It is important to address the affective labor inherent in developing an avatar. The avatar body-at once personal and intimately entangled with the self, but also distanced or forcibly severed through online anonymity-is a loaded construction that demands financial capital, but also an abundance of time and effort as well. The perceived effortlessness of building an avatar to someone not familiar with Second Life veils the inherent affective labor of creating a virtual stand-in for oneself; each body part, accessory, and skin connotes visible financial and labor in- 
vestments, symbolic of status in the hierarchies of Second Life's "worlding." ${ }^{5}$ A comparison can be drawn between the often-concealed labor economies of avatars and internet fashion bloggers. In her book Asians Wear Clothes on the Internet: Race, Gender and the Work of Personal Style Blogging, Minh-Ha T. Pham reveals how the work of fashion superbloggers conceals the complicated labor economy of clothing production. She notes, "what outfit posts' technological and aesthetic conventions conceal is not simply the labor of self-styling and consumerism but also, and just as importantly, the porousness of the boundaries between material and digital labour." ${ }^{6}$

The media products of style bloggers are seen by public consumers as a kind of "surplus value." Pham claims, working "just out of love for blogging and fashion, rather than for payment-transforms personal style blogging into highly gendered and racialized forms of 'emotion work."'7 Similarly, the avatar is seen as a "labor of love" requiring countless hours of technical labor in-world, and for many demands part- or full-time employment to afford additional in-world items. However, the labor of self-fashioning, through style blogging or avatar creation, is often understood as a form of play rather than labor. Pham recognizes how "much of the physical, emotional and intellectual work is obscured"8 in digital media production. Moreover, this affective labor extends itself into the register of intimacy, taxing the user emotionally as well as physically.

With the seemingly unlimited qualities, extensions, and accessories available to outfit a Second Life avatar, a crisis of representation may occur. In their text Virtual Intimacies, Shaka McGlottan grapples with the struggle of producing an online dating profile and the potentially injurious forms of racism that can be enacted in the virtual sphere. Writing primarily about queer networks of online dating and virtual hookup culture and how it has changed how gay men meet, interact, and enact random sexual encounters, Virtual Intimacies "describes a range of contacts and encounters, from the ephemeral to the enduring, made possible by digital and networked means...Virtual Intimacies also captures a dominant cultural attitude about these phenomena: they're trouble, a diminished and dangerous corruption of the real thing." ${ }^{\prime 9} \mathrm{Mc}-$ Glottan pushes back against the notion that the virtual itself is dangerous or less real. For them, virtuality is not opposed to the real, rather "virtuality refers to immanence, capacity and potentiality."10 Furthermore, intimacy is already virtual, since it is manifested through affective experience. In entering an online world such as Second Life, users are given the opportunity to feel and emote through their avatar characters: to experience the thrill of dating, or to feel the elation of purchasing a new pair of shoes. However, not all users' desires are so unproblematic; many may employ their avatar creations as veils through which to enact aggression. An inherent problem in the realness of the virtual realm is the reproduction of "real world" discrimination. As McGlottan notes, "online spaces reproduce and perhaps even heighten forms of racial injury, including ordinary microaggressions as well as overt or structural forms of racism." ${ }^{11}$

Of their online dating profile and the complex negotiations undergone to select an assemblage of image, text, and facts, McGlottan notes, "my Grindr profile reflects a complex set of negotiations in which I ambivalently grappled with the 
racialization of desire and my own positioning in a hyper-competitive erotic marketplace in which whiteness enjoys preeminence."12 Similar negotiations are reflected in the constructions of Second Life avatars. As Rosa Mikeal Martey and Mia Consalvo note, "with sufficient artistic and technical skills, residents can create nearly any type of avatar: from modelesque humans to scaled dragons, from clanking robots to flying spaghetti monsters. Yet spend some time in Second Life and you will see a curious homogeneity." ${ }^{13}$ While in theory, customization options are only limited by Second Life's interface, in reality, the technical skills required to make and manipulate one's avatar, economic barriers involved in buying skins, clothing, bodies, and accessories, and the "hypercompetitive erotic marketplace in which whiteness enjoys preeminence" make it difficult to express true freedom in the development of an avatar. ${ }^{14}$ Another key factor contributing to the homogeneity of avatar types is the in-world policing of the social sphere of Second Life, turning avatar bodies into signifiers, inhibiting certain users from entering particular sites in the virtual world and allowing them to pass into others.

The multiple layers of navigation undertaken in the building and play of an avatar points to the complexity of Second Life's social sphere. While some see the avatar as an outlet for exploring fantasies beyond ethics, others find Second Life to be an anxiety-free mode of socializing. Still others see it as a space for "trolling," enjoying the anonymity of an avatar. Artists have found Second Life and the avatar to be an engaging aesthetic and sculptural mode for building virtual worlds (Judith Doyle and Annabeth Robinson), creating machinima films (Skawennati and
$\mathrm{AbTeC})$, and engaging in virtual performances (micha cárdenas, Garrett Lynch and the Second Front performance group, Gazira Babeli, Yael Gilks, Bibbe Hansen, Doug Jarvis, Scott Kildall, Patrick Lichty, and Liz Solo).

EXPRESSING AN AVATAR: CRITIQUE THROUGH CREATIVITY

Mohawk artist, occasional writer, and former independent curator Skawennati's nine-episode machinima film series TimeTraveller ${ }^{\mathrm{TM}}$ (2008-2013) was produced entirely in Second Life. Through the eyes of her protagonists, Hunter and Karahkwenhawi, the viewers travel through time using the TimeTraveller ${ }^{\mathrm{TM}}$ virtual reality headset (fig. 1). As they journey through time and space, across a virtual North and South America, the viewers are asked to question problematic postcolonial modernity, consider the possibilities of decolonization, and imagine vibrant Indigenous futures (fig. 2). Skawennati and $\mathrm{AbTeC}$ (the research network Aboriginal Territories in Cyberspace) create representation for persons of color in the virtual space of Second Life, a crucial task given the apparent lack of representation and systematic racial biases noted by games studies scholar David R. Dietrich. ${ }^{15}$ Her primary mode of engaging with Second Life avatars is as actors, using machinima to choreograph complex narratives for each episode of TimeTraveller ${ }^{\mathrm{TM}}$. For Skawennati and $\mathrm{AbTeC}$, Second Life and its avatars are malleable, allowing the artist to establish an Indigenous presence online where she previously saw a lack, and to tell Canadian and global histories from an Indigenous perspective. TimeTraveller ${ }^{\mathrm{TM}}$ imagines vibrant Indigenous futures while simultaneously reminding us of Canada's colonial history; as Second Life allows for the design of fu- 
turistic avatars, Skawennati recreates imagery of Indigenous bodies in futuristic narratives that celebrate a multiplicity of identities. TimeTravel$l e r^{\mathrm{TM}}$ addresses the lack of an Indigenous presence in futuristic popular culture and science fiction through stories of pain, hardship, triumph, and love.

Through $\mathrm{AbTeC}$, the research network she cofounded with Jason Edward Lewis, Skawennati purchased virtual land in an important gesture that asserted agency for Indigenous communities.

Land ownership and access to space in Second Life works much as in the physical world in terms of hierarchies of wealth, with wealthy users restricting the movement and access of others. Initially, Second Life implemented a tax structure that charged users based on criteria generated by its creators. However, a crackdown on tax evaders caused an in-world uprising: a grassroots social movement was born, and within weeks the VR revolutionaries had won. In December of 2003, an entirely new tax system was initiated that was measured against in-world land ownership. More land meant higher taxation. ${ }^{18}$ Today, if you sign up for a membership, you will be met with the choice of the limited, free "basic" membership, or a premium paid membership, beginning at approximately $\$ 10$ USD per month. Paid members are granted the opportunity to buy property from Linden Labs, which requires further monthly maintenance fees. The cost of land varies: to purchase an entire island in Second Life users may spend up to $\$ 2,000$ with a $\$ 300$-a-month maintenance charge, while monthly rent can vary from $\$ 1.50$ to $\$ 150$.

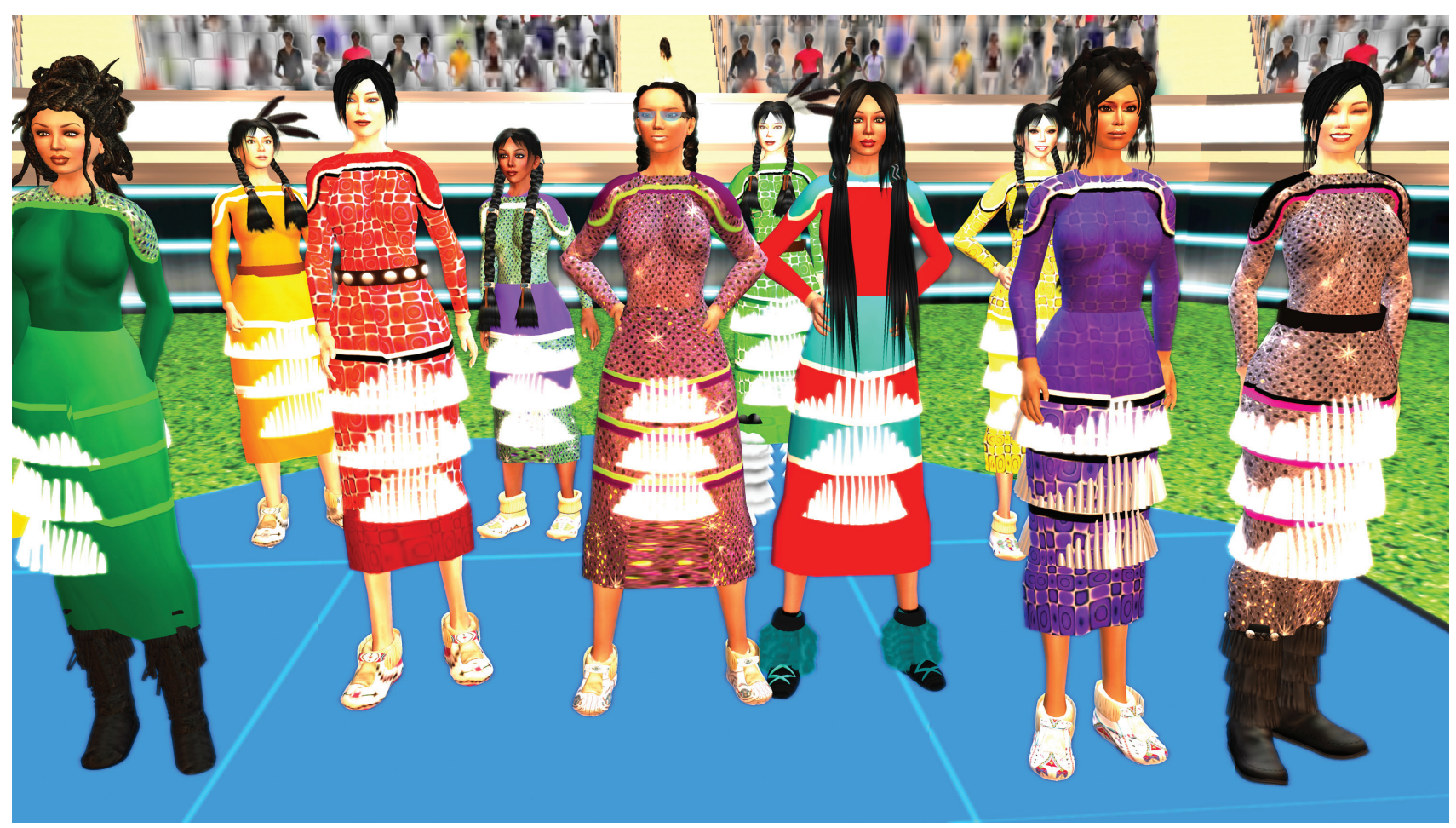

Figure 2. Skawennati, Jingle Dancers Assemble, TimeTraveller ${ }^{\mathrm{TM}}, 2008-2013$. Image courtesy of the artist. 


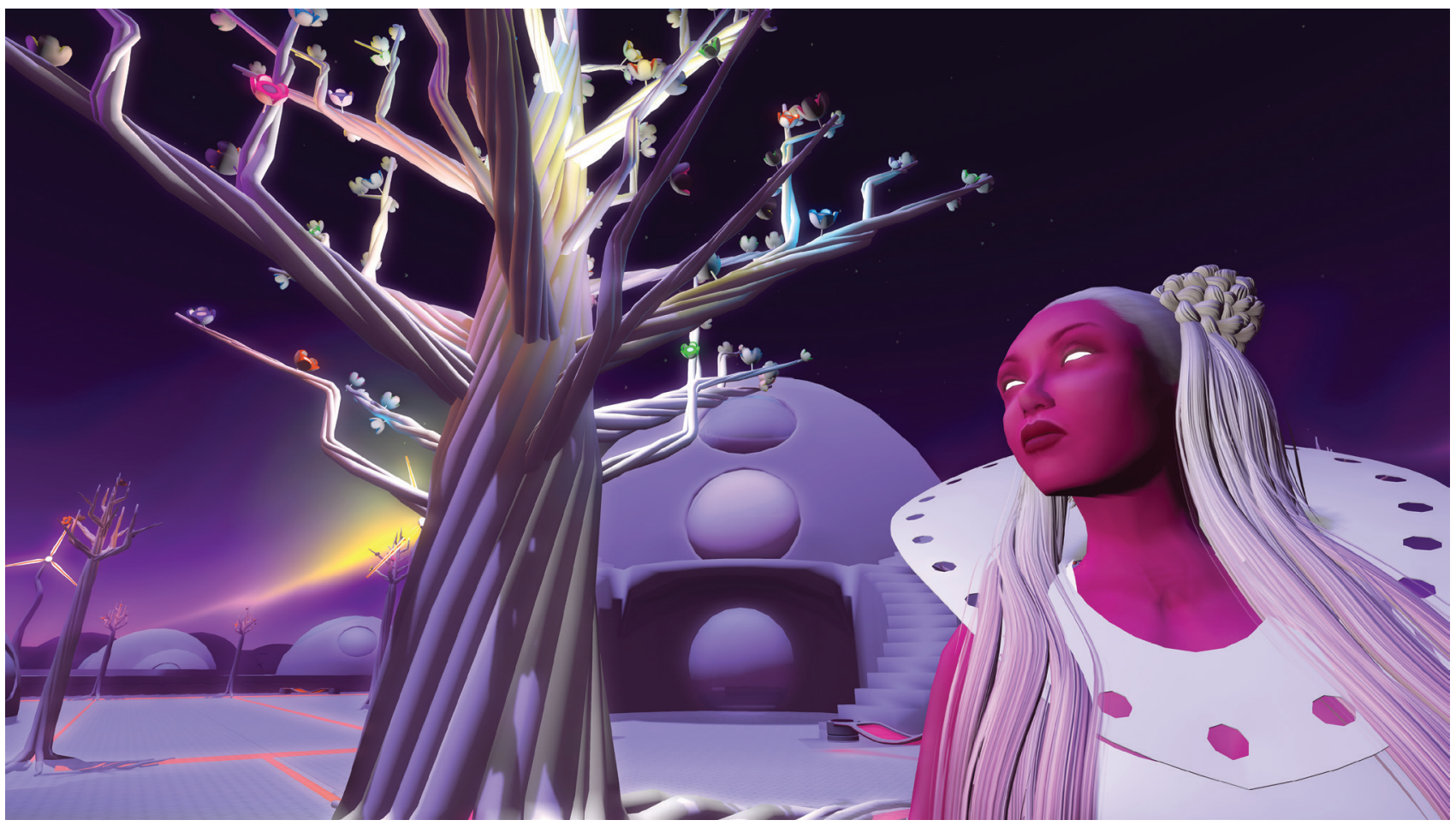

Figure 3. Skawennati, Becoming Sky Woman, She Falls for Ages, 2017. Image courtesy of the artist.

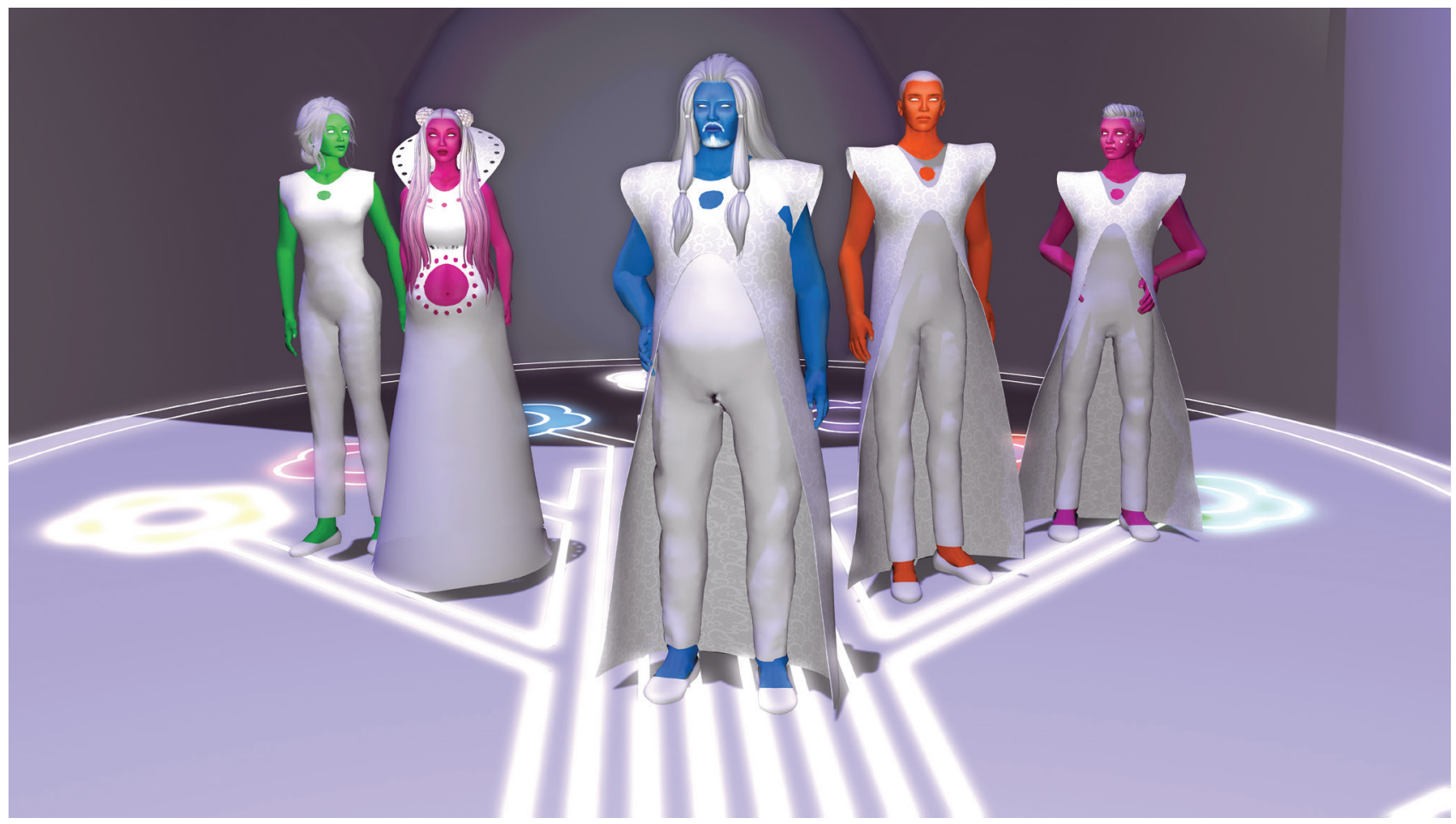

Figure 4. Skawennati, Ceremony, She Falls for Ages, 2017. Image courtesy of the artist.

92 | Video Game Art Reader | Fall 2018 
$\mathrm{AbTeC}$ 's land ownership critiques the hierarchy of wealth in Second Life, but also importantly suggests a provocation against the colonization and theft of Indigenous land throughout history. Skawennati states, "Second Life is a platform and a medium. [Our] island in Second Life is an Aboriginally determined space. I am not very interested in creating new platforms. I'm much more excited about shaping them, creating content for them, finding the killer app for them." ${ }^{16} \mathrm{AbTeC}$ 's ownership and usage of purchased virtual land is an important decolonial gesture. Claiming an Indigenous, or Aboriginal, territory in a virtual empire is a radical move towards framing Indigenous identity in the 21st century, enacting a reversal of colonial histories in Canada and abroad.

Skawennati continues to produce work in Second Life, including her 2017 machinima film She Falls for Ages (figs. 3 and 4) and her ongoing work with her own avatar character xox Voyager, seen in her piece Dancing with Myself (2015) (fig. 5). Of xox Voyager Skawennati says, "What I hope to show is not that I want to be like my avatar or my avatar wants to be like me but we want to be like each other." ${ }^{17}$ Furthermore, she continues to experiment with avatar creation, running workshops for Indigenous youth interested in creating personalized avatars through hacking and modding new skins, accessories, and landscapes that celebrate indigenous pasts, present, and futures.

Like Skawennti's digital art practice, artist and theorist micha cárdenas deals with issues of colonization, borderlands, and coloniality, often using Second Life avatar construction as an artistic tool. cárdenas' body of work is focused on studies of movement, performance, and mo-

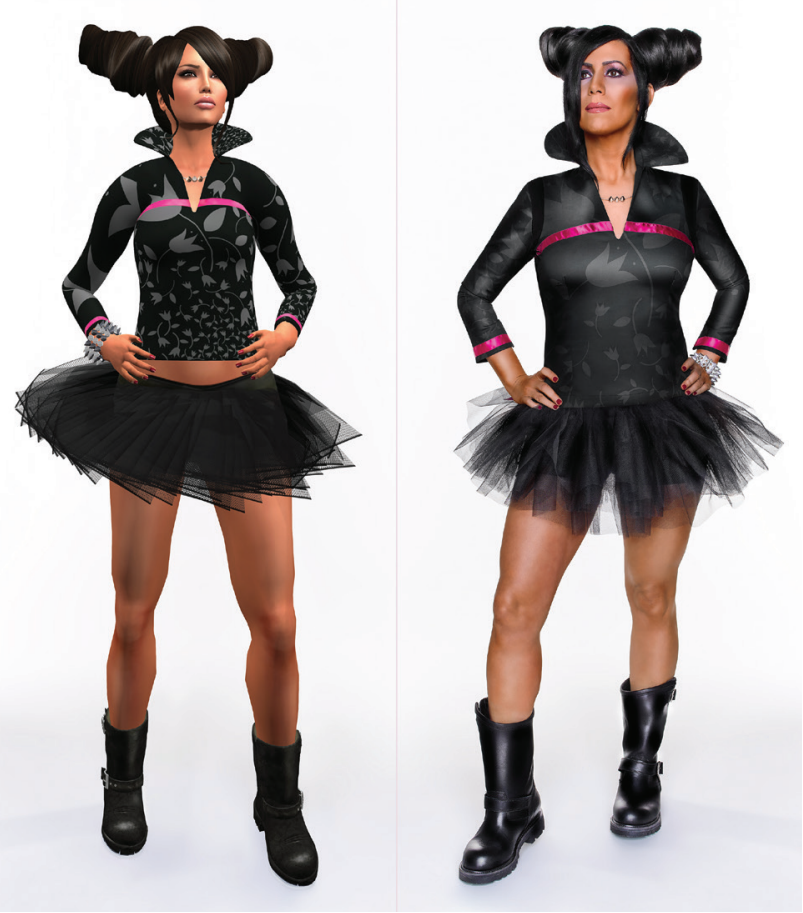

Figure 5. Skawennati, Dancing with Myself, 2015. Image courtesy of the artist.

bility as well as representations of transgender people of color in digital media. cárdenas' performance Becoming Dragon is conducted through virtual reality immersion as the artist navigates Second Life as her avatar character, dragon Azdel Slade (fig. 6). cárdenas' performance reflects on the one-year requirement of "Real Life Experience" that transgender people must fulfill in order to receive Gender Confirmation Surgery; she explores how this might equate with one year of "Second Life Experience," leading to "Species Reassignment Surgery" through her 365-hour, totally immersive performance as a dragon avatar. cárdenas spent these 365 hours immersed in the online 3D environment with a head mounted display and motion-capture system to map her movements into Second Life, only 
seeing the physical world through a video-feed (fig. 7). In this performance, cárdenas navigates the complex networks of social engagement between avatars, and is faced with the affective nature of the avatar image; cárdenas expresses the power of being defined in public, virtual space by one's created avatar:

Beyond the image, Second Life offers a social dimension to these constructed identities, in which one feels the moment of being "seen" by another. This is an essential part of becoming, the moment of social interaction and feedback when one's conception of one's self is affirmed and reified by others - the moment of passing. Considering sexual interactions, this moment of recognition is made even more powerful, as the new constructed identity is not only acknowledged by another participant in this online social space, but the other expresses an emotional response to one's appearance, gestures or presentation. ${ }^{19}$

cárdenas identifies the primary difference between interactions in Second Life versus other social media outlets as being "seen," essential to "becoming": unlike online chat forums, comment boards, and social media sites, Second Life users can create visual representations others encounter, affirm, and reify. For Uri McMillan, "avatars suggest a slippage between the 'other' and us, a reaching beyond the limits of where our bodies supposedly end. In this formulation, the 'subject' is not a bounded entity but a permeable one." ${ }^{20}$ However, with the possibilities of the avatar and the blurring between online and offline self comes a fraught navigation, especially in the limitations of building your avatar and navigating it in and around the Second Life virtual space. According to feminist game studies scholars Rosa Mikeal Martey and Mia Consalvo, social and cultural norms around appearance in this multiuser world also dictate a whole host of limitations upon avatar design. As Martey and Consalvo assert,
As a virtual world, Second Life is comprised of multiple subcultures and communities, many of which are made distinctive via their appearance and dress. Indeed, in Second Life an important part of identity formation and maintenance is conducted via appearance itself. Although residents may be able (and willing) to change clothes, skins, hair, and shape at a moment's notice, most have instead established a set of visual codes that situate them as part of a particular group, with a distinct history, culture, and way of dressing. ${ }^{21}$

In Second Life, visual representation is key to creating relations between avatars and allowing access to exclusive locations. To return to a quote from McGlotten, "creating a profile forces one to attend to one's own desirability and to one's own desire, neither of which is self-evident, and both of which demand articulation in virtual spaces as much (perhaps even more) than in real ones." 22

In a particularly relevant story told by micha cárdenas about her engagement in Second Life, her dragon avatar Azdel Slade was invited by a new friend to a number of sex clubs and S\&M dungeons in the virtual world. At one of the clubs Azdel Slade visited, they experienced a crowd resistant to the dragon avatar. After deciding to push the limits of the scene and beginning to pole dance, Azdel Slade was ejected from the club. For cárdenas "the ejection unveils the limits of the logic of Second Life." ${ }^{23}$ She goes on to narrate:

There are many different, heterogeneous spaces in Second Life that are owned and operated by various people, and many have their own rules...Dragons are not welcome in the sex club described because they break the illusion, they distract from the arousing, ostensibly transgressive, scene. "Your world. Your imagination," is the techno-utopic marketing slogan of Linden Labs, but this only applies if you own the land in question. ${ }^{24}$

However, if one does have access to one of the many restricted enclaves that the virtual 


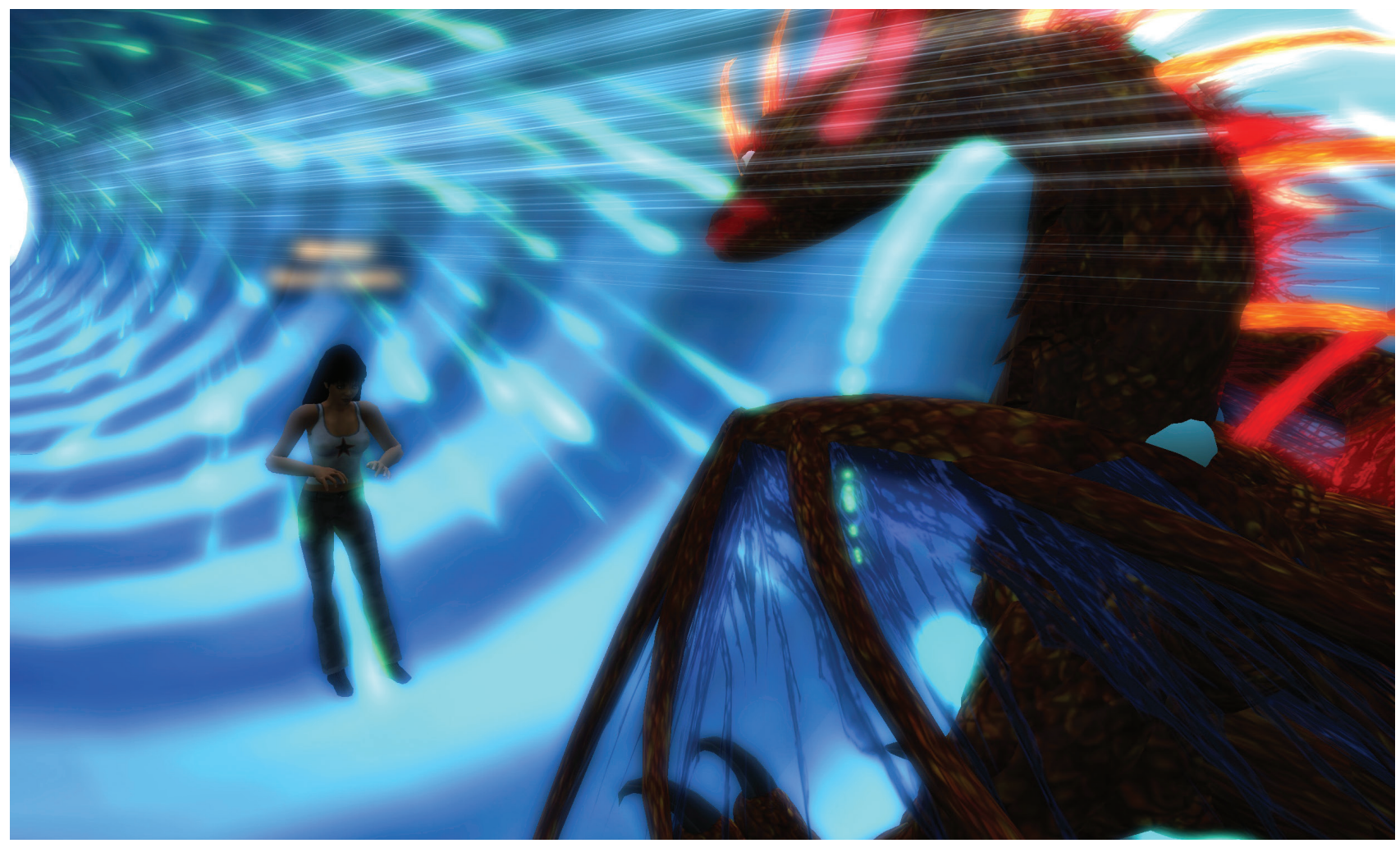

Figure 6. micha cárdenas, Becoming Dragon, 2008. Image courtesy of the artist.

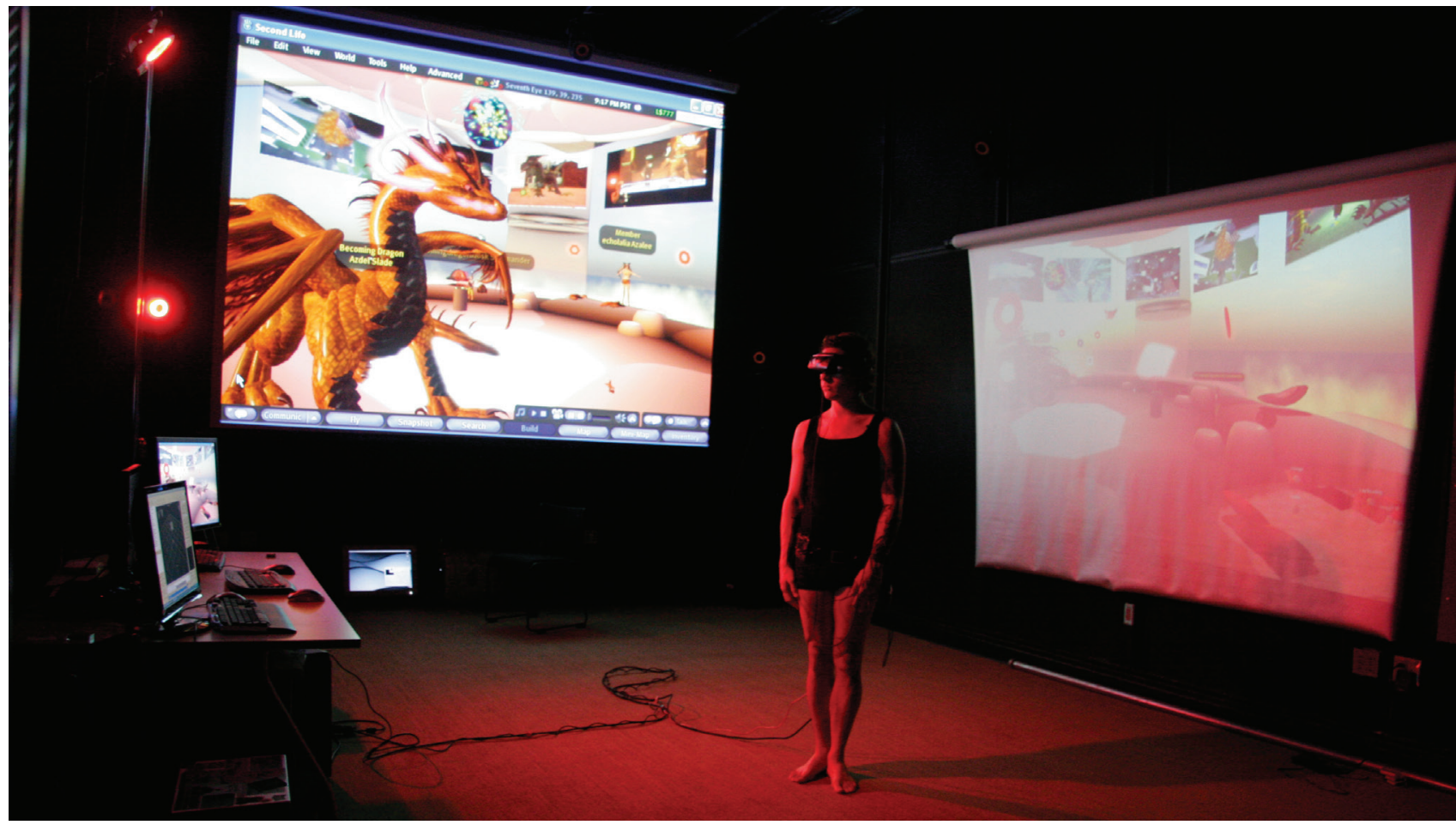

Figure 7. micha cárdenas, Becoming Dragon installation view, 2008. Image courtesy of the artist. 
world offers-such as Desperation Andromeda, a space for sci-fi sexual fantasies such as tentacle and alien sex-then Second Life can offer experimentations beyond the physical limits of reality. For cárdenas, "social, visual and embodied experimentation with these new configurations of gender and sexuality can open the mind up to new demands for everyday life in the physical world." 25

The aesthetic markers of an avatar can both restrict its users from particular sites and allow them to enter into others. The avatar becomes a loaded signifier, purveying a wealth of information to other Second Life inhabitants. The aesthetic of an avatar can connote many things: personality traits, sexual desires, hobbies and interests, and more. In Second Life, users' ownership of virtual space means that players are able to control access to some territories, and other territories remain restricted except for certain interest groups or types of avatars: furries have their spaces, vampires theirs, and BSDM avatars their own. There are problematic colonial imperatives to claim land, remove others, and police borders. The ownership and regulation of land and borders is a reflection of racialized and political tensions for refugees and displaced persons, as well as otherwise marginalized groups traversing borders in the physical world. Under the guise of creating safer spaces for certain types of avatar characters, closed borders and territories may act as exclusionary spaces for marginalized groups. Such practices differ from the ways on which $\mathrm{AbTeC}$ controls and regulates virtual land: their imperative is not to exclude others, but rather to protect Indigenous territory in cyberspace from vandals and squatters. AbTeC's land can be visited, and is open for tours to the public.
At the moment of its creation, the Second Life avatar enters into a complex network of sociopolitical and economic hierarchies. For McMillan, "exceeding delineations between the past and the present, slipping between the real and the virtual, and violating zones between objecthood and subjecthood, avatars suggest the paradoxical powers inherent in willfully alienating oneself from the limits of the human." 26 The virtual is productive for McGlottan and artists like micha cárdenas and Skawennati, as they mine potentials not yet actualized. However, they also find much of Second Life fraught with the racial tensions, gender inequality, sexual abuse, exclusion, and discrimination plaguing the physical world. Artistic interventions in virtual sites and avatar bodies can disrupt preconceived notions of virtual freedom by challenging the productivity of countercultures online, enacting the reclamation of land for Indigenous and other marginalized peoples in the virtual and physical worlds, defying gender norms, and critiquing the racial exclusion of bodies. $\rightarrow$ 


\section{Bio}

Treva Michelle Legassie is an interdisciplinary researcher, curator, artist, and a PhD candidate in Communication Studies at Concordia University. Her research questions the particular modes of collecting, classifying, conserving, and curating art that are becoming necessary in the present geological era of the Anthropocene. Her interdisciplinary research practice asks: how can curation and environmental site-specific art as "practices of care" help to reimagine response-able modes for living on a damaged planet?

Legassie is founder of the Curatorial Research Creation Collective at Milieux, Assistant Director of the Speculative Life Cluster, and a researcher at the Ethnography Lab in the Waterways group. Her writing has been published in Technoetic Arts: A Journal of Speculative Research, PUBLIC Journal, The Senses \& Society, InterARTive, JAWS, and AlterNative: An International Journal of Indigenous Peoples. She has also curated new media-based exhibitions such as Femynynytees (2018), \#NATURE (2016), and Influenc(Ed.) Machines, and co-ordinated Cheryl Sim's YMX: Land and Loss after Mirabel. 


\section{Notes}

1. Michael Rymaszewski, et al., Second Life: The Official Guide (Hoboken: John Wiley \& Sons, 2006$), 1$.

2. Uri McMillan, "Theorizing Queer Inhumanisms: Objecthood, Avatars, and the Limits of the Human," GLQ: A Journal of Lesbian and Gay Studies 21, no. 2-3 (2015): 227; McMillan, Embodied Avatars: Genealogies of Black Feminist Art and Performance (New York: NYU Press, 2015).

3. Dianna Baldwin and Julie Achterberg, "Introduction: The Big Bang Theory, or the Creation of Second Life," in Women and Second Life: Essays on Virtual Identity, Work and Play, ed. Dianna Baldwin and Julie Achterberg (Jefferson: McFarland \& Company, 2013), 6.

4. Ibid.

5. Tom Boellstorff, Coming of Age in Second Life: An Anthropologist Explores the Virtually Human (Princeton: Princeton University Press, 2008), 18.

6. Minh-Ha T. Pham, Asians Wear Clothes on the Internet: Race, Gender and the Work of Personal Style Blogging (Durham: Duke University Press 2015), 117.

7. Ibid., 183.

8. Ibid., 188.

9. Shaka McGlottan, Virtual Intimacies (Albany: SUNY Press, 2013), 7.

10. Ibid., 8 .

11. Ibid., 63.

12. Ibid., 61.

13. Mia Consalvo and Rosa Mikeal Martey, "Performing the Looking-Glass Self: Avatar Appearance and Group Identity in Second Life," Popular Communication 9 (2011): 166.

14. McGlottan, 61.

15. David R. Dietrich, "Avatars of Whiteness: Radical Expression in Video Game Characters," Sociological Inquiry 83, no. 1 (2012): 82-105.

16. Skawennati, Questions regarding TimeTraveller ${ }^{\mathrm{TM}}$ in an email to the author, April 11, 2016.

17. Ibid.

18. Baldwin and Achterberg.

19. micha cárdenas, "Becoming Dragon: A Transversal Technology Study," CTheory 9, April 29, 2010, http: / / ctheory.net/ articles.aspx?id=639.

20. McMillan, 227.

21. Martey and Consalvo, 178.

22. McGlottan, 68.

23. cárdenas.

24. Ibid.

25. Ibid.

26. McMillan, 227-228. 


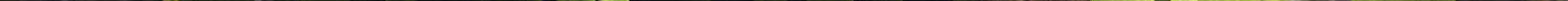

